\title{
On the putative role of Pelota in stem
}

\section{cell differentiation}

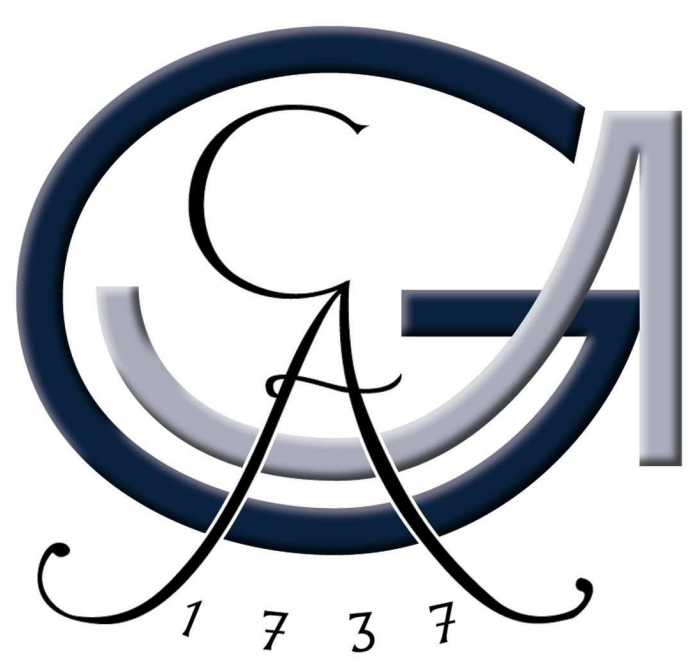

Dissertation

zur Erlangung des Doktorgrades

der Mathematisch-Naturwissenschaftlichen Fakultäten der Georg-August-Universität zu Göttingen

vorgelegt von

Aleksandra Kata

aus Łódź, Polen 
D 7

Referent:

Prof. Dr. med Dr. h.c. W. Engel

Korreferentin:

Prof. Dr. S. Hoyer-Fender

Tag der mündlichen Prüfung: 


\section{TABLE OF CONTENTS}

TABLE OF CONTENTS i

ABBREVIATIONS v v

1. INTRODUCTION 1

$\begin{array}{ll}\text { 1.1. The pelota gene } & 1\end{array}$

1.2. The function of pelota gene in Saccharomyces cerevisiae and Drosophila melanogaster $\quad 4$

1.3. The phenotype of Pelota knockout mice 5

$\begin{array}{ll}\text { 1.4. Aims of the study } & 7\end{array}$

2. MATERIALS AND METHODS 8

$\begin{array}{lc}\text { 2.1. MATERIALS } & 8\end{array}$

$\begin{array}{ll}\text { 2.1.1. Chemicals } & 8\end{array}$

2.1.2 Solutions, buffers and media $\quad 11$

$\begin{array}{ll}\text { 2.1.3 Laboratory materials } & 13\end{array}$

$\begin{array}{ll}\text { 2.1.4 Sterilisation of solutions and equipments } & 13\end{array}$

$\begin{array}{ll}\text { 2.1.5 Media, antibiotics and agar-plates } & 13\end{array}$

2.1.5.1 Media for bacteria 13

2.1.5.2 Media for cell and embryo culture $\quad 14$

2.1.5.3 Antibiotics $\quad 15$

2.1.5.4 IPTG/X-Gal plate $\quad 15$

2.1.6 Bacterial strains $\quad 15$

$\begin{array}{ll}\text { 2.1.7 Plasmids } & 16\end{array}$

$\begin{array}{ll}\text { 2.1.8 Synthetic oligonucleotides } & 16\end{array}$

$\begin{array}{ll}\text { 2.1.9 Mouse strains } & 17\end{array}$

2.1.10 Antibodies 17

$\begin{array}{ll}\text { 2.1.11 Enzymes } & 18\end{array}$

$\begin{array}{ll}\text { 2.1.12 Radioactive substances } & 18\end{array}$

$\begin{array}{ll}2.1 .13 \text { Kits } & 18\end{array}$

$\begin{array}{ll}\text { 2.1.14 Equipment } & 19\end{array}$

$\begin{array}{ll}2.2 \\ M E T H O D S & 20\end{array}$

$\begin{array}{ll}\text { 2.2.1 Isolation of nucleic acids } & \mathbf{2 0}\end{array}$ 


\section{TABLE OF CONTENTS}

2.2.1.1 Isolation of plasmid DNA

2.2.1.2 Isolation of genomic DNA

2.2.1.3 Isolation of total RNA from tissue samples and cultured cells 21

2.2.2 Determination of nucleic acid concentration

2.2.3 Determination of transgene integration - GenomeWalker Universal

Kit

2.2.4 Gel electrophoresis

2.2.4.1 Agarose gel electrophoresis of DNA

2.2.4.2 Agarose gel electrophoresis of RNA

2.2.4.3 SDS-PAGE gel for separation of proteins

2.2.5 Purification of DNA fragments from agarose gel

2.2.6 Enzymatic modifications of DNA

2.2.6.1 Restriction of DNA

2.2.6.2 Ligation of DNA fragments

2.2.6.3 TA-Cloning

2.2.6.4 Dephosphorylation

2.2.7 Transformation of competent bacteria 25

2.2.8 Polymerase Chain Reaction (PCR) 26

2.2.8.1 Genotyping PCRs

2.2.8.2 Generation of Southern probes

2.2.8.3 Reverse transcription PCR (RT-PCR)

2.2.8.4 Quantitive Real-Time PCR

2.2.8.5 Quantitive Real-Time RT-PCR

2.2.9 Protein manipulation methods

2.2.9.1 Isolation of total protein lysate 30

2.2.9.2 Determination of protein concentration 31

2.2.10 Blotting techniques

2.2.10.1 Southern blotting of DNA 31

2.2.10.2 Northern blotting of RNA 32

2.2.10.3 Western blotting of protein 32

2.2.11 "Random Prime" method for generation of ${ }^{32} P$ labeled DNA 32

2.2.12 Non-radioactive dye terminator cycle sequencing 33

2.2.13 Hybridisation of nucleic acids 33

$\begin{array}{ll}\text { 2.2.14 Histological techniques } & 34\end{array}$ 


\section{TABLE OF CONTENTS}

2.2.14.1 Tissue preparation for paraffin-embedding

2.2.14.2 Sections of the paraffin block 34

2.2.14.3 Immunofluorescence staining $\quad 34$

2.2.14.4 Phalloidin staining of cells 35

2.2.14.5 Alkaline phosphatase staining of cells 35

2.2.14.6 Hematoxylin-eosin $(H \& E)$ staining of the histological sections $\quad 35$

2.2.14.7 Apoptosis detection $\quad 36$

2.2.15 Eukaryotic cell culture methods 36

2.2.15.1 Preparation of MEFs feeder layers 36

2.2.15.2 Trypsinisation of eukaryotic cells 37

2.2.15.3 Cryopreservation and thawing of eukaryotic cells 37

2.2.15.4 Isolation and handling of primary mouse embryonic $\begin{array}{ll}\text { fibroblasts (MEFs) } & 37\end{array}$

2.2.15.5 Growth of ES cells on feeder layer 37

2.2.15.6 Differentiation of ES cells 38

2.2.16 Production of targeted embryonic stem cell clones 39

2.2.16.1 Electroporation of ES cells 39

2.2.16.2 Growing ES cells for Southern blot analysis 39

2.2.17 Flow cytometry (FACS) procedure for apoptosis detection and cell surface staining $\quad 39$

2.2.18 Production of chimeras by injection of ES cells into blastocysts $\quad 40$

2.2.19 Detection of chimerism and mice breeding 40

2.2.20 Preparation of cKO ESCs from cKO mice 41

2.2.21 Tamoxifen (TAM) treatment of mice

2.2.22 Hydroxytamoxifen (OHT) treatment of generated cKO ESCs 41

2.2.23 Generation of teratomas in SCID mice 41

2.2.24 Bone marrow transplantation 44

2.2.25 Fertility test of Stra8 mice

2.2.26 Preparation of adaptor oligos 4

$\begin{array}{ll}\text { 2.2.27 Computer analysis } & 43\end{array}$

3. RESULTS

3.1 Generation and characterization of pelota conditional knockout mouse $\quad 44$

3.1.1. Generation of a conditional knockout (cKO) construct 45 


\section{TABLE OF CONTENTS}

3.1.2. Isolation of homologous recombinant ESC clones

3.1.3. Generation of chimeric mice

3.1.4. Generation of an ESC line

3.1.5. Conditional knockout system - verification of recombination efficiency by generation of cKO/EIIaCre mouse line

3.1.6. The role of Pelota in germ cell development - testis-specific cKO/Stra8-Cre mouse line

3.1.6.1. Generation of Pelo ${ }^{\mathrm{F} /}$-Stra8-Cre mouse

3.1.6.2. Histological analysis of testes during postnatal development

3.1.6.3. Spermatogenesis of Pelo ${ }^{\mathrm{F} /}$-Stra8-Cre mice is affected at premeiotic stages

3.1.6.4. Quantitative expression analysis of premeiotic markers in Pelo ${ }^{\mathrm{F} / \mathrm{-}}$ Stra8-Cre mice

3.1.6.5. Analysis of Pelo ${ }^{\mathrm{F} /} \mathrm{Stra8}-\mathrm{Cre}$ fertility

3.1.7. Tamoxifen-dependent pelota deletion in cKO?CreERTmouse line $\quad \mathbf{7 0}$

3.1.7.1. TAM treatment of Pelo ${ }^{\mathrm{F} /-}$ Stra8-Cre mice 71

3.1.7.2. Effects of pelota deletion in Pelo ${ }^{\Delta /-}$ CreERT animals $\quad 73$

3.1.8. Pelota-deficient ESC line - functional characterization 80

3.2. Transgenic mice overexpressing Pelota $\quad 89$

3.2.1. Testis-specific transgenic lines $\quad 89$

$\begin{array}{ll}\text { 3.2.2. EvaL6 as a rescue for pelota knockout mice } & 94\end{array}$

4. DISSCUSSION

$\begin{array}{ll}\text { 4.1. Brief overview of the results } & 97\end{array}$

4.2. Embryonic stem cell fate shift from pluripotent to differentiated state 99

4.3. Signal transduction in differentiation and pluripotency $\quad 101$

4.4. Pelota in germ cell differentiation $\quad 105$

4.5. miRNA in pluripotent stem cells during differentiation $\quad 107$

$\begin{array}{lr}\text { 4.6. Future perspectives } & 107\end{array}$

$\begin{array}{ll}\text { 5. Summary } & 109\end{array}$

$\begin{array}{ll}\text { 6. References } & 111\end{array}$

$\begin{array}{ll}\text { Acknowledgements } & 121\end{array}$

$\begin{array}{lr}\text { Curriculum vitae } & 122\end{array}$ 


\begin{tabular}{|c|c|}
\hline $129 / \mathrm{Sv}$ & 129/Sv/Ola mouse strain \\
\hline $\mathrm{AP}$ & Alkaline Phosphatase \\
\hline ATP & Adenosinetriphosphate \\
\hline bp & base pair \\
\hline BLAST & Basic Local Alignment Search Tool \\
\hline BSA & Bovine Serum Albumin \\
\hline${ }^{\circ} \mathrm{C}$ & Celsius Degree \\
\hline C57BL & C57BL/6J mouse strain \\
\hline cDNA & complementary DNA \\
\hline $\mathrm{cKO}$ & conditional knockout \\
\hline $\mathrm{d}$ & day/s \\
\hline dATP & desoxyriboadenosintriphosphate \\
\hline $\mathrm{dH}_{2} \mathrm{O}$ & destilled water \\
\hline DAPI & Diamidino-2-phenylindole dihydrochloride \\
\hline $\mathrm{dCTP}$ & Desoxyribocytosinetriphosphate \\
\hline DMEM & Dulbecco's Modified Eagle Medium \\
\hline DEPC & Diethylpyrocarbonate \\
\hline DNA & Deoxyribonucleic acid \\
\hline DNAse & Deoxyribonuclease \\
\hline dNTP & deoxynucleotidetriphosphate \\
\hline $\mathrm{dT}$ & deoxythymidinate \\
\hline DTT & Dithiothreitol \\
\hline EDTA & Ethylene Diamine Tetraacetic Acid \\
\hline $\mathrm{ES}$ & Embryonic Stem \\
\hline et al. & et alii (and others) \\
\hline $\mathrm{EtBr}$ & Ethidium Bromide \\
\hline Fig. & Figure \\
\hline FCS & Fetal Calf Serum \\
\hline FVB & $\mathrm{FVB} / \mathrm{N}$ mouse strain \\
\hline g & gravity \\
\hline HPRT & hypoxanthin-phosphoribosyl-transferase \\
\hline $\mathrm{ICM}$ & Inner Cell Mass \\
\hline IPTG & Isopropyl-ß-thiogalactopyranoside \\
\hline $\mathrm{kb}$ & kilobase \\
\hline $\mathrm{kDa}$ & kiloDalton \\
\hline $\mathrm{mg}$ & milligram \\
\hline $\mathrm{ml}$ & milliliter \\
\hline$\mu l$ & microliter \\
\hline$\mu \mathrm{m}$ & micrometer \\
\hline $\min$ & minute \\
\hline $\mathrm{mM}$ & millimolar \\
\hline mRNA & Messenger-RNA \\
\hline $\mathrm{NaAc}$ & Sodium Acetate \\
\hline NCBI & National Center for Biotechnology \\
\hline $\mathrm{Neo}$ & Neomycin \\
\hline ng & nanogram \\
\hline $\mathrm{nm}$ & nanometer \\
\hline nt & nucleotide \\
\hline
\end{tabular}




OD
ORF
PBS
PCR
PFA
PMSF
RNA
RNase
RT-PCR
RT
Sdha
SDS
Tris
U
UTR
Vol.
WT
X-Gal

Symbols of nucleic acids

A

C

G

$\mathrm{T}$

$\mathrm{U}$

\section{Symbols of amino acids}

$\begin{array}{ll}\text { A } & \text { Ala } \\ \text { B } & \text { Asx } \\ \text { C } & \text { Cys } \\ \text { D } & \text { Asp } \\ \text { E } & \text { Glu } \\ \text { F } & \text { Phe } \\ \text { G } & \text { Gly } \\ \text { H } & \text { His } \\ \text { I } & \text { Ile } \\ \text { K } & \text { Lys } \\ \text { L } & \text { Leu } \\ \text { M } & \text { Met } \\ \text { N } & \text { Asn } \\ \text { P } & \text { Pro } \\ \text { Q } & \text { Gln } \\ \text { R } & \text { Arg } \\ \text { S } & \text { Ser } \\ \text { T } & \text { Thr } \\ \text { V } & \text { Val } \\ \text { W } & \text { Trp } \\ \text { Y } & \text { Tyr } \\ \text { Z } & \text { Glx }\end{array}$

Optical Density

Open Reading Frame

Phosphate Buffered Saline

Polymerase Chain Reaction

Paraformaldehyde

Phenylmethanesulfonilfluoride

Ribonucleic Acid

Ribonuclease

Reverse-Transcription-PCR

Room Temperature

Succinate dehydrogenase

Sodium Dodecyl Sulfate

Tris(hydroxymethyl)-aminomethane

\section{Unit}

untranslated region

Volume

Wild Type

5-brom-4-chlor-3-indolyl-ß-Dgalactopyranoside

Adenosine

Cytidine

Guanosine

Thymidine

Uridine

Alanine
Asparagine or Aspartic acid
Cysteine
Aspartic acid
Glutamic acid
Phenylalanine
Glycine
Histidine
Isoleucine
Lysine
Leucine
Methionine
Asparagine
Proline
Glutamine
Arginine
Serine
Threonine
Valine
Tryptophan
Tyrosine
Glutamine or Glutamic acid 


\section{INTRODUCTION}

\section{INTRODUCTION}

\subsection{The pelota gene}

The murine pelota (Pelo) gene is located on chromosome 13. It consists of three exons (300, 729 and 598 bp long), but protein coding sequences are found only in two of them - start codon (ATG) and termination codon (TGA) are situated in second and third exon, respectively. Murine Pelo cDNA in comparison to that of Drosophila, has a 394 bp shorter 3'UTR ( insertion in fruit fly cDNA. This fact can be of great importance for gene functionality in mammals (Shamsadin et al., 2002). The amino acid sequence (385 residues) shares $70 \%$ homology with Drosophila Pelo and 36\% with yeast Dom34 (Shamsadin et al., 2002).

Pelo gene has been identified in Drosophila melanogaster (Castrillon et al., 1993) and successive studies have revealed its broad expression in diverse species from archaebacteria to human (Lalo et al., 1994; Bult et al., 1996; Ragan et al., 1996; Shamsadin et al., 2000, 2002). Similarity in protein structure between various organisms indicates that it is highly conserved during evolution (Fig.1). The fact that the phenotype of a null dom34 (pelota homologue) mutant in yeast has been rescued by expression of Drosophila pelota (Davis and Engebrecht, 1998) is additional evidence for evolutionary conservation of the gene.

Structural analysis of pelota protein has revealed, that it consists of three conserved domains (Fig.1B, Fig. 2). Two of them (central and C-terminal ones) are related to domains composing eRF1 (an eukaryotic release factor 1), which is involved in termination step of protein synthesis (Frolova et al., 1994; Eurwilaichitr et al., 1999). Therefore, pelota was originally classified to eRF family, but in the course of time certain differences between Pelo and eRF proteins were brought to light. In contrary to central domain of eRF1, Pelo lacks universal GGQ (glycine-glycine-glutamine) sequence motif (Lee et al., 2007) enabling recognition of a stop codon at the A site of the ribosome and stimulation of peptidyl-tRNA bond hydrolysis (Song et al., 2000). Instead, the central domain of Pelo contains a strictly conserved tripeptide PGF (proline-glycine-phenylalanine) which strongly influences endoribonuclease function (Passos et al., 2009) and may be responsible for interaction with ribosomes (Lee et al., 2007). This sequence discrepancy suggests some functional differences between Pelo and eRF1. 


\section{INTRODUCTION}
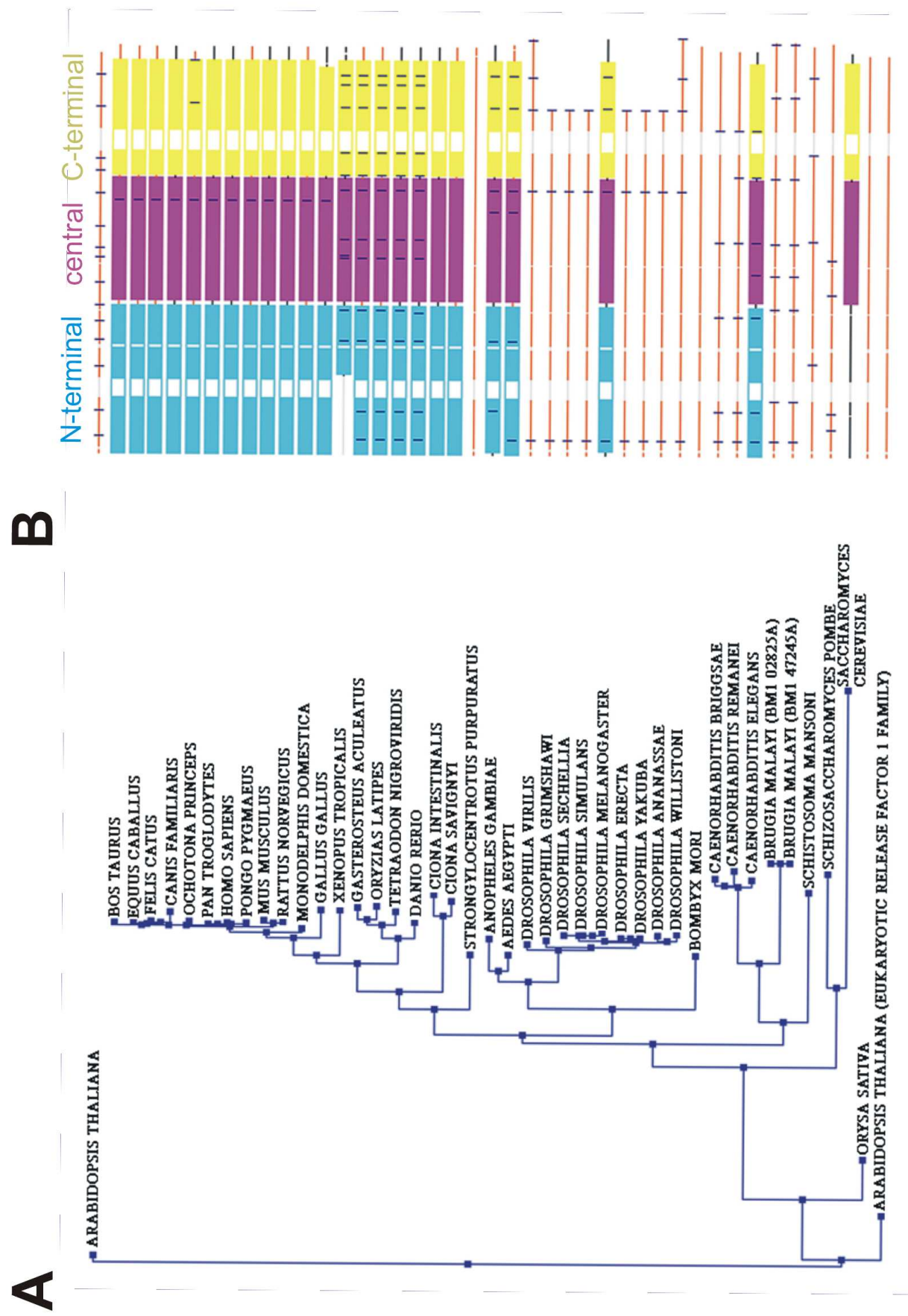

Figure 1. A phylogenetic tree of Pelota amino acid sequences (A) and alignment of domain structures $(B)$ of various species.

The tree (A) originates from the TreeFam database. Blue, pink and yellow boxes in panel $B$ represent Pfam domains ( $N$-terminal, central and $C$-terminal, respectively); lines stand for regions not belonging to domains. Light-coloured lines are equivalents of mismatched fragments. Short vertical lines show splicing sides. 


\section{INTRODUCTION}

Moreover, Pelo N-terminal domain markedly differs from eRF1 (Song et al., 2000; Lee et al., 2007; Graille et al., 2008). It contains Sm-fold structure which serves either to recognize mRNA stem loops or to recruit mRNA decay machinery (Wilusz \& Wilusz, 2005; Tritschler et al., 2007). Nonetheless, the way of RNA recognition probably differs from one used by Sm-fold-containing proteins, because the Sm structure of Dom34 lacks two motifs involved in RNA binding (Graille et al. 2008). It has been found in yeast and Thermoplasma acidophilum that Pelo N-terminal domain exhibits endonuclease activity dependent on divalent metal ion what has unvailed a first known Sm-containing domain with catalytic features (Lee et al., 2007). Furthermore, there is a putative leucine zipper motif in C-terminal domain that participates in interactions with other proteins (Busch and Sassone-Corsi, 1990). Shamsadin et al. (2002) have disclosed putative phosphorylation sites along the whole sequence by screening of the PROSITE protein motif library, such as motifs for protein kinase C, casein kinase II and tyrosine kinase. Besides, they have detected two Nglycosylation and three $\mathrm{N}$-myristoylation sites. It is unknown till now which of the sites play a role in protein functionality (Fig.2).

However, Pelo and eRF1 share some similarities. Graille et al. (2008) have compared eRF1 and S. cerevisiae Dom34 C-terminal domains which are suggested to interact with eRF3 (an eukaryotic release factor 3) and Hbs1 (ㅍsp70 subfamily $\underline{B}$ suppresor $\underline{1}$, yeast eRF3 homologue), respectively. Both interaction partners belong to the GTPase family and are responsible for recognition of stop codon and enhancing of polypeptide chain release (SalasMarco and Bedwell, 2004). Their study has revealed striking similarities of protein structural motifs being crucial for the interaction. Moreover, they have demonstrated that Dom34 enhances GTP binding to Hbs1, what is neccessary for peptidyl-tRNA hydrolysis upon GTP hydrolysis. The feature is convergent to eRF1 impact (Graille et al., 2008).

Pelota protein is localised in the cytoplasm, but it has been found to contain also a putative nuclear localization signal (NLS) at the N-terminus which is conserved from Drosophila to human (Eberhart and Wasserman, 1995; Davis and Engebrecht, 1998; Shamsadin et al., 2000; 2002). Nevertheless, generation of pelota mutant version in Drosophila, where NLS was disrupted, did not lead to loss of Pelo function. Cytoplasmatic distribution of the protein was observed as it was shown in controls. The finding indicates that Pelo is located in the cytoplasm and the putative nuclear motif is meaningless for Pelota functionality (Xi et al., 2005). 


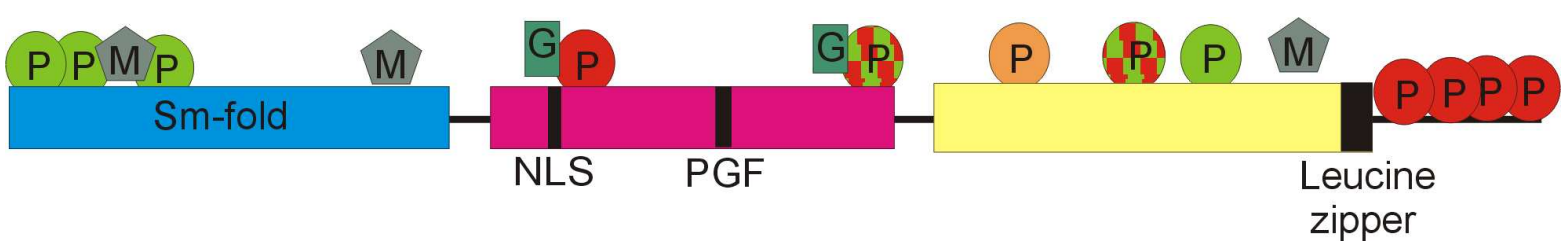

Figure 2. Scheme of PELO protein domains and putative posttranslational modifications $N$-terminal domain containing amino acid range from 1 to 131 (marked in blue); a putative nuclear localization signal (NLS) was found in central domain ranging from 136 to 268 aa (marked in pink) contains a conserved PGF motif (210-212 aa); C-terminal domain from 271 to 370 aa (marked in yellow) contains leucine zipper motif at the end. $P$ in greenprotein kinase C phosphorylation sites (aa: 38-40, 43-45, 58-60,342-344); $P$ in red-casein kinase II phosphorylation sites (aa: 176-179, 374-377, 380-383, 381-384, 382-385); $P$ in green and red-phosphorylation sites common for protein kinase $C$ and casein kinase II (aa: 252-255, 335-338); $P$ in orange - tyrosine kinase phosphorylation site (276-282 aa); $G$ in dark green - N-glycosylation sites (aa: 174-177, 236-239); $M$ in grey - N-myristoylation sites (aa: 54-59, 97-102, 357-362).

\subsection{The function of pelota gene in Saccharomyces cerevisiae and Drosophila melanogaster}

Drosophila pelota null mutants exhibit spermatogenesis arrest. The initial generation of spermatogonia and four rounds of mitotic division producing spermatocytes are unaffected, but then the cells are arrested in premeiotic G2 phase and meiotic divisions never occured. In such accumulated spermatocytes some processes were observed to be disrupted, such as spindle formation and nuclear envelope breakdown (Castrillon et al., 1993). Nonetheless, germ cell development continued and resulted in $4 \mathrm{~N}$ spermatids possessing head and tail structures. This indicates that Pelo protein does not influence spermiogenesis, but is required for G2/M transition during meiotic division. However, the role of Pelo is not restricted to meiosis - it also plays a role in fly eye development what suggests that Pelo is also functionally important in somatic growth (Ebenhart and Wasserman, 1995).

The detailed study of fruit fly ovary has shown that Pelota participates in germ stem cell (GSC) maintenance. In Drosophila, self-renewal of the germline is controlled by BMP (bone morphogenetic protein) signal which represses a Bam-dependent differentiation pathway. Xi et al. (2005) demonstrated that loss of Pelo leads to rapid differentiation of GSCs and loss of germline. Furthermore, they detected that BMP signal is downregulated in mutant GSCs, but it has no influence on expression of bam - the gene that is necessary and sufficient for the progression of oogenesis (Ohlstein and McKearin, 1997). To confirm the obtained results, a bam/pelota double null mutant was generated where differentiation was 


\section{INTRODUCTION}

still observed. It indicates that Pelo represses a Bam-independent differentiation pathway. In accordance with these findings, overexpression of pelota did not result in downregulation of Bam and had no effect on GSC maintenance and differentiation (Xi et al., 2005).

Analysis of dom34, a pelota ortholog in Sacharomyces cerevisiae, revealed that its null mutant fails to segregate chromosomes properly and produces less amount of spores in comparison to wild type yeast owing to lack of efficient G1 phase progression. It was suggested that bulk protein translation is impaired, so the key proteins for the phase of cell cycle are not translated (Davis and Engebrecht, 1998). Further studies have shown that Dom34 protein indeed is involved in translation process. Namely, it recognizes stalled ribosomes and cleaves mRNA in an endonucleolytic way in conjunction with Hbs1p, a member of the GTPase family. At present it is unclear whether it is a mRNA-specific or only a structure-specific process, but it is assigned to so called No-Go decay pathway. This pathway degrades mRNA, which cannot be translated due to stalled ribosomes on it (Doma and Parker, 2006; Lee et al., 2007).

\subsection{The phenotype of Pelota knockout mice}

Pelota has been also characterized in human and mouse. It has been found that mouse pelota expression starts early in embryonic development and is maintained in all adult tissues including all testicular developmental stages (Shamsadin et al., 2000; 2002).

To examine the function of PELO in mammals, the gene was disrupted by homologous recombination (Adham et al., 2003). Heterozygous mice did not exhibit apparent developmental malfunctions what proves that a single allele of the gene is sufficient for normal growth. However, PELO turned out to be crucial for proper embryogenesis due to fetal lethality of Pelo $^{-/}$animals. To estimate the time point for their death, embryos of different age were collected and genotyped. It was found that implantation is not affected in pelota-deficient embryos - the mean number of dissected E6.5- or E7.5-deciduae from $\mathrm{Pelo}^{+/}$intercrosses was similar to those received from wild-type crosses. The critical stage when embryos died was E7.5. The morphology of mutant embryos was abnormal and the embryos were reduced in size. Although all embryonic germ layers (ectoderm, mesoderm and endoderm) could be found, the extraembryonic region was substantially diminished. It was suggested that growth impairment was owing to defect in mitotic division, but not in development of germ layers. To prove this hypothesis, embryos at the stage of blastocyst 


\section{INTRODUCTION}

(E3.5) were isolated and cultured in vitro. Pelo ${ }^{-/-}$blastocysts were able to attach to the dish and to hatch from zona pellucida. They began to grow, but failed to expand and died within 4 days in the culture, whereas trophoblast cells remained alive and continued growing. It was demonstrated that only the cells mitotically active (i.e. ICM) are affected, but those which do not divide - survive. This can be related to former findings in Drosophila and yeast that Pelo influences cell cycle regulation (Eberhart and Wasserman, 1995; Davis and Engebrecht, 1998). It was also shown in yeast that pelota deficiency leads to meiosis arrest and subsequent production of $4 \mathrm{~N}$ spermatids, what suggests failure in chromosome segregation. An examination of cellular DNA content of murine Pelo-/- cells showed significant increase of aneuploid cells what indicates that PELO influences genomic stability. 


\section{INTRODUCTION}

\subsection{Aims of the study}

Comparing up-to-date findings regarding Pelota structure and function in Drosophila and yeast versus mammals, some questions arise.

Molecular mechanism of murine PELO function has not been demonstrated yet. The best way to study it, is a system based on in vitro cultures, where pelota is knocked out. It would be possible to investigate the basis of a putative proliferation defect of pelotadeficient cells. It would also facilitate creating more comprehensive system to discover the pathway/mechanism, in which pelota is involved.

As it was impossible to establish an embryonic stem cell line from Pelo ${ }^{-/}$blastocysts, we generated conditional knockout mouse. It enabled us to generate pelota-deficient ESC lines, where we could study whether PELO controls the maintanence of pluripotency and the differentiation processes.

Moreover, a conditional knockout mouse model can be used to study the consequences of PELO depletion in living animal. Due to the fact that spermatogenesis is a process where differentiation of pluripotent cells occurs in very apparent way during the whole life span, the conditional knockout mouse is a suitable model for studies of cell transformation from pluripotent up to differentiated state. Therefore, we generated testisspecific conditional knockout mice and analyzed available (Buyandelger, 2006) transgenic mice with testis-specific pelota overexpression.

Finally, to clearly demonstrate that the phenotype obtained in $\mathrm{Pelo}^{-/-}$mice specifically results from pelota deletion, we bred transgenic mice with ubiquitous overexpression of pelota gene together with classical knockout mice. The aim was to show whether exogenous PELO protein is able to rescue pelota-deficient phenotype. 


\section{MATERIALS AND METHODS}

\subsection{MATERIALS}

\subsubsection{Chemicals}

1 kb DNA Ladder

100 bp DNA Ladder

Acetic acid

Agar

Agarose

Ammonium acetate

Ammonium persulfate

Ampicillin

Ampuwa

Aprotinin

Aqua Poly/Mount

Bacto-tryptone

Bacto-Yeast-Extract

Blocking powder

BSA

Cell culture media

Chemiluminescent Substrate

Chloroform

Coomassie Blue G-250

Diethyl pyrocarbonate (DEPC)

Dimethyl sulfoxid (DMSO)

Dithiothreitol

dNTPs

EDTA

EGTA

Ethanol

Ethidium bromide

Eukitt-quick hardening mounting medium
Invitrogen, Karlsruhe

Invitrogen, Karlsruhe

Merck, Darmstadt

Difco, Detroit, USA

Invitrogen, Karlsruhe

Fluka, Neu Ulm

Sigma, Deisenhofen

Sigma, Deisenhofen

Fresenius, Bad Homburg

Sigma, Deisenhofen

Polysciences, Inc, USA

Difco, Detroit, USA

Difco, Detroit, USA

Boehringer, Mannheim

Biomol, Hamburg

PAN-Systems, Nürnberg

Pierce, Rockford, IL

Baker, Deventer, NL

Sigma, Deisenhofen

Sigma, Deisenhofen

Merck, Darmstadt

Sigma, Deisenhofen

Invitrogen, Karlsruhe

ICN Biomedicals, Eschwege

Applichem, Darmstadt

Baker, Deventer, NL

Sigma, Deisenhofen

Fluka, Neu Ulm 
FBS

Ficoll 400

Formaldehyde

Formamide

Glutaraldehyde

Glycerol

Glycine

Goat serum

$\mathrm{HCl}$

$\mathrm{H}_{2} \mathrm{O}_{2}$

HEPES

4-Hydroxytamoxifen

Horse serum

IPTG

Isopropanol

$\mathrm{KCl}$

$\mathrm{KH}_{2} \mathrm{PO}_{4}$

Lambda DNA

Leupeptin

Lipofectamine 2000

Methanol

2-Mercaptoethanol

$\mathrm{MgCl} 2$

Milk powder

$\mathrm{NaCl}$

$\mathrm{Na}_{2} \mathrm{HPO}_{4}$

$\mathrm{NaH}_{2} \mathrm{PO}_{4}$

$\mathrm{NaHCO}_{3}$

$\mathrm{NaN}_{3}$

$\mathrm{NaOH}$

Nonidet P40

NuPAGE Novex Bis-Tris 4-12\% Gel

NuPAGE MOPS/MES SDS running buffer

NuPAGE SDS sample buffer
Invitrogen, Karlsruhe

Amersham Pharmalia, Freiburg

Invitrogen, Karlsruhe

Fluka, Neu Ulm

Sigma, Deisenhofen

Invitrogen, Karlsruhe

Biomol, Hamburg

PAN-Systems, Nürnberg

Merck, Darmstadt

Merck, Darmstadt

Merck, Darmstadt

Sigma, Deisenhofen

PAN-Systems, Nürnberg

Biomol, Hamburg

Merck, Darmstadt

Merck, Darmstadt

Merck, Darmstadt

Roche, Penzberg

Sigma, Deisenhofen

TM Invitrogen, Karlsruhe

Merck, Darmstadt

Serva, Heidelberg

Merck, Darmstadt

Roth, Karlsruhe

Merck, Darmstadt

Merck, Darmstadt

Merck, Darmstadt

Merck, Darmstadt

Merck, Darmstadt

Merck, Darmstadt

Fluka, Neu Ulm

Invitrogen, Karlsruhe

Invitrogen, Karlsruhe

Invitrogen, Karlsruhe 
Orange G

OptiMEM I

Paraformaldehyde

PBS

Penicillin/Streptomycin

Peptone

Phalloidin

Phenol

Phosphoric acid

Picric acid

Proteinase K

Protein marker

$\left[{ }^{32} \mathrm{P}\right]-\mathrm{dCTP}$

RediprimeTM II

RNase A

RNase away

RNase Inhibitor

RNA length standard

Salmon sperm DNA

SDS

SeeBlue Plus2 Pre-Stained Standard

Select Peptone

S.O.C Medium

Sodium acetate

Sodium citrate

Sun flower oil

SuperScript II

T4 DNA ligase

Tamoxifen

TRI reagent

Tris base

Triton X-100

Trypsin

Tween-20
Sigma, Deisenhofen

Invitrogen, Karlsruhe

Merck, Darmstadt

PAN-Systems, Nürnberg

PAN-Systems, Nürnberg

Roth, Karlsruhe

Sigma, Deisenhofen

Biomol, Hamburg

Merck, Darmstadt

Fulka, Neu Ulm

Roche, Penzberg

Biorad, Sigma

Amersham Pharmalia, Braunschweig

Amersham Pharmacia, Freiburg

Qiagen, Hilden

Biomol, Hamburg

Roche, Penzberg

Invitrogen, Karlsruhe

Sigma, Deisenhofen

Serva, Heidelberg

Invitrogen, Karlsruhe

Gibco/BRL, Eggenstein

Invitrogen, Karlsruhe

Merck, Darmstadt

Merck, Darmstadt

Sigma, Deisenhofen

Invitrogen, Karlsruhe

Promega, Mannheim

Sigma, Deisenhofen

Sigma, Deisenhofen

Sigma, Deisenhofen

Serva, Heidelberg

PAN-Systems, Nürnberg

Sigma, Deisenhofen 
Vectashield (DAPI)

$\mathrm{X}-\mathrm{Gal}$

Xylene

Yeast extract
Vector, Burlingame

Biomol, Hamburg

Merck, Darmstadt

Roth, Karlsruhe

\subsubsection{Solutions, buffers and media}

All standard buffers and solutions were prepared according to Sambrook et al. (1989).

Annealing buffer (10x)

Denaturation solution

Depurination solution

E-buffer (10x)

Bouin's solution

Ligation buffer (10x)

Loading buffer
100 mM TrisHCl pH 7.5

$1 \mathrm{M} \mathrm{NaCl}$

10 mM EDTA

$1.5 \mathrm{M} \mathrm{NaCl}$

$0.5 \mathrm{M} \mathrm{NaOH}$

$250 \mathrm{mM} \mathrm{HCl}$

$300 \mathrm{mM} \mathrm{NaH} 2 \mathrm{PO}_{4}$

50 mM EDTA

15 volume of Picric acid (in $\mathrm{H}_{2} \mathrm{O}$ )

5 volumes 37\% Formaldehyde

1 volume Acetic acid

$600 \mathrm{mM}$ Tris/HCl (pH 7.5)

$80 \mathrm{mM} \mathrm{MgCl}{ }_{2}$

$100 \mathrm{mM}$ DTT

15\% Ficoll 400

10 mM EDTA (pH 8)

$0,25 \%$ Orange $\mathrm{G}$

$1 \%$ Glycerol 
Lysis buffer I

Lysis buffer II

Lysis buffer A

Neutralisation solution

$\operatorname{SSC}(20 x)$

TBE buffer $(5 \mathrm{x})$

TE buffer
$50 \mathrm{mM}$ Tris/HCl (pH 8.0)

100 mM EDTA

$0.5 \%$ SDS

$100 \mathrm{mM}$ Tris/HCl (pH 8.0)

$5 \mathrm{mM}$ EDTA

$200 \mathrm{mM} \mathrm{NaCl}$

$0.2 \% \mathrm{SDS}$

$100 \mu \mathrm{g} / \mathrm{ml}$ Proteinase K

$50 \mathrm{mM}$ Tris/HCl pH 7.0

$100 \mathrm{mM} \mathrm{NaCl}$

$5 \mathrm{mM} \mathrm{MgCl} 2$

$2 \%$ Triton $\mathrm{X}-100$

$2 \% \operatorname{SDS}$

$1 \mathrm{mM}$ PMSF

$1 \mathrm{mM}$ aprotinin

$1 \mathrm{mM}$ leupeptin

1 Protease inhibitor cocktail tablet/10ml buffer

$1.5 \mathrm{M} \mathrm{NaCl}$

$1 \mathrm{M}$ Tris/ $\mathrm{HCl}(\mathrm{pH} 7.0)$

$3 \mathrm{M} \mathrm{NaCl}$

$0.3 \mathrm{M}$ sodium citrate $(\mathrm{pH} 7.0)$

$450 \mathrm{mM}$ Tris base

$450 \mathrm{mM}$ Boric acid

20 mM EDTA (pH 8)

$10 \mathrm{mM}$ Tris/HCl (pH 8.0)

$1 \mathrm{mM}$ EDTA 


\subsubsection{Laboratory materials}

The laboratory materials, which are not listed here, were bought from Schütt and Krannich (Göttingen).

Cell culture flask

Culture slides

Disposable filter Minisart NMI

Filter paper 0858

Hybond C

Hybond N

HPTLC Aluminum folio

Microcentrifuge tubes

Petri dishes

Pipette tips

RotiPlast paraffin

Transfection flasks

Superfrost slides

Whatman blotting paper

(GB 002, GB 003 and GB 004)

$\mathrm{X}$-ray films
Greiner, Nürtingen

BD Falcon, Heidelberg

Sartorius, Göttingen

Schleicher and Schüll, Dassel

Amersham, Braunschweig

Amersham, Braunschweig

Merck, Darmstadt

Eppendorf, Hamburg

Greiner, Nürtingen

Eppendorf, Hamburg

Roth, Karlsruhe

Lab-Tek/Nalge, Nunc, IL, USA

Menzel, Gläser

Schleicher and Schüll, Dassel

Amersham, Braunschweig

\subsubsection{Sterilisation of solutions and equipments}

All solutions that are not heat sensitive were sterilised at $121^{\circ} \mathrm{C}, 105 \mathrm{~Pa}$ for $60 \mathrm{~min}$ in an autoclave (Webeco, Bad Schwartau). Heat sensitive solutions were filtered through a disposable sterile filter ( 0.2 to $0.45 \mu \mathrm{m}$ pore size). Plastic wares were autoclaved as above. Glasswares were sterilised overnight in an oven at $220^{\circ} \mathrm{C}$.

\subsubsection{Media, antibiotics and agar-plates}

\subsubsection{Media for bacteria}

LB Medium ( $\mathrm{pH} 7.5)$

1\% Bacto-trypton 


$$
\begin{aligned}
& 0.5 \% \text { Yeast extracts } \\
& 1 \% \mathrm{NaCl} \\
& 1 \% \text { Bacto-trypton } \\
& 0.5 \% \text { Yeast extracts } \\
& 1 \% \mathrm{NaCl} \\
& 1.5 \% \text { Agar }
\end{aligned}
$$

LB-Agar

The LB medium was prepared with distilled water, autoclaved and stored at $4{ }^{\circ} \mathrm{C}$.

\subsubsection{Media for cell and embryo culture}

M2 and M16 media were purchased from Sigma (Deisenhofen) and were used for washing and cultivation of mouse preimplantation embryos.

Embryonic stem (ES) cell medium:

DULBECCO’s Modified Eagles Media (DMEM)

$1 \mathrm{mM}$ Non essential amino acids

$1 \mathrm{mM}$ Sodium pyruvate

$10 \mu \mathrm{M} \beta$-Mercaptoethanol

2 mM L-Glutamine

$20 \%$ FCS

$1000 \mathrm{U} / \mathrm{ml}$ Recombinant leukaemia inhibitory factor (LIF)

Fibroblast cell medium (MEFs):

DULBECCO’s Modified Eagles Media (DMEM)

2 mM L-Glutamine

$10 \%$ FCS

$1 \%$ penicillin/streptomycin

For long time storage of the cells in liquid nitrogen, the following freezing medium was used:

Freezing medium:

$20 \%$ FCS

$10 \%$ DMSO in DMEM

KO medium:

Knockout DMEM optimized for ES cells (Gibco)

$20 \%$ knockout supplement 


\author{
$1 \mathrm{mM}$ Non essential amino acids \\ $1 \mathrm{mM}$ Sodium pyruvate \\ $10 \mu \mathrm{M}$ ß-Mercaptoethanol \\ 2 mM L-Glutamine \\ $20 \%$ FCS \\ factor (LIF) \\ Embryonic stem (ES) cell medium \\ $400 \mu \mathrm{g} / \mathrm{ml} \mathrm{G} 418$ \\ $2 \mu \mathrm{M}$ gancyclovir
}

1000 U/ml Recombinant leukaemia inhibitory

Selective medium:

\title{
2.1.5.3 Antibiotics
}

Stock solutions were prepared for the antibiotics. They were filtered through sterile disposable filters and stored at $-20^{\circ} \mathrm{C}$. When antibiotics were needed, in each case, they were added after the autoclaved medium has cooled down to a temperature lower than $55^{\circ} \mathrm{C}$.

$\begin{array}{lll}\text { Antibiotics } & \text { Stock solution } & \text { Working solution } \\ \text { Ampicillin } & 50 \mathrm{mg} / \mathrm{ml} & 50 \mu \mathrm{g} / \mathrm{ml} \\ \text { Kanamycin } & 25 \mathrm{mg} / \mathrm{ml} & 50 \mu \mathrm{g} / \mathrm{ml}\end{array}$

\subsubsection{IPTG/X-Gal plate}

LB-agar with $50 \mu \mathrm{g} / \mathrm{ml}$ ampicillin, $100 \mu \mathrm{M}$ IPTG and $0.4 \% \mathrm{X}$-Gal was poured into Petri dishes. The dishes were stored at $4^{\circ} \mathrm{C}$.

\subsubsection{Bacterial strains}

E. coli DH5 $\alpha$

E. coli BL21 (DE3)
K-12 strain,F- \$80d lacZAM15 endA1 recA1 hsdR17 (rk-, mk+) sup E44 thi-1

d- gyrA96 (lacZYA-arg)

(Invitrogen, Karlsruhe)

B strain, F- omp T hsd SB(rB-mB-) gal, Dcm (Novagen, Darmstadt) 


\subsubsection{Plasmids}

pBluesript SK (+/-)

(Stratagene, La Jolla, USA)

pGEMTeasy

(Promega, Wisconsin, USA)

\subsubsection{Synthetic oligonucleotides}

The synthetic oligonucleotide primers used in this study were obtained from OPERON and dissolved in $\mathrm{dH}_{2} \mathrm{O}$ (Ampuwa) to a final concentration of $100 \mathrm{pmol} / \mu \mathrm{l}$.

\begin{tabular}{|c|c|}
\hline Name & Sequence \\
\hline 3'regionA_F & 5' CATTATCCACTGCCCACATTC 3' \\
\hline 3'region_R & 5' TAGAACTGGCCTTCTCGCAC 3' \\
\hline cKO_3'ext_F & 5' GCGAATACGTCAGCAGAAG 3' \\
\hline cKO_3'ext_R & 5' GAGTCACAAGTGGGCAATG 3' \\
\hline Cre_R & 5' AGTGAAACAGCATTGCTGTCA 3' \\
\hline EIIa-CreF & 5' CCAGGCTAAGTGCCTTCTCTACA 3' \\
\hline EIIa-CreR & 5' AATGCTTCTGTCCGTTTGCCGGT 3' \\
\hline EvaL1_F & 5' TCTCTTGTTCTAAGATGTGCTGTG 3' \\
\hline EvaL1_GenomeWalk_F2 & 5' ACCCTGGCGTTACCCAACTTAATCGC 3' \\
\hline EvaL1_R & 5' AAAGGGGCTCGATTAGATGAACT 3' \\
\hline m18S_F & 5' CGCAAATTACCCACTCCCG 3' \\
\hline m18S_R & 5' TTCCAATTACAGGGCCTCGAA 3' \\
\hline mc-Kit_F & 5' GCCACGTCTCAGCCATCTG 3' \\
\hline mc-Kit_R & 5' GTCGGGATCAATGCACGTCA 3' \\
\hline mDAZL_F & 5' CTCCACCTTCGAGGTTTTACC 3' \\
\hline mDAZL_R & 5' GTGATTTCGGTTTCATCCATC 3' \\
\hline mPelo.RT-PCR-F2 & 5' ATCCAGCGCCACATAAACTT 3' \\
\hline mPelo.RT-PCR-R2 & 5' СТСТCCACCTGCTTGAGTCC 3' \\
\hline mPlzf_F & 5' CTCCGTAAGCGTCCCCTCTGC 3' \\
\hline mPlzf_R & 5' GGTGCAGGCTAGCACCGTCC 3' \\
\hline mSDHA_F & 5' GCTTGCGAGCTGCATTTGG 3' \\
\hline mSDHA_R & 5' CATCTCCAGTTGTTCTCTTCCA 3' \\
\hline mSox3_F & 5'CACATGAAGGAGTAGTACCCGGACTA 3' \\
\hline mSox_R & 5' TGAGCAGCGTCTTGGTCTTG 3' \\
\hline
\end{tabular}




mStra8_F
mStra8_R
mVASA_F
mVASA_R
Pelo_F11
Pelo_R14
Pelota3'F2
Pelota3'R2
PGK_cKO_R1
RosaCreER-F
RosaCreER-R
Stra8_F
Trans.pEF-F
Trans.pUB-F
Trans.hPelo-R1

mStra8_F

5' CTGTTGCCGGACCTCATG 3'

5' TCACTTCATGTGCAGAGATGATG 3'

5' GAGAAGTGGGTTTCCTTCTGG 3'

5' GAAAACCCTCTGCTTCGAGTC 3'

5' TGAGCCCAGACTGTACGTGAC 3'

5' AACGTCAAAGGAGGCGGTCAG 3'

5' GGTATCATGGCCTCTATTCAG 3'

5' GCACAGACATGACCAATACG 3'

5' CCACTTGTGTAGCGCCAAGTG 3'

5' ACCAGCCAGCTATCAACTC 3'

5'TATACGCGTGCTAGCGAAGATCTCCATCTTCCAGCAG 3'

5' GCGCTCCTAGTGTGCCAGTTTGAT 3'

5' CATTCTCAAGCCTCAGACAGTG 3'

5' TCAGTGTTAGACTAGTAAATTG 3'

5' GAGGACTCTGTCTGTACCTTG 3'

\subsubsection{Mouse strains}

Strains C57BL/6J, 129/Sv, CD-1 and NMRI were initially ordered from Charles River Laboratories, Wilmington, USA, and kept in Animal Facility of Institute of Human Genetics, Göttingen. ROSA26CreERT (Berns A, Netherlands) and EIIaCre (Lakso et al., 1996) mice were kindly provided by Prof. Dr. med. H. Hahn, Institute of Human Genetics, Göttingen.

\subsubsection{Antibodies}

Goat anti-mouse $\mathrm{IgG}$ alkaline phosphatase conjugate

Goat anti-rabbit IgG alkaline phosphatase conjugate

Goat anti-rabbit GFP antiserum

Rabbit anti-mouse IgG Cy3 conjugate

Goat anti-rabbit IgG FITC conjugate

Rabbit anti-mouse IgG FITC conjugate

Mouse monoclonal anti $\beta$-tubulin

Goat anti-rabbit IgG horse radish preoxidase conjugate
Sigma, Deisenhofen Sigma, Deisenhofen Sigma, Deisenhofen Sigma, Deisenhofen Sigma, Deisenhofen Sigma, Deisenhofen Sigma, Deisenhofen Sigma, Deisenhofen 
Rabbit anti-mouse IgG horse radish preoxidase conjugate

Rabbit anti Pelota polyclonal antibody

mouse anti GCNA1 monoclonal antibody

Rabbit anti HSP110 polyclonal antibody

Rabbit anti Apg1 polyclonal antibody

Rabbit anti Apg2 polyclonal antibody

Rabbit anti CyclinA1 polyclonal antibody
Sigma, Deisenhofen

Institute of Human Genetics

G. Enders, University of Kansas, USA

Sigma, Steinheim

Santa Cruz Biotechnology, Heidelberg

Santa Cruz Biotechnology, Heidelberg

Santa Cruz Biotechnology, Heidelberg

\subsubsection{Enzymes}

Antarctic Phosphatase

FideliTag DNA Polymerase

Immolase DNA Polymerase

Klenow Fragment

Proteinase K

Platinum Taq polymerase

Restriction enzymes (with supplied buffers)

RNase A

RNase $\mathrm{H}$

RNase inhibitor

Superscript-II

Taq polymerase

T4 DNA ligase

Trypsin

\subsubsection{Radioactive substances}

$\alpha-32 \mathrm{P}-\mathrm{dCTP}$

\subsubsection{Kits}

AP Kit (86C-1 KT)

(Sigma, Deisenhofen)

Endo Free Plasmid Maxi Kit

GenomeWalker Universal Kit
(Qiagen, Hilden)

(Clontech)
(BioLabs, Frankfurt am Mein)

(USB, Staufen)

(Bioline, Luckenwalde)

(Invitrogen, Karlsruhe)

(Sigma, Deisenhofen)

(Invitrogen, Karlsruhe)

(Invitrogen, Karlsruhe)

(Qiagen, Hilden)

(Invitrogen, Karlsruhe)

(Invitrogen, Karlsruhe)

(Invitrogen, Karlsruhe)

(Invitrogen, Karlsruhe)

(Promega, Mannheim)

(Invitrogen, Karlsruhe) 
Labelling System

Megaprime DNA Labeling Kit

Midi Plasmid Kit

Mini Plasmid Kit

PCR Purification Kit

QIAquick Gel Extraction Kit

RNAeasy Kit

RediprimeTM II Random Prime
(Qiagen, Hilden)

(Amersham Pharmacia, Freiburg)

(Invitrogen, Karlsruhe)

(Qiagen, Hilden)

(Qiagen, Hilden)

(Qiagen, Hilden)

(Qiagen, Hilden)

(Amersham Pharmacia, Freiburg)

\subsubsection{Equipment}

Autoclave

Centrifuge 5415D

Centrifuge 5417R

Biophotometer

DNA Sequencer Modell Megabace 1000

Microscope BX60

GeneAmp PCR System 9600

Histocentre 2 embedding machine

Microtiterplate-Photometer

Molecular Imager FX

Phosphoimager Screen

Semi-Dry-Blot Fast Blot

Spectrophotometer Ultraspec 3000

SpeedVac concentrator SVC $100 \mathrm{H}$

Thermomixer 5436

TurboblotterTM

UV StratalinkerTM1800
(Webeco, Bad Schwartau)

(Eppendorf, Hamburg)

(Eppendorf, Hamburg)

(Eppendorf, Hamburg)

(Amersham, Freiburg)

(Olympus, München)

(Perkin Elmer, Berlin)

(Shandon, Frankfurt aM.)

(BioRad laboratories, München)

(BioRad laboratories, München)

(BioRad laboratories, München)

(Biometra, Göttingen)

(Amersham, Freiburg)

(Schütt, Göttingen)

(Eppendorf, Hamburg)

(Schleicher \& Schüll, Dassel)

(Leica, Nußloch) 


\subsection{METHODS}

\subsubsection{Isolation of nucleic acids}

\subsubsection{Isolation of plasmid DNA (Sambrook et al., 1989)}

\section{Small-scale isolation of plasmid DNA (Birnboim and Doly, 1979)}

A single bacterial colony was inoculated into $5 \mathrm{ml} \mathrm{LB}$ medium, containing an appropriate antibiotic, and incubated at $37^{\circ} \mathrm{C}$ for $12-16$ hours with a shaking speed of 160 rpm. $0.2 \mathrm{ml}$ of this culture was used for glycerol stock and rest of it was centrifuged at 4000 $\mathrm{x} \mathrm{g}$ for $10 \mathrm{~min}$. The pellet was resuspended in $100 \mu \mathrm{l}$ of resuspension solution P1 (Invitrogen). The bacterial cells were lysed with $200 \mu \mathrm{l}$ of lysis solution P2 (Invitrogen), incubated at RT for $5 \mathrm{~min}$ and then neutralised with $150 \mu \mathrm{l}$ of neutralisation solution P3 (Invitrogen). The precipitated solution was incubated at RT for $5 \mathrm{~min}$ and centrifuged at $13000 \times \mathrm{g}$ at RT. The supernatant was transferred into a new tube, where $1 \mathrm{ml}$ of $100 \%$ ethanol was added to precipitate the DNA. Then it was incubated for $30 \mathrm{~min}$ at RT, centrifuged at full speed for $20 \mathrm{~min}$, and finally the pellet was washed with $350 \mu \mathrm{l}$ of $70 \%$ ethanol and after air-drying dissolved in $30 \mu \mathrm{l}$ of $\mathrm{dH}_{2} \mathrm{O}$.

P1: 50 mM Tris/HCl, pH 8.0; 10 mM EDTA; $100 \mu \mathrm{g} / \mathrm{ml}$ RNase A

P2: $200 \mathrm{mM} \mathrm{NaOH} ; 1 \%$ SDS

P3: 3 M Potassium acetate, $\mathrm{pH} 5.5$

\section{Large-scale preparation of Endotoxin free plasmid DNA using the Qiagen Maxi Kit}

A single clone was inoculated into $5 \mathrm{ml} \mathrm{LB}$ medium, containing an appropriate antibiotic. The preculture was incubated for 12 hours at $37^{\circ} \mathrm{C}$ with shaking. Then it was diluted 500 times in $100 \mathrm{ml}$ of the same medium and incubated overnight at $37^{\circ} \mathrm{C}$ with shaking. Next day it was centrifuged at $6000 \mathrm{x} g$ for $15 \mathrm{~min}$. The pellet was resuspended in 5 $\mathrm{ml}$ of solution P1 and cells were lysed with P2 and P3 as described above. The precipitated solution was centrifuged at $20000 \mathrm{x}$ g for $30 \mathrm{~min}$ at $4^{\circ} \mathrm{C}$. Meanwhile, the column (Qiagentip), that was provided with the maxi preparation kit, was equilibrated with $10 \mathrm{ml}$ of QBT solution. After centrifugation, the lysate was poured into this equilibrated column to allow the DNA to bind with the resin present on the bottom of the column. The column was then washed twice with $10 \mathrm{ml}$ of solution QC. Finally, the DNA was eluted with $5 \mathrm{ml}$ of QF 
solution. For precipitation of the DNA, $3.5 \mathrm{ml}$ of isopropanol was added, mixed thoroughly and then centrifuged at $14000 \mathrm{x} \mathrm{g}$ for $30 \mathrm{~min}$ at $4{ }^{\circ} \mathrm{C}$. The obtained pellet was washed with $70 \%$ ethanol and dissolved in $100 \mu \mathrm{l}$ of TE buffer.

QBT: $750 \mathrm{mM}$ Sodium chloride; $50 \mathrm{mM}$ MOPS pH 7.0; $15 \%$ Ethanol; $0.5 \%$ Triton X-100

QC: 1 mM Sodium chloride; 50 mM MOPS pH 7.0; $15 \%$ Ethanol

QF: 1.25 M Sodium chloride; $50 \mathrm{mM}$ Tris/ $\mathrm{HCl} \mathrm{pH} 8.5$

\subsubsection{Isolation of genomic DNA}

\section{Isolation of genomic DNA from tissue samples (Laird et al., 1991)}

$1 \mathrm{~cm}$ of the mouse tail was incubated in $700 \mu \mathrm{l}$ of lysis buffer I containing $35 \mu \mathrm{l}$ proteinase $\mathrm{K}(10 \mu \mathrm{g} / \mu \mathrm{l})$ at $55^{\circ} \mathrm{C}$ overnight in Thermomixer 5436. The tissue lysate was centrifuged at $14000 \mathrm{x}$ g for $15 \mathrm{~min}$ and the supernatant was transferred into a new e-cup. Then, DNA was precipitated by adding an equal volume of isopropanol, mixed by inverting several times and centrifuged at $14000 \mathrm{x}$ g at RT for $15 \mathrm{~min}$. DNA was washed with $1 \mathrm{ml}$ of $70 \%$ ethanol, dissolved in $50-100 \mu \mathrm{l}$ of $\mathrm{dH}_{2} \mathrm{O}$ and incubated at $60^{\circ} \mathrm{C}$ for $10 \mathrm{~min}$.

\section{Isolation of genomic DNA from cultured cells}

Cells were washed with PBS and incubated overnight in $500 \mu$ of lysis buffer II at $37^{\circ} \mathrm{C}$. Next, equal volume of isopropanol was added, mixed by inverting several times and incubated for $10 \mathrm{~min}$ at RT. Then, centrifuged for $15 \mathrm{~min}$ at maximal speed. After washing the pellet with $70 \%$ ethanol, the DNA was dissolved in $80 \mu \mathrm{l}$ of $\mathrm{dH}_{2} \mathrm{O}$ and incubated at $60^{\circ} \mathrm{C}$ for $10 \mathrm{~min}$.

\subsubsection{Isolation of total RNA from tissue samples and cultured cells}

Total RNA isolation reagent is an improved version of the single-step method for total RNA isolation. The composition of reagent includes phenol and guanidine thiocyanate in a mono-phase solution. 100-200 $\mathrm{mg}$ of tissue sample was homogenised in $1 \mathrm{ml}$ of TRI Reagent by using an e-cup homogeniser. The sample volume did not not exceed $10 \%$ of the volume of reagent used for the homogenisation. To isolate total RNA from cultured cells, $350 \mu \mathrm{l}$ of reagent was added to the Petri dish $(6 \mathrm{~cm})$. Cells were homogenised with a rubber scraper and the lysate was transferred into a microcentrifuge tube, where it was incubated at $4^{\circ} \mathrm{C}$ for $5 \mathrm{~min}$ to permit the complete dissociation of nucleoprotein complexes. Then, $0.2 \mathrm{ml}$ of chloroform was added, mixed vigorously, and stored at $4^{\circ} \mathrm{C}$ for $10 \mathrm{~min}$. After 
centrifugation at $12000 \mathrm{xg}$ for $15 \mathrm{~min}$ at $4^{\circ} \mathrm{C}$, the upper aqueous phase was transferred into a new tube. The RNA was precipitated by adding $0.5 \mathrm{ml}$ of isopropanol. Finally, the pellet was washed twice with $75 \%$ ethanol and dissolved in 30-80 $\mu$ l of RNase free water (DEPC$\left.\mathrm{dH}_{2} \mathrm{O}\right)$.

\subsubsection{Determination of nucleic acid concentration}

The concentration of nucleic acids was determined spectrophotometrically by measuring absorption of the samples at $260 \mathrm{~nm}$. The quality of nucleic acids i.e. contamination with salt and protein was estimated by ratio of absorbance $260 \mathrm{~nm} / 280 \mathrm{~nm}$. The correct value of the ratio is 1,8 for DNA and 2,0 for RNA.

\subsubsection{Determination of transgene integration - GenomeWalker Universal Kit}

GenomeWalker Kit helps to find unknown genomic DNA sequences adjacent to a known sequence. First step was to construct pools which consist of adaptor-ligated genomic DNA fragments (i.e. libraries). Thereafter, primary PCR was done by using outer adaptor primer (AP1) provided in the kit and outer gene-specific primer (EvaL1_GenomeWalk_F1 for EvaL1 line). Diluted primary PCR mixture was then used as a template for nested PCR with a nested adaptor primer (AP2) provided in the kit and nested gene-specific primer (EvaL1_GenomeWalk_F2). The obtained result was a major PCR product from at least three of four libraries. All fragments were sequenced. The one, which began with a known sequence at the 5' end of EvaL1_GenomeWalk_F2 primer and extended into the unknown adjacent genomic DNA, was further cloned, sequenced and compared to mouse genome sequence.

The procedure was exactly followed according to manufacturer's protocol (GenomeWalker Universal Kit - User Manual, cat. no. 638904, Clontech).

\subsubsection{Gel electrophoresis}

Gel electrophoresis is the technique which enables separation of nucleic acids and proteins in an electrical field according to their mobility which is directly proportional to macromolecule's charge to mass ratio. 


\subsubsection{Agarose gel electrophoresis of DNA}

Agarose gels were used to run nucleic acid molecules from as small as 50 bases to more than $20 \mathrm{~kb}$, depending on the concentration of the agarose. Usually, 1 g agarose was added to $100 \mathrm{ml}$ of $0.5 \mathrm{x}$ TBE buffer and boiled in the microwave to dissolve the agarose, then cooled down to about $60^{\circ} \mathrm{C}$ before adding $3 \mu \mathrm{l}$ of ethidium bromide $(10 \mathrm{mg} / \mathrm{ml})$. This $1 \%$ agarose gel was poured into a horizontal gel chamber.

\subsubsection{Agarose gel electrophoresis of RNA (Hodge, 1994)}

mRNA molecules often have complementary regions that can form secondary structures. Therefore, RNA was pre-treated with formaldehyde and formamide in order to denature the secondary structure of RNA and it was run on an agarose gel containing formaldehyde. $1.25 \mathrm{~g}$ of agarose was added to $100 \mathrm{ml}$ of $1 \mathrm{x}$ E buffer and dissolved by heating in a microwave. After cooling it to about $60^{\circ} \mathrm{C}, 25 \mathrm{ml}$ of formaldehyde (37\%) was added, stirred and poured into a vertical gel chamber. RNA samples $(10-30 \mu \mathrm{g})$ were mixed with double volume of sample buffer, then denatured at $65^{\circ} \mathrm{C}$ for $10 \mathrm{~min}$ and chilled on ice. After adding loading buffer (equal volume to RNA sample), the gel was loaded and run at $70-80 \mathrm{~V}$ at $4^{\circ} \mathrm{C}$ for $4-5$ hours.

Sample buffer/ 1 sample: $2 \mu$ 10x E buffer; $3 \mu 1$ 37\% formaldehyde; $8 \mu 1$ 40\% formamide; Loading buffer: $40 \mu \mathrm{l} 1 \%$ ethidium bromide in $500 \mu \mathrm{l}$ standard loading buffer

\subsubsection{SDS-PAGE gel for separation of proteins}

NuPage 4-12\% Bis-Tris gel is SDS-PAGE gel with 4-12\% percentage gradient what allows more efficient separation of proteins. $20.5 \mu \mathrm{l}$ of whole protein lysate was mixed with $7.5 \mu \mathrm{l} 4 \mathrm{x}$ NuPage sample buffer and $2 \mu \mathrm{l}$ 1M DTT. Then, the samples were denatured in $95^{\circ} \mathrm{C}$ for $10 \mathrm{~min}$ and chilled in ice. The gel electrophoresis was run in $1 \mathrm{x}$ MOPS buffer or 1 x MES buffer (Invitrogen). As a weight marker, a pre-stained molecular weight standard (See Blue Plus2, Invitrogen) was loaded. The gel was run at $100 \mathrm{~V}$ for $2-3$ hours at RT. 


\subsubsection{Purification of DNA fragments from agarose gel}

To extract and purify DNA of $70 \mathrm{bp}$ to $10 \mathrm{~kb}$ in length from agarose gels, QIAquick gel extraction kit (Qiagen) was used. Up to $400 \mathrm{mg}$ agarose can be processed during single isolation. 3 volumes of QG buffer were added to an agarose gel piece and then incubated at $50^{\circ} \mathrm{C}$ for $10 \mathrm{~min}$. After the gel slice was dissolved, the solution was applied to a QIAquick column and centrifuged for $1 \mathrm{~min}$. The flow through was discarded and the column was washed with $0.75 \mathrm{ml}$ of PE buffer. After drying, the column was placed into a fresh microcentrifuge tube. To elute DNA, $50 \mu \mathrm{l}$ of $\mathrm{dH}_{2} \mathrm{O}$ was applied to the centre of the QIAquick membrane and the column was centrifuged for $1 \mathrm{~min}$.

\subsubsection{Enzymatic modifications of DNA}

\subsubsection{Restriction of DNA}

Restriction enzyme digestions were performed by incubating double-stranded DNA with a restriction enzyme in amount of max. 1/10 reaction volume in a buffer recommended by the supplier, and at the optimal temperature for the specific enzyme. Standard digestions included 2-10 U enzyme per $1 \mu \mathrm{g}$ DNA. Usually incubation time was $1-3$ hours at $37^{\circ} \mathrm{C}$. For genomic DNA digestion, the reaction solution was incubated overnight at $37^{\circ} \mathrm{C}$.

\subsubsection{Ligation of DNA fragments}

The cloning of an insert DNA into a vector (digested with appropriate restriction enzyme) was carried out in the following ligation reaction mix in total volume of $10 \mu \mathrm{l}$ :

- $30 \mathrm{ng}$ vector DNA (digested)

- 50-100 ng insert DNA (1:3, vector: insert ratio)

- $1 \mu$ ligation buffer (10x)

- $1 \mu \mathrm{lT} 4 \mathrm{DNA}$ ligase $(5 \mathrm{U} / \mu \mathrm{l})$

The reactions were performed at $4^{\circ} \mathrm{C}$ overnight. 
2.2.6.3 TA-Cloning (Clark, 1988; Hu, 1993)

Taq polymerase and other DNA polymerases have a terminal transferase activity that results in the non-template addition of a single nucleotide to the $3^{\prime}$ ends of PCR products. In the presence of all $4 \mathrm{dNTPs}$, dATP is preferentially added. This terminal transferase activity is the basis of the TA-cloning strategy. For cloning of PCR products, a pGEMTeasy vector system that has 5'T overhangs was used. The following substances were mixed:

- $50 \mathrm{ng}$ of pGEMTeasy vector

- 150 ng PCR product

- $1 \mu \mathrm{l}$ of T4 DNA Ligase buffer (x10)

- $1 \mu \mathrm{l}$ of T4 DNA Ligase

The reactions were done in a total volume of $10 \mu \mathrm{l}$ and incubated overnight at $4^{\circ} \mathrm{C}$.

\subsubsection{Dephosphorylation}

The removal of 5' phosphate groups from DNA was done by using of Antarctic Phosphatase (BioLabs). Dephosphorylation mixture was prepared as follows:

$1 \mu \mathrm{g}$ DNA

$2 \mu 1$ 10x AP buffer

$1 \mu 1$ 5U Antarctic Phosphatase

The mixture of $20 \mu \mathrm{l}$ was then incubated at $37^{\circ} \mathrm{C}$ for either 15 (for $5^{\prime}$ extension) or $60 \mathrm{~min}$ (for 3' extension). Afterwards, the enzyme was inactivated for $10 \mathrm{~min}$ in $65^{\circ} \mathrm{C}$.

\subsubsection{Transformation of competent bacteria (Ausubel et al., 1994)}

Transformation of bacteria was done by gently mixing $50 \mu$ l-aliquot of competent bacteria (Invitrogen) with $10 \mu \mathrm{l}$ of ligation reaction. After incubation for $30 \mathrm{~min}$ on ice, bacteria were heat-shocked for $45 \mathrm{sec}$ at $37^{\circ} \mathrm{C}$ and cooled down for $2 \mathrm{~min}$ on ice. After adding 450-900 $\mu \mathrm{l}$ of S.O.C. medium, the mixture was incubated at $37^{\circ} \mathrm{C}, 400 \mathrm{rpm}$, for 1 hour to allow recovery of heat shocked bacteria which then were plated on LB-agar plates. 


\subsubsection{Polymerase Chain Reaction (PCR)}

In general, the PCR reaction contained the following substances:

- 10 ng DNA

- $1 \mu \mathrm{l}$ forward primer $(10 \mathrm{pmol})$

- $1 \mu \mathrm{l}$ reverse primer $(10 \mathrm{pmol})$

- $\quad 1 \mu 110 \mathrm{mM}$ dNTPs

- $5 \mu 110$ x PCR buffer

- $\quad 1.5 \mu \mathrm{l} 50 \mathrm{mM} \mathrm{MgCl} 2$

- $0.5 \mu \mathrm{l}$ Taq DNA Polymerase (5 U/ $\square \mathrm{l}$ )

- Up to $50 \mu \mathrm{ld} \mathrm{d}_{2} \mathrm{O}$

The reaction mixture was placed in a $200 \mu \mathrm{l}$ reaction tube and placed in a thermocycler.

Thermal cycling was carried out for 35 cycles with denaturation at $95^{\circ} \mathrm{C}$ for $30 \mathrm{sec}$, annealing at $55-60^{\circ} \mathrm{C}$ for $30 \mathrm{sec}$ and extension at $72^{\circ} \mathrm{C}$ for $30 \mathrm{sec} .-1 \mathrm{~min}$ (depending on the product size).

\subsubsection{Genotyping PCRs}

\section{Flox/-/A PCR}

Ingredients:

$\mathrm{H}_{2} \mathrm{O}$

buffer

$\mathrm{MgCl}_{2}$

dNTPs

Pelo_F11

Pelo_R14

PGK_cKO_R1

Taq Platinum

DNA

\section{CreEIIa PCR}

Ingredients:

$\mathrm{H}_{2} \mathrm{O}$

buffer

$\mathrm{MgCl}_{2}$

dNTPs

EllaCre_F

EllaCre_R

Taq Platinum

DNA
$11,6 \mu \mathrm{l}$

$1,5 \mu \mathrm{l}$

$0,3 \mu \mathrm{l}$

$0,3 \mu \mathrm{l}$

$0,3 \mu \mathrm{l}$

$0,3 \mu \mathrm{l}$

$0,3 \mu \mathrm{l}$

$0,15 \mu \mathrm{l}$

$0,5 \mu \mathrm{l}$
Program:

$94^{\circ} \mathrm{C}-5 \mathrm{~min}$

$94^{\circ} \mathrm{C}-30 \mathrm{sec}$.

$65^{\circ} \mathrm{C}-50$ sec.

$72^{\circ} \mathrm{C}-30 \mathrm{sec}$.

$72^{\circ} \mathrm{C}-7 \mathrm{~min}$
Program:

$94^{\circ} \mathrm{C}-5 \mathrm{~min}$

$94^{\circ} \mathrm{C}-30 \mathrm{sec}$

$67^{\circ} \mathrm{C}-40 \mathrm{sec}$.

$72^{\circ} \mathrm{C}-40$ sec.

$72^{\circ} \mathrm{C}-7 \mathrm{~min}$ 


\section{Cre PCR (cKO/Stra8 line)}

Ingredients:

$\begin{array}{ll}\mathrm{H}_{2} \mathrm{O} & 20 \mu \mathrm{l} \\ \text { buffer } & 2,5 \mu \mathrm{l} \\ \mathrm{MgCl}_{2} & 0,75 \mu \mathrm{l} \\ \text { dNTPs } & 0,5 \mu \mathrm{l} \\ \text { Stra8_F } & 0,5 \mu \mathrm{l} \\ \text { Cre_R } & 0,5 \mu \mathrm{l} \\ \text { Taq Platinum } & 0,15 \mu \mathrm{l} \\ \text { DNA } & 0,5 \mu \mathrm{l}\end{array}$

\section{CreERT PCR}

Ingredients:

$\mathrm{H}_{2} \mathrm{O}$

buffer

$\mathrm{MgCl}_{2}$

dNTPs

RosaCreER_F

RosaCreER_R

Taq Platinum

DNA

\section{EvaL1 PCR}

Ingredients:

$\begin{array}{ll}\mathrm{H}_{2} \mathrm{O} & 18 \mu \mathrm{l} \\ \text { buffer } & 2,5 \mu \mathrm{l} \\ \mathrm{MgCl}_{2} & 1 \mu \mathrm{l} \\ \text { dNTPs } & 0,5 \mu \mathrm{l} \\ \text { EvaL1_F } & 1 \mu \mathrm{l} \\ \text { EvaL1_R } & 0,5 \mu \mathrm{l} \\ \text { EvaL1_GenomeWalk_F2 } & 0,5 \mu \mathrm{l} \\ \text { Taq Platinum } & 0,15 \mu \mathrm{l} \\ \text { DNA } & 0,5 \mu \mathrm{l}\end{array}$

$1 \mu \mathrm{l}$

$0,2 \mu 1$

$0,5 \mu \mathrm{l}$

$0,5 \mu \mathrm{l}$

$0,15 \mu \mathrm{l}$

$0,5 \mu \mathrm{l}$
Program:

$94^{\circ} \mathrm{C}-5 \mathrm{~min}$

$94^{\circ} \mathrm{C}-45 \mathrm{sec}$.

$57^{\circ} \mathrm{C}-55 \mathrm{sec}$.

$72^{\circ} \mathrm{C}-1$ min $20 \mathrm{sec}$.

$72^{\circ} \mathrm{C}-7 \mathrm{~min}$

Program:

$94^{\circ} \mathrm{C}-5 \mathrm{~min}$

$94^{\circ} \mathrm{C}-30 \mathrm{sec}$

$56^{\circ} \mathrm{C}-30 \mathrm{sec}$

$72^{\circ} \mathrm{C}-50 \mathrm{sec}$

$30 x$

$72^{\circ} \mathrm{C}-7 \mathrm{~min}$

$35 x$

Program:

$94^{\circ} \mathrm{C}-5 \mathrm{~min}$

$94^{\circ} \mathrm{C}-30 \mathrm{sec}$

$60^{\circ} \mathrm{C}-45 \mathrm{sec}$.

$72^{\circ} \mathrm{C}-30 \mathrm{sec}$.

$72^{\circ} \mathrm{C}-7 \mathrm{~min}$

AdamL1, AdamL9, EvaL6

The PCRs were performed according to established protocols for these lines (Buyandelger, 2006).

\subsubsection{Generation of Southern probes}

\section{5'external probe}

The probe was generated by Buyandelger (2006).

Internal probe (3'probe, 266bp)

The probe was amplified by PCR as follows: 


\begin{tabular}{lll} 
Ingredients: & & \multicolumn{1}{l}{ Program: } \\
$\mathrm{H}_{2} \mathrm{O}$ & $17,5 \mu \mathrm{l}$ & $94^{\circ} \mathrm{C}-5 \mathrm{~min}$ \\
buffer & $2,5 \mu \mathrm{l}$ & $94^{\circ} \mathrm{C}-30 \mathrm{sec}$. \\
$\mathrm{MgCl}_{2}$ & $1 \mu \mathrm{l}$ & $60^{\circ} \mathrm{C}-50 \mathrm{sec}$. \\
dNTPs & $1 \mu \mathrm{l}$ & $72^{\circ} \mathrm{C}-45 \mathrm{sec}$. \\
Pelota3'_F2 & $1 \mu \mathrm{l}$ & $72^{\circ} \mathrm{C}-7 \mathrm{~min}$ \\
Pelota3,_R2 & $1 \mu \mathrm{x}$ \\
Taq Platinum & $0,15 \mu \mathrm{l}$ & \\
DNA & $0,5 \mu \mathrm{l}$ &
\end{tabular}

The PCR product was subcloned into pGEMTeasy and sequenced. The 266 bp EcoRI fragment was purified and used as a probe for Southern blot.

\section{3'external probe (885bp)}

It was amplified by PCR as follows:

Ingredients:

$\begin{array}{ll}\mathrm{H}_{2} \mathrm{O} & 19,8 \mu \mathrm{l} \\ \text { buffer } & 2,5 \mu \mathrm{l} \\ \mathrm{MgCl}_{2} & 0,5 \mu \mathrm{l} \\ \text { dNTPs } & 0,5 \mu \mathrm{l} \\ \text { cKO_3'ext_F } & 0,5 \mu \mathrm{l} \\ \text { cKO_3'ext_R } & 0,5 \mu \mathrm{l} \\ \text { Taq Platinum } & 0,15 \mu \mathrm{l} \\ \text { DNA } & 0,5 \mu \mathrm{l}\end{array}$

Program:

$94^{\circ} \mathrm{C}-5 \mathrm{~min}$

$94^{\circ} \mathrm{C}-30 \mathrm{sec}$.

$58^{\circ} \mathrm{C}-30 \mathrm{sec}$.

$72^{\circ} \mathrm{C}-45 \mathrm{sec}$.

$72^{\circ} \mathrm{C}-7 \mathrm{~min}$

$35 \mathrm{x}$

The PCR product was subcloned into pGEMTeasy and sequenced. The 885 bp EcoRI fragment was purified and used as a probe for Southern blot.

\subsubsection{Reverse transcription PCR (RT-PCR)}

RT-PCR generates cDNA fragments from RNA templates and helps to determine the expression of genes in specific tissues or in different development stages.

1-5 $\mu \mathrm{g}$ of total RNA was mixed with $1 \mu \mathrm{l}$ of oligo $(\mathrm{dT}) 18$ primer $(10 \mathrm{pmol} / \mu \mathrm{l})$ in a total volume of $12 \mu \mathrm{l}$. For denaturation the mixture was heated to $70^{\circ} \mathrm{C}$ for $10 \mathrm{~min}$ and then quickly chilled on ice. After a brief centrifugation, the following substances were added to the mixture:

- $4 \mu 15$ x first strand buffer

- $2 \mu 10.1$ M DTT

- $\quad 1 \mu 110 \mathrm{mM}$ dNTPs

- $1 \mu \mathrm{R}$ Rasin $(10 \mathrm{U} / \mu \mathrm{l})$ 
The reaction was incubated at $42^{\circ} \mathrm{C}$ for $2 \mathrm{~min}$. Then, $1 \mu \mathrm{l}$ of reverse transcriptase enzyme (Superscript II, Invitrogen) was added and the mixture was incubated at $42^{\circ} \mathrm{C}$ for 50 min for the first strand cDNA synthesis. Next, the reaction was inactivated by heating at $70^{\circ} \mathrm{C}$ for $15 \min 1 \mu \mathrm{l}$ of the first strand reaction was used for the PCR reaction.

\subsubsection{Quantitive Real-Time PCR}

DNA was isolated from transgenic mice tails by the method described above (2.2.1.2.1). Serial dilutions of sample and standard DNA's were made. Standard DNA (a mixture of Founder DNA and two F1 males) was serially diluted to 20, 10, 5, 2.5, 1.25 and $0.625 \mathrm{ng} / \mu \mathrm{l}$ for the generation of standard curve, while each sample DNA (transgenic mice) was diluted to a concentration of $10 \mathrm{ng} / \mu \mathrm{l}$. Primers were designed to generate amplicons less than $200 \mathrm{bp}$, thus enhancing the efficiency of PCR amplification. Real-Time quantitative PCR was performed using QuantiTect SYBR Green PCR Master mix (Quiagen) in an ABI Prism 7900HT sequence detection system. Each reaction was run in triplicate and the melting curves were analysed to ensure that only a single product was amplified. $18 \mathrm{~S}$ primers were used for the normalisation of each DNA sample. Quantitative real-time PCR reactions of DNA specimens and standards were conducted in a total volume of $10 \mu 1$ with 5 $\mu l$ of 2 x QuantiTect SYBR-Green PCR-Master-Mix, $1 \mu \mathrm{l}$ of each forward and reverse primer in a final concentration of $9 \mu \mathrm{M}$ and $2.5 \mu \mathrm{l}$ of DNA.

The following cycling parameters were used:

$2 \min 50^{\circ} \mathrm{C}$

$15 \min 95^{\circ} \mathrm{C}$

$\left.\begin{array}{l}15 \sec 95^{\circ} \mathrm{C} \\ 30 \sec 60^{\circ} \mathrm{C} \\ 30 \sec 72^{\circ} \mathrm{C}\end{array}\right\} 40 \mathrm{x}$

$15 \sec 95^{\circ} \mathrm{C}$

$15 \sec 60^{\circ} \mathrm{C}$ melting curve

$15 \sec 95^{\circ} \mathrm{C}$

Standard curves of the threshold cycle number versus the log number of copies of genes were generated for transgenic integration sites and were used to extrapolate the number of integration sites of transgene. Quantitative Real-Time PCR results were reported 
as the number of transgenic allele in comparison to transgenic allele in founder mouse. The samples were normalized by reference to $18 \mathrm{~S}$ gene.

\subsubsection{Quantitive Real-Time RT-PCR}

In general Quantitative Real-Time RT-PCR for mRNAs was performed as for DNA (2.2.2.8.3). cDNA synthesis was done according to section 2.2.8.2 with preceding DNAse treatment. $5 \mu \mathrm{l} 2 \mathrm{x}$ QuantiTect SYBR-Green PCR-Master-Mix, $1 \mu$ Forward Primer $(9 \mu \mathrm{M})$, $1 \mu \mathrm{l}$ Reverse Primer $(9 \mu \mathrm{M}), 0.3 \mu \mathrm{MgCl} 2(50 \mathrm{mM})$ and $1 \mu \mathrm{l}$ of cDNA (in a $1 / 20$ dilution) were mixed with RNase free water to a total volume of $10 \mu$ l. The following PCR program was used:

$2 \min 50^{\circ} \mathrm{C}$

$15 \min 95^{\circ} \mathrm{C}$

$15 \sec 95^{\circ} \mathrm{C}$

$30 \sec 55^{\circ} \mathrm{C}$

$30 \sec 72^{\circ} \mathrm{C}$

$15 \sec 95^{\circ} \mathrm{C}$

$15 \sec 60^{\circ} \mathrm{C}$ melting curve

$15 \sec 95^{\circ} \mathrm{C}$

Primer sequences are provided in section 2.1.9. Sdha was used as endogenous reference. For standard curves, a mixture of NMRI testes cDNA and cKO/Stra8_Cre testes cDNA was used. Selection of the appropriate sample for the standard curve was based on preliminary experiments testing detection of expression of each gene by RT-PCR (2.2.8.2). Reliability of Real-time PCR data was also assessed in connection with the respective dissociation curves.

\subsubsection{Protein manipulation methods}

\subsubsection{Isolation of total protein lysate}

Approximately $100 \mathrm{mg}$ of tissue was homogenised in 200 - $500 \mu \mathrm{l}$ lysis buffer A. Then, the samples were treated with ultrasound on ice $2 \times 1 \mathrm{~min}$, centrifuged at $8000 \mathrm{x}$ for $20 \mathrm{~min}$ at $4^{\circ} \mathrm{C}$ and the supernatant was aliquoted in several microcentrifuge tubes. The tubes were frozen in liquid nitrogen and stored at $-80^{\circ} \mathrm{C}$. 
$5 \times 10^{6}$ cells $/ \mathrm{ml}$ were washed with cold phosphate buffered saline (PBS) and resuspended in $50-200 \mu \mathrm{l}$ of lysis buffer A. The cells were left on ice for $30 \mathrm{~min}$, treated with ultrasound on ice $2 \times 30 \mathrm{sec}$ and centrifuged at $24000 \mathrm{x} \mathrm{g}$ for $20 \mathrm{~min}$ at $4^{\circ} \mathrm{C}$. The supernatant with protein extract was either used immediately or stored at $-80^{\circ} \mathrm{C}$ for later use.

\subsubsection{Determination of protein concentration (Bradford, 1976)}

To determine the protein concentration, Bio-Rad protein assay was employed. The BSA stock solution of $1 \mathrm{mg} / \mathrm{ml}$ was diluted in order to obtain standard dilutions in range of $10 \mu \mathrm{g} / \mathrm{ml}$ to $100 \mu \mathrm{g} / \mathrm{ml}$. The dye reagent concentrate (Bio-Rad Laboratories $\mathrm{GmbH}$ ) was diluted 1:5 with $\mathrm{H}_{2} \mathrm{O}$ and $2 \mu$ sample were added. The absorption of the color reaction was measured at $595 \mathrm{~nm}$ in a spectrophotometer.

\subsubsection{Blotting techniques}

\subsubsection{Southern blotting of DNA (Southern, 1975)}

After electrophoresis of DNA, the gel was treated with $0.25 \mathrm{M} \mathrm{HCl}$ for depurination for 20 - $30 \mathrm{~min}$, with denaturation solution for $30 \mathrm{~min}$ and neutralisation solution for $45 \mathrm{~min}$. The transfer of the DNA to the nitrocellulose membrane was done in a Turbo-Blot apparatus (Schleicher \& Schuell, Dassel). About 25-28 Whatman filter papers (GB 003) were layered on a Stack Tray, followed by 4 Whatman filter papers (GB 002) and 1 Whatman filter paper (GB 002) soaked with $20 \times$ SSC. The equilibrated nitrocellulose filter, that was also soaked with $20 \mathrm{x}$ SSC, was laid on the top. The agarose gel, treated as described above, was placed on the filter and was covered with 3 Whatman filter papers GB 002 soaked with $20 \mathrm{x}$ SSC. The buffer tray was filled with $20 \mathrm{x}$ SSC. Finally a wick, which was soaked with $20 \mathrm{x}$ SSC, and the wick cover were put on top of the blot. The transfer was carried out for overnight. Finally, after disassembling of the blot, the DNA was fixed onto the filter by baking at $80^{\circ} \mathrm{C}$ for at least 2 hours. 


\subsubsection{Northern blotting of RNA}

The procedure performed for the transfer of RNA onto a nitrocellulose filter was the same as described above (2.2.10.1). However, the gel did not need to be denaturated, but was transferred directly onto the filter.

\subsubsection{Western blotting of protein (Gershoni and Palade, 1982)}

After electrophoresis of proteins, the SDS PAGE gel and the PVDF membrane were moistened with transfer buffer. Four pieces of filter paper were soaked in transfer buffer and placed on the semi dry transfer machine's lower plate. Then, wet membrane and the gel were put, avoiding any air bubbles. Another four soaked Whatman papers were placed on the pile to complete the sandwich model. The upper plate was placed over this sandwich and the transfer was carried out at $3.5 \mathrm{~mA} / \mathrm{cm}^{2}$ for $1 \mathrm{hr}$.

After blotting, the gel was stained with Comassie blue overnight at RT in order to check the amount of proteins which were not transferred.

\subsubsection{1 "Random Prime" method for generation of ${ }^{32} \mathrm{P}$ labeled DNA (Denhardt, 1966; Feinberg and Vogelstein, 1984)}

RediprimeTM II Random Prime Labeling System (Amersham Pharmacia) was used for labelling of DNA probes. The method depended on the random priming principle developed by Feinberg and Vogelstein (1984). The reaction mix contained dATP, dGTP, dTTP, Klenow fragment (4-8 U) and random oligodeoxyribonucleotides. Firstly, 25-50 ng DNA were denaturated in a total volume of $46 \mu \mathrm{l}$ at $95^{\circ} \mathrm{C}$ for $10 \mathrm{~min}$ and quickly chilled on ice for $5 \mathrm{~min}$. After pipetting the denaturated probe into RediprimeTM II Random Prime Labelling System cup, $4 \mu \mathrm{l}$ of $[\alpha-32 \mathrm{P}] \mathrm{dCTP}(3000 \mathrm{Ci} / \mathrm{mmol})$ were added to the reaction mixture. The labelling reaction was carried out at $37^{\circ} \mathrm{C}$ for $45 \mathrm{~min}$. The labelled probe was purified from uncorporated $[\alpha-32 \mathrm{P}]$ dCTP by using illustra ${ }^{\mathrm{TM}}$ Probe Quant ${ }^{\mathrm{TM}}$ G-50 Micro Cloumns (GE Healthcare). 


\subsubsection{Non-radioactive dye terminator cycle sequencing}

Non-radioactive sequencing was performed with the Dye Terminator Cycle Sequencing-Kit (ABI PRISM). The reaction products were analysed with automatic sequencing equipment, MegaBase DNA Sequencer. For the sequencing reaction, four different dye labelled dideoxy nucleotides were used (Sanger et al., 1977), which, when exposed to an argon laser, emit fluorescent light that can be detected and interpreted.

The reaction was carried out in a total volume of $10 \mu \mathrm{l}$ containing $1 \mu \mathrm{g}$ plasmid DNA or 100-200 ng purified PCR products, 10 pmol primer and $4 \mu 1$ reaction mix (contained dNTPs, dideoxy dye terminators and Taq DNA polymerase). Elongation and chain termination took place during the following program in a thermocycler: 4 min denaturation followed by 25 cycles at $95^{\circ} \mathrm{C}, 30 \mathrm{sec} ; 55^{\circ} \mathrm{C}, 15 \mathrm{sec}$, annealing; $60^{\circ} \mathrm{C}, 4 \mathrm{~min}$, elongation. After the sequencing reaction, the DNA was precipitated with $1 / 10$ volume $3 \mathrm{M}$ sodium acetate and 2.5 volume $100 \%$ ethanol and washed in $70 \%$ ethanol. The pellet was dissolved in $4 \mu \mathrm{l}$ of loading buffer, denaturated at $95^{\circ} \mathrm{C}$ for $3 \mathrm{~min}$, and finally loaded on the sequence gel.

\subsubsection{Hybridisation of nucleic acids (Denhardt, 1966)}

A membrane for hybridization was equilibrated in $2 \times$ SSC and transferred to a hybridisation bottle. After adding $12 \mathrm{ml}$ of Rapid-hyb buffer (GE Healthcare) and sheared denaturated salmon DNA, the membrane was incubated for 2 hours in the hybridisation oven at $65^{\circ} \mathrm{C}$. Then, the labelled probe was denaturated at $95^{\circ} \mathrm{C}$ for $10 \mathrm{~min}$, chilled on ice for $5 \mathrm{~min}$, and added to the hybridisation solution. The hybridisation was carried out overnight in the oven. Next day, the filter was washed for 10 min with 2 x SSC, then with 2 $\mathrm{x}$ SSC containing $0.2 \% \mathrm{SDS}$ at $65^{\circ} \mathrm{C}$ for $10-20 \mathrm{~min}$. Finally, the membrane was washed with $0.2 \times$ SSC containing $0.1 \%$ SDS at the hybridisation temperature. After drying the filter, it was sealed in Saran wrap and exposed to autoradiography overnight at $-80^{\circ} \mathrm{C}$. The film was developed in X-Ray Automatic Processor Curix 60. 


\subsubsection{Histological techniques}

\subsubsection{Tissue preparation for paraffin-embedding}

The freshly prepared tissues were fixed in Bouin's solution or $4 \%(\mathrm{w} / \mathrm{v})$ paraformaldehyde for 6 - 24 hours to prevent alterations in the cellular structure. The dehydration process was accomplished by passing the tissue through a series of increasing alcohol concentrations, i.e. $70 \%, 80 \%, 90 \%, 96 \%, 100 \%$ ethanol for 1 hour at RT and isopropanol overnight. Later, the alcohol was removed from the tissue by incubation in $25 \%$, $50 \%, 75 \%$ and $100 \%$ xylene. Next step was incubation of the tissues in paraffine at $60^{\circ} \mathrm{C}$ for 12-24 hours. Before embedding, the paraffin was changed at least three times. Finally, the tissue was placed in embedding mold and melted paraffin was poured into the mold to form a block. The block was cooled and became ready for sectioning.

\subsubsection{Sections of the paraffin block}

Paraffin blocks were clamped into the microtome (Hn 40 Ing., Nut hole, Germany). The thickness of the section was $5 \mu \mathrm{m}$. The sections were floated on $40^{\circ} \mathrm{C}$ water to allow actual spread. Then, they were put onto slides. After complete drying at $37^{\circ} \mathrm{C}$, slides were stored at $4^{\circ} \mathrm{C}$ for further analysis.

\subsubsection{Immunofluorescence staining}

\section{For mouse tissues:}

Tissue sections were incubated twice for $10 \mathrm{~min}$ in xylene to remove the paraffin. Then, they were re-hydrated in a decreasing ethanol series $(100 \%, 96 \%, 70 \%, 50 \%$, and $30 \%$ ) for 2 min each. For immunofluorescence staining, the sections were washed in PBS and then incubated with a blocking solution containing $10 \%$ goat serum and $0.02 \%$ Tween20 in PBS for 2 hours at RT. Then, they were incubated with primary antibodies for overnight in a humidified chamber at $4^{\circ} \mathrm{C}$. Subsequently, they were rinsed three times for 5 min in PBS and an appropriate secondary antibody was put for 1 hour. Finally, the slides were washed three times for $5 \mathrm{~min}$ in PBS and the nuclei were counterstained with DAPI. Immunostaining of the sections was examined using a fluorescence equipped microscope (BX60; Olympus). 


\section{For cells:}

Cells were fixed in $4 \%$ paraformaldehyde in PBS for $15 \mathrm{~min}$ at $4^{\circ} \mathrm{C}$, rinsed in PBS and incubated in $50 \mathrm{mM} \mathrm{NH}_{4} \mathrm{Cl}$ (PBS) for $10 \mathrm{~min}$ at RT. After washing in PBS (2 x), the cells were $3 \mathrm{x}$ washed in 0,2\% Triton X-100 (PBS) for $4 \mathrm{~min}$. Next, the primary antibody with appropriate dilution was applied for overnight at $4^{\circ} \mathrm{C}$. Cells were washed $2 \mathrm{x}$ in $0,2 \%$ Triton X-100 (PBS) for 4 min and incubated with Cy3- conjugated IgG for 1 hour at RT. One drop of mounting medium with DAPI was dispensed onto the slides after washing with PBS. Fluorescent cells were visualised with Olympus BX60 microscope.

\subsubsection{Phalloidin staining of cells}

Cells were washed twice in PBS for $5 \mathrm{~min}$, fixed for $15 \mathrm{~min}\left(4^{\circ} \mathrm{C}\right)$ in $4 \%$ paraformaldehyde and washed 3 times in PBS. Then, they were incubated for 1 hour in phalloidin (diluted 1:1000) conjugated with $\mathrm{Cy} 3$ and washed 3 times in PBS. The slides were mounted with DAPI-containing medium.

\subsubsection{Alkaline phosphatase staining of cells}

Cells were washed with PBS, fixed for $30 \mathrm{sec}$. with fixation solution (Sigma) and washed with $\mathrm{dH}_{2} \mathrm{O}$ for 1 min. Incubation with staining solution was applied for 15 min in RT. Next, the cells were washed for $2 \mathrm{~min}$ in water and incubated with neutral red for 10-20 sec. Afterwards, they were washed in tapped water and left for drying.

\subsubsection{Hematoxylin-eosin (H\&E) staining of the histological sections}

Tissue sections were first incubated three times in xylene for 3 min each, followed by incubation in $100 \%$ for $3 \mathrm{~min}, 95 \%$ and $80 \%$ ethanol for 2 min each. Thereafter slides were washed in $\mathrm{dH}_{2} \mathrm{O}$ for $5 \mathrm{~min}$ and stained for $3 \mathrm{~min}$ in hematoxylin. The staining was followed by rinsing with deionised water and washing in tap water for $10 \mathrm{~min}$. The treated slides were dipped fast in acid ethanol ( $1 \mathrm{ml}$ concentrated $\mathrm{HCl}$ in $400 \mathrm{ml} 70 \%$ ethanol) for 8-12 times to destain and in amonium water $(0,25 \%)$, rinsed in tap water for 2 min and in deionised water for $2 \mathrm{~min}$, stained in eosin for $1 \mathrm{~min}$ and then incubated in 70\%, 80\%, 90\%, 95\% and 100\% ethanol for $2 \mathrm{~min}$ each. Finally, the stained slides were incubated in xylene for $15 \mathrm{~min}$ and mounted with Eukitt-quick hardening mounting medium. 


\subsubsection{Apoptosis detection}

ApopTag Peroxidase Apoptosis Detection Kit was used for analysis of apoptotic cells in testis sections $(5 \mu \mathrm{m})$. The sections were firstly deparafinized, dehydrated and washed 2 x $5 \mathrm{~min}$ in PBS. Next, the slides were incubated for $15 \mathrm{~min}$ at RT in $20 \mu \mathrm{g} / \mathrm{ml}$ Proteinase $\mathrm{K}$ and washed $2 \times 2$ min in $\mathrm{dH}_{2} \mathrm{O}$. To block endogenous peroxidase, tissues were incubated in $3 \% \mathrm{H}_{2} \mathrm{O}_{2}$ for $5 \mathrm{~min}$ at RT. After $2 \times 5$ min washing in PBS, the tissues were covered for $10 \mathrm{sec}$. with equilibration buffer. Next, Working Strength TdT Enzyme (30\% enzyme in reaction buffer) was applied for 1 -hour incubation at $37^{\circ} \mathrm{C}$ in darkness. To stop the reaction, the slides were incubated for 10 min shaking at RT in Stop/Wash buffer (1:34 in $\mathrm{dH}_{2} \mathrm{O}$ ) and then washed $3 \times 1$ min with PBS. Next step was incubation with antidigoxigenin for $30 \mathrm{~min}$ at RT in darkness and washing $4 \times 2$ min with PBS. Then the slides were stained with Working Strength Peroxidase Substrate (2\% DAB Substrate in DAB Dilution buffer) for $6 \mathrm{~min}$ at RT, washed $3 \times 1 \mathrm{~min}$ and $1 \times 5$ min with $\mathrm{dH}_{2} \mathrm{O}$. They were covered by AquaPolyMount liquid.

\subsubsection{Eukaryotic cell culture methods}

The cells were cultured at $37^{\circ} \mathrm{C}$ in a humidified incubator with $5 \% \mathrm{CO}_{2}$.

\subsubsection{Preparation of MEFs feeder layers}

A frozen aliquot of MEFs was quickly thawed at $37^{\circ} \mathrm{C}$ and transferred to $10 \mathrm{ml} \mathrm{MEF}$ medium. After centrifugation at $1000 \mathrm{x} g$ for $5 \mathrm{~min}$, the cell pellet was gently resuspended in $10 \mathrm{ml}$ MEFs medium and plated on a $50 \mathrm{ml}$ culture flask. Cells were incubated at $37^{\circ} \mathrm{C}$ in $5 \% \mathrm{CO}_{2}$. When the cells formed a confluent monolayer after three days, they were trypsinised, transferred to five $10 \mathrm{~cm}$ dishes and grown until they formed confluent monolayer, or directly treated with mitomycin $\mathrm{C}(1 \mathrm{mg} / \mathrm{ml})$ for 3 hours. Then, the cells were washed twice with $10 \mathrm{ml}$ PBS, resuspended with $10 \mathrm{ml}$ medium and centrifuged. Next, they were resuspended in MEFs medium and plated onto dishes, which were pretreated with $0.1 \%$ gelatine for $30 \mathrm{~min}$. The feeder cells were left to attach by incubation overnight at $37^{\circ} \mathrm{C}, 5 \% \mathrm{CO}_{2}$ or used after 2 hours of incubation. Before adding ES cells on the feeder layer, the medium was changed to ES cell medium. 


\subsubsection{Trypsinisation of eukaryotic cells}

Cells were washed twice with sterile PBS and incubated in minimal amount trypsinEDTA (0.5 g/l trypsin, $0.2 \mathrm{~g} / \mathrm{l}$ EDTA) at $37^{\circ} \mathrm{C}$ for $5 \mathrm{~min}$. Trypsin was inhibited by addition of growth medium, in which the cells were subsequently resuspended. The enzyme was removed by centrifugation at $1000 \mathrm{x} g$ for $3 \mathrm{~min}$. Cells were resuspended in an appropriate volume of cell culture medium and transferred into a new flask/plate with medium.

\subsubsection{Cryopreservation and thawing of eukaryotic cells}

Trypsinised cells were spun down (1000 x g for $5 \mathrm{~min}$ ) in $4 \mathrm{ml}$ of growth medium. The supernatant was aspirated and the cells were resuspended in freezing medium (DMEM, $20 \% \mathrm{FCS}, 10 \% \mathrm{DMSO})$. Aliquots of the cells were kept for 2 days at $-80^{\circ} \mathrm{C}$ and then stored in liquid nitrogen. For revitalisation, frozen cells were quickly thawed and cells were inoculated in a suitable amount of growth medium, centrifuged and plated.

\subsubsection{Isolation and handling of primary mouse embryonic fibroblasts (MEFs)}

In order to isolate mouse embryonic fibroblasts (MEFs), pregnant female mice were sacrificed at $13-15$ p.c. by cervical dislocation. Uterine horns were dissected and placed into a Petri dish containing PBS. Then each embryo was separated from its placenta and surrounding membranes. Embryo heads were taken for genotyping and the whole gastric system was removed. Such prepared embryos were sheared, put in $10 \mathrm{ml}$ of trypsin-EDTA (1-2ml per embryo) and incubated for aprox. $5 \mathrm{~min}$. An obtained cell suspension was transferred to $10 \mathrm{ml}$ falcon tube and about 2 volumes of fresh medium was added, then cenrifugated at $1000 \mathrm{x}$ g for $5 \mathrm{~min}$ and plated out at 1 embryo equivalent per $10 \mathrm{~cm}$ dish. Medium was changed the following day.

\subsubsection{Growth of ES cells on feeder layer}

One aliquot of frozen ES cells was quickly thawed at $37^{\circ} \mathrm{C}$ and cells were transferred to a $12 \mathrm{ml}$ tube containing $6 \mathrm{ml}$ ES cell medium. After centrifugation, the cell pellet was resuspended in $5 \mathrm{ml}$ ES cell medium and plated on $6 \mathrm{~cm}$ dishes containing feeder layer. Next day the medium was changed. The second day, cells were washed with PBS, treated with 2 
$\mathrm{ml}$ trypsin/EDTA at $37^{\circ} \mathrm{C}, 5 \% \mathrm{CO}_{2}$ for $5 \mathrm{~min}$, resuspended with $5 \mathrm{ml} \mathrm{ES}$ medium and centrifuged. The cell pellet was resuspended in $10 \mathrm{ml} \mathrm{ES}$ cell medium and distributed either to 5 or 6 dishes $(6 \mathrm{~cm})$ or to 2 dishes $(10 \mathrm{~cm})$ containing feeder layers. The cells were passaged every second day as described above.

\subsubsection{Differentiation of ES cells}

\section{Random differentiation by generation of embryoid bodies (EBs)}

After trypsinization, cells were transferred to sterile bacterial dish, where they were cultured in $10 \mathrm{ml}$ ES medium without LIF for 10 days. Afterwards, EBs were either collected for analysis or trypsinized and plated on gelatin-coated 6-well plates in $2 \mathrm{ml}$ medium without LIF.

\section{Neuronal differentiation (Kawasaki et al., 2000)}

Undifferentiated mouse ES cells were expanded on gelatin-coated cell culture dishes in Glasgow minimal essential medium (GIBCO-Invitrogen, Karlsruhe, Germany) containing $1 \%$ fetal calf serum (FCS), 10\% knockout replacement, $2 \mathrm{mM}$ glutamine, 0.1 non essential amino acids, $1 \mathrm{mM}$ sodium pyruvate, $0.1 \mathrm{mM}$ 2-mercaptoethanol, $2000 \mathrm{U} / \mathrm{ml}$ leukemia inhibitory factor (GIBCO). The neuronal differentiation was induced in a culture on mitomycin C-inactivated PA6 feeder cells. The differentiation medium was composed of GMEM supplemented with $10 \% \mathrm{KSR}, 2 \mathrm{mM}$ glutamine, $1 \mathrm{mM}$ sodium pyruvate, $0.1 \mathrm{mM}$ nonessential amino acids, and $0.1 \mathrm{mM}$ 2-mercaptoethanol. ES cells were cultured on PA6 feeder cells in differentiation medium for 8 days before it was replaced with induction medium and cultured for an additional 6 days. The induction medium consisted of G-MEM including N-2 supplement (GIBCO), $100 \mu \mathrm{M}$ tetrahydrobiopterin (Sigma), $200 \mu \mathrm{M}$ ascorbic acid, $2 \mathrm{mM}$ glutamine, $1 \mathrm{mM}$ sodium pyruvate, $0.1 \mathrm{mM}$ nonessential amino acids, and 0.1 $\mathrm{mM}$ 2-mercaptoethanol. After 4 days of differentiation, the medium was changed daily. On day 14 of the culture cells were analyzed. 


\subsubsection{Production of targeted embryonic stem cell clones}

\subsubsection{Electroporation of ES cells}

ES cells, which have grown for two days in $10 \mathrm{~cm}$ dishes, were trypsinised. The cell pellet was washed in $20 \mathrm{ml}$ PBS, centrifuged and resuspended in $1 \mathrm{ml}$ PBS. The $0.8 \mathrm{ml}$ of cell suspension was mixed with $40 \mu \mathrm{g}$ of linearised DNA-construct and transferred into an electroporation cuvette. The electroporation was performed at $240 \mathrm{~V}, 500 \mu \mathrm{F}$ with the BioRad gene pulserTM apparatus. After electroporation, the cuvette was placed on ice for 20 min. The cell suspension was transferred from cuvette into $20 \mathrm{ml}$ of ES cell medium and plated onto two $10 \mathrm{~cm}$ dishes containing feeder layers. The medium was changed every next day. Two days after the electroporation, the drugs for selection were added (active G418 at $400 \mu \mathrm{g} / \mathrm{ml}$ and gancyclovir at $2 \mu \mathrm{M})$. The medium was changed every day. After about eight days of selection, drug resistant colonies have appeared and were ready for screening by Southern blot analysis.

\subsubsection{Growing ES cells for Southern blot analysis}

The drug resistant colonies that were formed after about eight days of selection were picked with a drawn-out Pasteur pipette under a dissecting microscope. Each colony was transferred into a 24-well plate containing feeders and ES cell medium. After 2 days, the ES cells were trypsinised with $100 \mu \mathrm{l}$ trypsin for $5 \mathrm{~min}$ and resuspended in $500 \mu \mathrm{l}$ ES cell medium. Half of the cell suspension in each well was transferred to a well on two different 24-well plates, one gelatinised plate, and the other containing feeder cells (master plate). The gelatinised plate was used for preparing DNA and the master plate was kept frozen.

\subsubsection{Flow cytometry (FACS) procedure for apoptosis detection and cell surface staining (Kanwar et al. 2008)}

$1 \times 10^{6}$ cells per measurement were washed in 5-ml tubes with PBS and resuspended in $100 \mu \mathrm{l}$ PBS before cell surface staining with $1 \mu \mathrm{g}$ of the respective antibodies: anti-CD3 (clone CT-CD3, rat IgG2a, phycoerythrin [PE]-labeled; Caltag Laboratories, Hamburg, Germany), anti-CD4 (clone CT-CD4, rat IgG2a, PE or tricolor [TC]-labeled; Caltag), antiCD8a (clone CT-CD8a, rat IgG2a, fluorescein isothiocyanate [FITC] or PE-labeled), anti- 
CD8b (clone CT-CD8b, rat IgG2a, PElabeled; Caltag), anti-CD19 (clone 6D5, rat IgG2a, FIT C-labeled; Caltag), anti-CD25 (clone 7D4, rat IgM, FITClabeled, Becton Dickinson), anti-CD45R/B220 (clone RA3-6B2, rat IgG2a, PE-labeled; Caltag). TC-conjugated streptavidin (SA1006, Caltag) was used as the secondary reagent. Appropriate isotype controls were purchased from Caltag Laboratories. The cells were stained for $45 \mathrm{~min}$ at $4{ }^{\circ} \mathrm{C}$ before being washed and resuspended in $200 \mu \mathrm{l}$ PBS.

Exposure of phosphatidylserine as a membrane parameter of apoptosis was determined by staining cells for $45 \mathrm{~min}$ at $4{ }^{\circ} \mathrm{C}$ in binding buffer $(10 \mathrm{mM}$ HEPES/NaOH, pH 7.4, $140 \mathrm{mM} \mathrm{NaCl}, 2.5 \mathrm{mM} \mathrm{CaCl}$ ) with $5 \mu \mathrm{l}$ annexin V-FITC (Becton Dickinson) in combination with $1 \mu \mathrm{g} / \mathrm{ml}$ propidium iodide (Sigma) to distinguish early apoptotic from late apoptotic or necrotic cells. The cells were resuspended in $200 \mu \mathrm{l}$ annexin binding buffer before measurement. DNA histograms were obtained after propidium iodide staining of cells fixed in ethanol as described previously (Ormerod et al. 1992; Dressel et al. 2000). Flow cytometry was performed on a FACScan flow cytometer with CellQuest software (Becton Dickinson, Heidelberg, Germany); 10,000 to 50,000 cells per sample were counted.

\subsubsection{Production of chimeras by injection of ES cells into blastocysts}

The standard procedure is to inject 10-20 ES cells from $129 / \mathrm{Sv}$, which are recombinant for the targeted locus, into the blastocoel cavity of recently cavitated blastocysts that have been recovered by flushing the uteri of day 4 pregnant mice $(\mathrm{C} 57 \mathrm{BL} / 6 \mathrm{~J})$. After injection, embryos are cultured for a short period (2-3 hrs) to allow reexpansion of the blastocoel cavity and then transferred to the uterine horns of day three pseudopregnant mice. Pseudopregnant females are obtained by mating 6-8 weeks old oestrous females with vasectomised males. Chimeric mice have been generated in Max Planck Institute for experimental medicine.

\subsubsection{Detection of chimerism and mice breeding}

Chimeric males (and sometimes females) are bred to wildtype mice to ascertain contribution of the ES cells to germline. Once a germline chimera has been identified, the first priority will be to obtain and maintain the targeted allele in living animals. The chimeras were bred with C57BL/6J. 


\subsubsection{Preparation of cKO ESCs from cKO mice}

Uterus was isolated from pregnant (E3.5) female and both its horns were cut to open it. Next, it was flushed with M2 medium through opened horns to wash out the blastocysts onto the plate. Then, the blastocysts were collected and transferred to $\mathrm{KO}$ medium on gelatine-pretreated plate. After 4 days, one could observe ESCs growing on the layer of trophoblast cells. The clones were picked and plated into separate wells of 24-well plate with feeder layer, they were cultured in ES medium. To confirm their genotype, genomic DNA was isolated and genotyping PCR was performed.

\subsubsection{Tamoxifen (TAM) treatment of mice}

The adult mice were injected intraperitoneally with $1 \mathrm{mg} /$ day for 5 days. 10-day-old and 15-day-old mice were injected with 0.2-0.3 mg dose per day depending on the weight.

\section{Preparation of tamoxifen}

$50 \mathrm{mg}$ TAM were suspended in $500 \mu \mathrm{l} 100 \%$ ethanol. Next, $4 \mathrm{ml}$ of sunflower oil was added and it was mixed till powder was dissolved. An obtained solution $(1 \mathrm{mg} / 100 \mu \mathrm{l})$ was aliquoted and stored in $-20^{\circ} \mathrm{C}$ max. for 4 weeks.

\subsubsection{Hydroxytamoxifen (OHT) treatment of generated cKO ESCs}

Cells were treated with $1 \mu \mathrm{M}$ OHT for 2 days what resulted in complete silencing of floxed pelota allele.

\subsubsection{Generation of teratomas in SCID mice}

SCID (Severe Combined Immuno Deficiency) mice, resident in the Institute of Human genetics in Göttingen, were injected with $10^{6}$ ES cells suspended in $200 \mu \mathrm{lPBS}$. The injection was done subcutaneously. 


\subsubsection{Bone marrow transplantation}

Bone marrow of TAM-treated cKO mice was isolated by flushing femoral bones of TAM-treated mice. After washing in PBS, the cells were counted. 3x $10^{6}$ cells were intravenously injected to immune-defficient mice, resident in the institute.

\subsubsection{Fertility test of Stra8 mice}

To check fertility of deficient mice, they were bred with wild type mice. If female mouse became pregnant it meant that mutant male was fertile. The offsprings were counted to estimate if subfertility appeared.

\subsubsection{Preparation of adaptor oligos}

Sequences of linkers were designed as follows:

\section{Linker containing LoxP site}

5' AGCTTGGTACCATAACTTCGTATAGCATACATTATACGAAGTTATGAATTCA 3'

5' AGCTTGAATTCATAACTTCGTATAATGTATGCTATACGAAGTTATGGTACCA 3'

\section{KpnI/Tsp509I linker}

5' GACTGTCGACACT 3'

5' AATTAGTGTCGACAGTGGTAC 3'

\section{SpeI/XhoI/NotI linker}

5' CTAGTACTACTACTCTCGAGACTGC 3'

5' GGCCGCAGTCTCGAGTAGTAGTA 3'

Both oligonucleotides ( $8 \mu \mathrm{l} 10 \mu \mathrm{M}$ of each) of each linker were subsequently annealed in $45 \mu \mathrm{l}$ of $1 \mathrm{x}$ annealing buffer in following program:

$94^{\circ} \mathrm{C}-4 \min ; 85^{\circ} \mathrm{C}-4 \min ; 75^{\circ} \mathrm{C}-4 \min ; 70{ }^{\circ} \mathrm{C}-4 \min ; 68^{\circ} \mathrm{C}-10 \mathrm{~min} ; 65^{\circ} \mathrm{C}-10 \mathrm{~min}$; $62{ }^{\circ} \mathrm{C}-10 \mathrm{~min} ; 60{ }^{\circ} \mathrm{C}-10 \mathrm{~min} ; 58^{\circ} \mathrm{C}-10 \mathrm{~min} ; 56{ }^{\circ} \mathrm{C}-10 \mathrm{~min} ; 53^{\circ} \mathrm{C}-4 \mathrm{~min} ; 37^{\circ} \mathrm{C}-15$ min Then the reaction mixture was placed on ice ready to be ligated $(5 \mu \mathrm{l})$ with desired clone. 


\subsection{Computer analysis}

For the analysis of the nucleotide sequences, programs like BLAST, BLAST2, MEGABLAST and other programs from National Center for Biotechnology Information (NCBI) were used (www.ncbi.nlm.nih.gov). For protein studies ExPASy tools (www.expasy.ch) were used. Mouse genome sequence and other analysis on mouse genes, transcripts and putative proteins were done in Ensembl database (www.ensembl.org). 


\section{RESULTS}

\subsection{Generation and characterization of pelota conditional knockout mouse}

The lethality of pelota conventional knockout embryos $\left(\mathrm{Pelo}^{-/-}\right)$at postimplantation stage became an essential obstacle to determination of pelota function in different developmental processes, such as organogenesis, gametogenesis and tumorgenesis. Furthermore, we were not able to establish Pelo-deficient cell lines, which can help to describe the molecular role of Pelo in stem cell self-renewal and RNA decay. To overcome this early lethality of $\mathrm{Pelo}^{-/-}$mice, we have generated a conditional knockout mouse model using Cre/LoxP system to inactivate pelota in a tissue-specific and time-controled manner (Lakso et al., 1992; Pichel et al., 1993).

We have constructed a pelota conditional knockout (cKO) allele, where the exons 2 and 3 are flanked with two LoxP elements. We expected that insertion of these elements in introns 1 and 3 would not disrupt the expression of floxed Pelo allele (Pelo ${ }^{\mathrm{F}}$ ) and thereby Pelo $^{\text {flox/flox }}$ (allele flanked by LoxP sites) mice would develop normally. To silence the gene, that is to excise the LoxP-flanked region of Pelo ${ }^{F}$ allele, we have generated three mouse lines by introduction of three transgenic Cre recombinase alleles in the genome of Pelo ${ }^{\mathrm{F} / \mathrm{F}}$ or Pelo $^{\mathrm{F} /-}$ (Fig. 3).

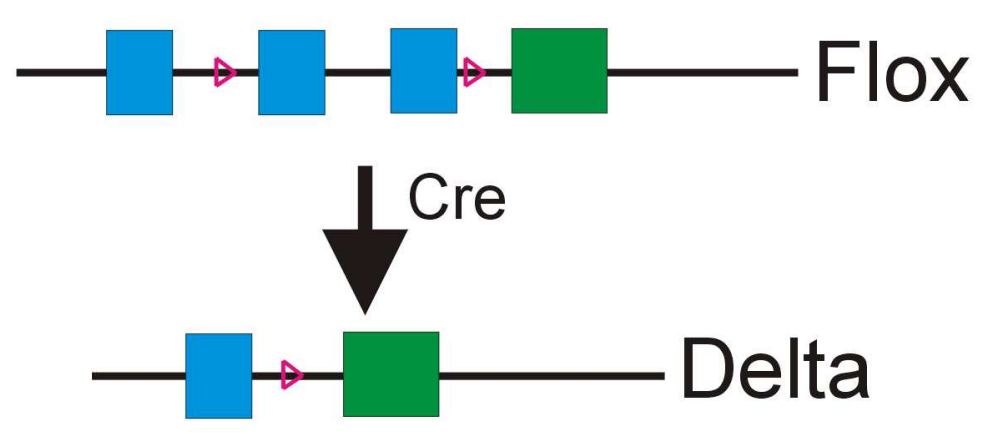

Figure 3. Simplified scheme of conditional knockout (cKO) system

Blue squares represent pelota exons, whereas green one is a symbol of Neo cassette. Pink triangles stand for LoxP sites, which are recombined upon Cre recombinase activation.

EIIaCre recombinase is expressed under the control of adenovirus EIIa promoter (Lakso et al., 1996). It is active in oocytes and shortly after fertilization (Dooley et al., 1989). 
Therefore, we expected that Cre-mediated recombination would occur at one-cell stage and effectively delete LoxP-flanked Pelo fragment (Williams-Simons and Westphal, 1999). The Pelo ${ }^{\mathrm{F} / \mathrm{F}}$ EIIaCre line was generated in order to determine whether obtained Pelo ${ }^{\Delta / \Delta}$ or Pelo ${ }^{\Delta /-}$ embryos would die at E7.5 mimicking the classical knockout mouse $\left(\right.$ Pelo $\left.^{--}\right)$phenotype.

Second Cre recombinase helped us with functional characterization of pelota in spermatogenesis. The transgenic Stra8-Cre allele (generated by Dev and Shirneshan) was introduced into the second line. The recombinase is expressed under Stra8 (stimulated by retinoic acid gene $\underline{8}$ ) promoter. Its expression is limited to spermatogonia (OuladAbdelghani et al., 1996; Baltus et al., 2006). We expected that excision of floxed pelo allele would occur in spermatogonia and their derivative cells.

For spatiotemporal inactivation of Pelo ${ }^{\mathrm{F} / \mathrm{F}}$ allele we used ubiquitously expressed Rosa26-CreERT knock-in allele (available in the Institute of human genetics). The Cre recombinase is fused with the ligand-binding domain of human estrogen receptor (ERT) that binds tamoxifen (TAM) but not estrogen. The floxed pelota allele can be excised in various tissues and cultured cells after administration of tamoxifen to animals. The mouse line allows the study of the effects of pelota disruption on development of different tissues. It also enabled us to establish Pelo ${ }^{\mathrm{F} / \mathrm{F}}$ CreERT embryonic stem cells (ESCs) for identification of the role of PELO in proliferation and differentiation.

\subsubsection{Generation of a conditional knockout (cKO) construct}

The 12.5-kb-long genomic fragment (containing the pelota gene and its flanking regions) was used for the generation of the pelota $\mathrm{cKO}$ construct. To clone a 5 ' region of the construct, a 1622 bp PstI/EcoRI fragment composed of third exon (clone 1 in Fig. 4A) was cloned into pBluescript vector (clone 2 in Fig. 4B). Next, clone 1 was digested with SpeI and PstI enzymes in order to obtain $1573 \mathrm{bp}$ fragment containing part of first exon and the whole second exon. After cloning into pGEMTeasy vector, clone 3 (Fig. 4C) was digested with HindIII, dephosphorylated and ligated with a linker containing LoxP element (pink triangle in Fig. 4D) and KpnI/EcoRI restriction sites (clone 4, Fig. 4D). To ligate both fragments possessing exons, a SpeI/PstI-digested insert of clone 4 was ligated into clone 2 resulting in clone 5 (Fig.4E). 
A
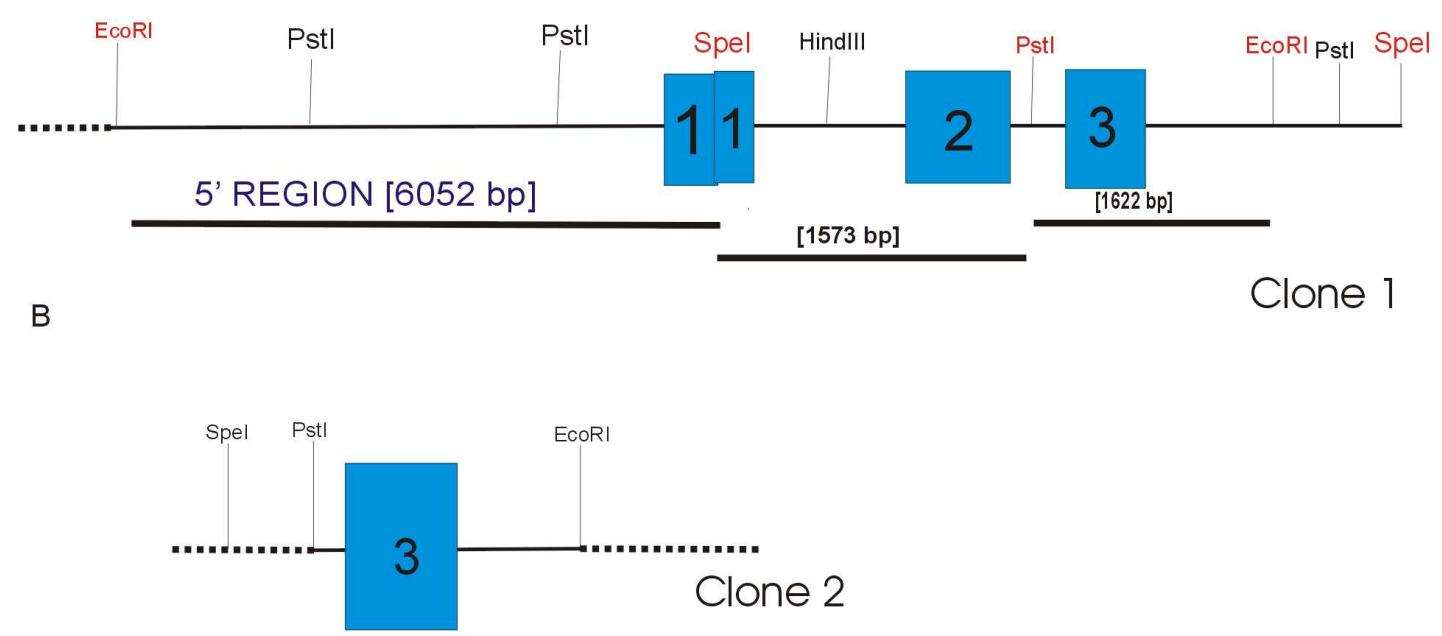

C

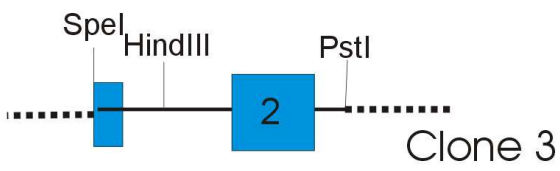

D

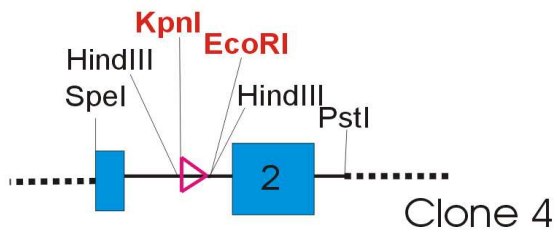

E

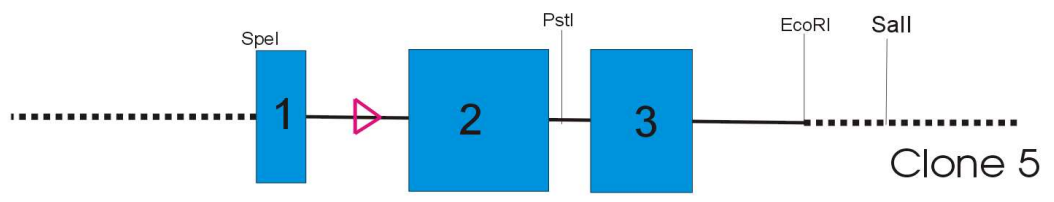

F

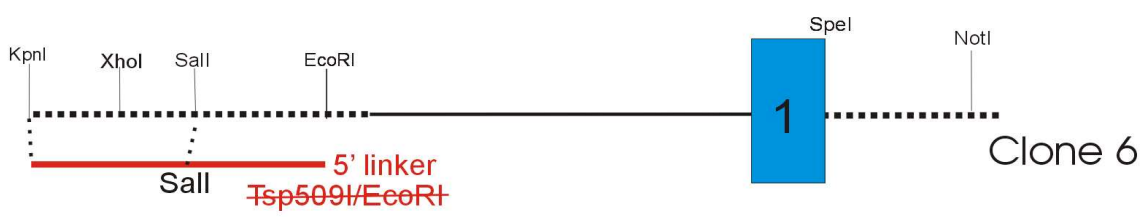


G

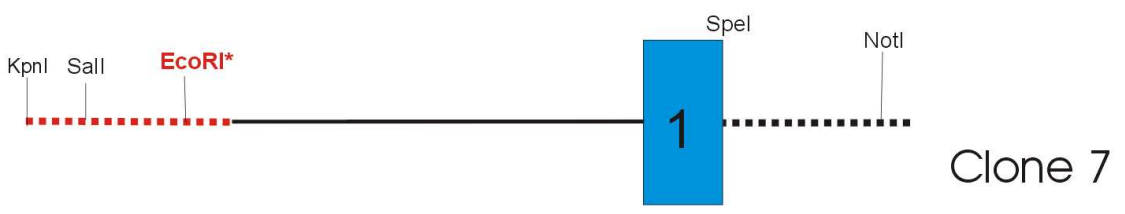

$\mathrm{H}$
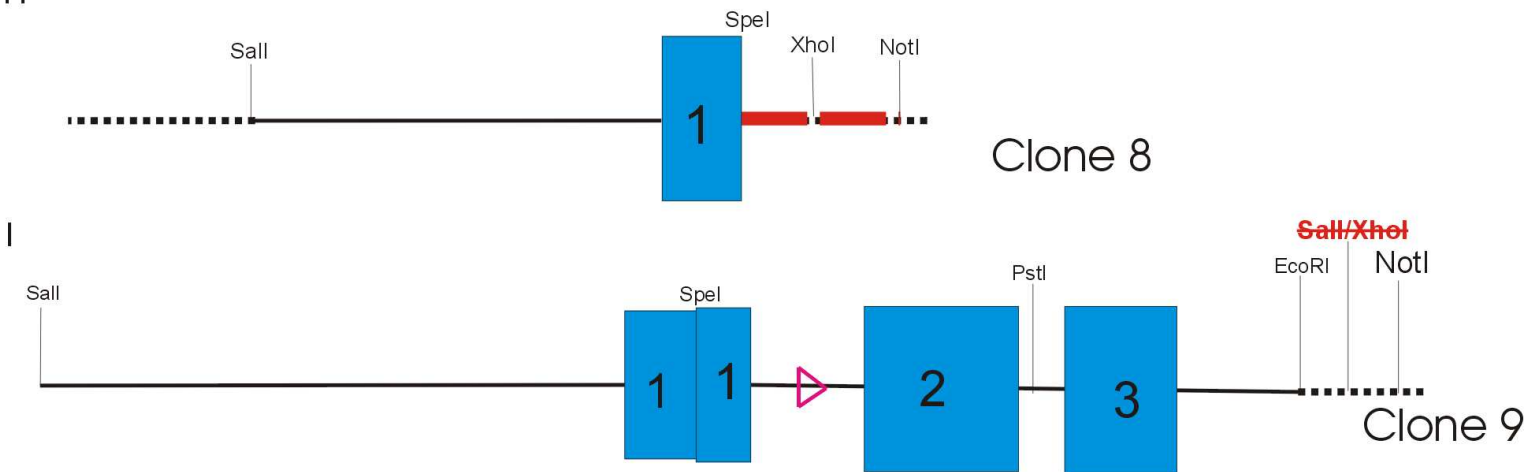

Figure 4. The scheme representing cloning strategy for generation of 5' region of conditional knockout construct.

A-clone 1; B - clone 2; C-clone 3; D-clone 4; E-clone 5; F-clone 6; G-clone 7, EcoRI* - inactivated EcoRI site; H - clone 8; I - clone 9. Dotted lines stand for vector sequences; pink triangle is a symbol of LoxP site; red lines - linker sequence; detailed description of the figures in the text.

To construct 5' region, clone 1 (Fig. 4A) was digested with EcoRI and SpeI. The obtained 6052-bp-long fragment was subcloned into pBluescript (clone 6 in Fig. 4F). To enable further cloning, one needed to exclude EcoRI and XhoI sites from clone 6. To reach the goal, a KpnI/Tsp509I linker containing KpnI, SalI and Tsp509I sites was designed (Fig. $4 F)$. It was cloned into clone 6 digested with KpnI and EcoRI. Tsp509I end is compatibile with EcoRI, but such ligation leads to inactivation of the EcoRI site in clone 7 (Fig.4F, G). Subsequently, another linker (SpeI/XhoI/NotI) was cloned into SpeI/NotI digested clone 7 (clone 8 in Fig. 4H). SpeI/SalI fragment from clone 5 (Fig. 4E) was isolated and cloned in SpeI/XhoI-digested clone 8 to give clone 9 (Fig. 4I). SalI and XhoI restriction sites are compatibile in an analogous way to EcoRI and Tsp509I, so XhoI site was eliminated from the final clone 9 (Fig. 4I, marked in red).

Next step was the generation of 3' homologous region. Clone 1 (Fig. 4A) was digested with EcoRI and a 3.3kb-long fragment was subcloned into pBluescript (Fig. 5A). To exclude SpeI site from multicloning site of clone 10, it was digested with BamHI and NotI, filled-up by T4 Polymerase and blunt-end ligated (Fig. 5B). To elongate the 3' arm it was necessary to amplify a $1.47 \mathrm{~kb}$ fragment which is localized 3' downstream from $3.3 \mathrm{~kb}$ 
region. After amplification (by using 3'regionA_F and 3'region_R primers), the $1.47 \mathrm{~kb}$ fragment was inserted into pGEMTeasy vector to generate clone 12 (Fig. 5C). Sequencing of the product confirmed the lack of mutations. To finish the $3^{\prime}$ arm of the construct, SpeI/XhoI fragment of clone 11 was ligated with clone 12 (clone 13 in Fig. 5D).

A

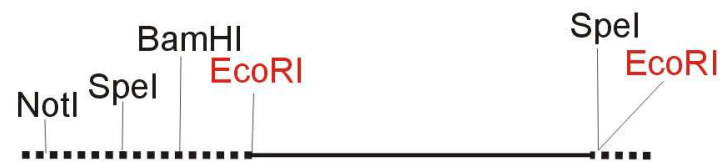

Clone 10

B

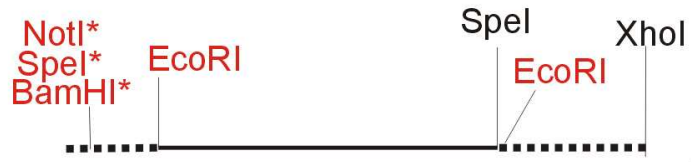

Clone 11

C

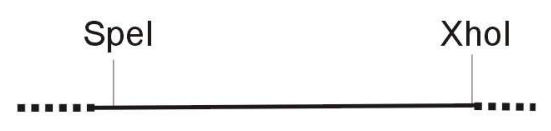

Clone 12

D

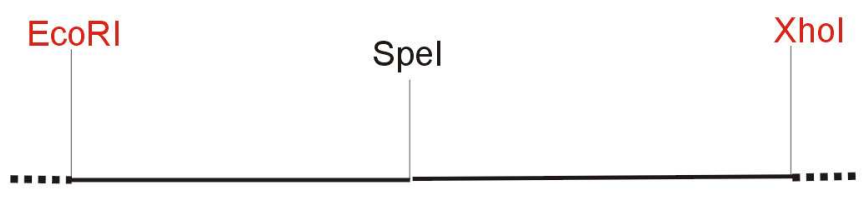

Clone 13

Figure 5. The scheme representing cloning strategy for generation of 3' homologous region of conditional knockout construct.

A - clone 10; B - clone 11, NotI*/SpeI*/BamHI* - removed restriction sites; $C$ - clone 12; $D$ - clone 13. Dotted lines stand for vector sequences; detailed description of the figures in the text. 
Last step of the construct preparation was cloning of both generated regions into final vector pPNT4. SalI/NotI fragment of clone 9 (Fig. 3I) was inserted upstream from the LoxP site of the vector, whereas EcoRI/XhoI insert from clone 13 (Fig. 5D) was introduced downstream from neomycin phosphotransferase (Neo) gene. Downstream from 3' arm in the vector, Herpes simplex virus thymidine kinase $(T K)$ gene was located what enabled negative selection of embryonic stem cells (ESCs) transfected with the construct (Fig. 6).

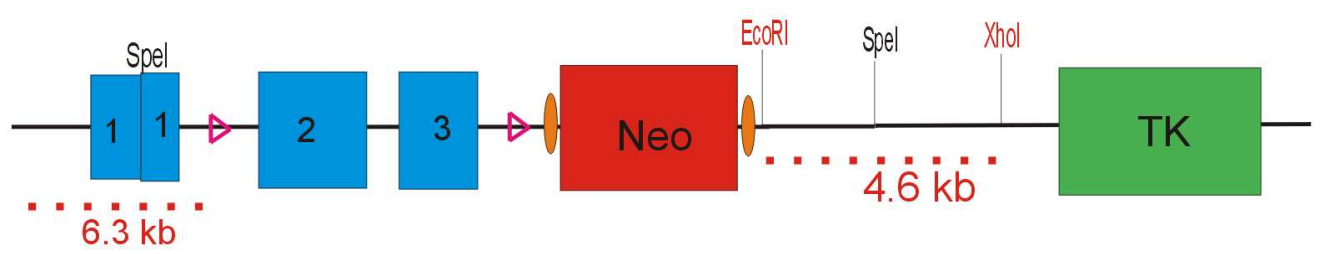

Figure 6. Final conditional knockout construct.

Exons 2 and 3 are flanked by LoxP elements (pink triangles). The neomycin cassette (Neo) is flanked by Flp/FRT elements (orange ovals). Red dotted lines stand for homologous arms of the construct; $T K$ - thymidine kinase.

\subsubsection{Isolation of homologous recombinant ESC clones}

R1 ES cells were trypsinized, washed and suspended in PBS. Approximately $2 \times 10^{7}$ cells/ml were mixed with $40 \mu \mathrm{g}$ linearized construct (digested with SalI) and the mixture was electroporated at $240 \mathrm{~V}$ and $500 \mu \mathrm{F}$ using a Bio-Rad Gene Pulser apparatus. The transfected cells were plated on G418-resistant mouse embryonic fibroblasts (MEFs) and cultured in nonselective medium for 36 hours. Then selective medium was applied for 10 days. Afterwards, resistant clones were picked and further cultured on 24-well plates for DNA isolation and cell freezing.

To find a correct homologous recombinant ESC clone, DNA of 100 ESC clones were screened by Southern analysis using 5' external probe (Fig. 7). After DNA digestion with EcoRI, a $15 \mathrm{~kb}$ band was expected for the wild type allele and a $13 \mathrm{~kb}$ band for the flox allele (Fig. 7). I found 42 clones that gave correct results. Four of them were selected for further analysis. BsrGI- and AseI-digested DNA was hybridized with 3' external and internal probe, respectively (Fig.7). As shown in Fig. 8, ESC clone no. 22 and 60 turned out to be correct, bands of expected size were detected (Fig. 8B, C). To confirm the absence of additional insertion of cKO construct in other loci of ESC genome, BsrgI-digested DNA of the clones was hybridized with the probe for Neomycin cassette. The expected result was obtained - single band of $15.2 \mathrm{~kb}$ (Fig. $8 D$ ). An internal probe recognized a $7 \mathrm{~kb}$ fragment 
(Flox allele) and a 5.2kb fragment (wild-type allele) in AseI-digested DNA, what further confirmed the lack of another insertion. The clone 60 was chosen for blastocyst injection.
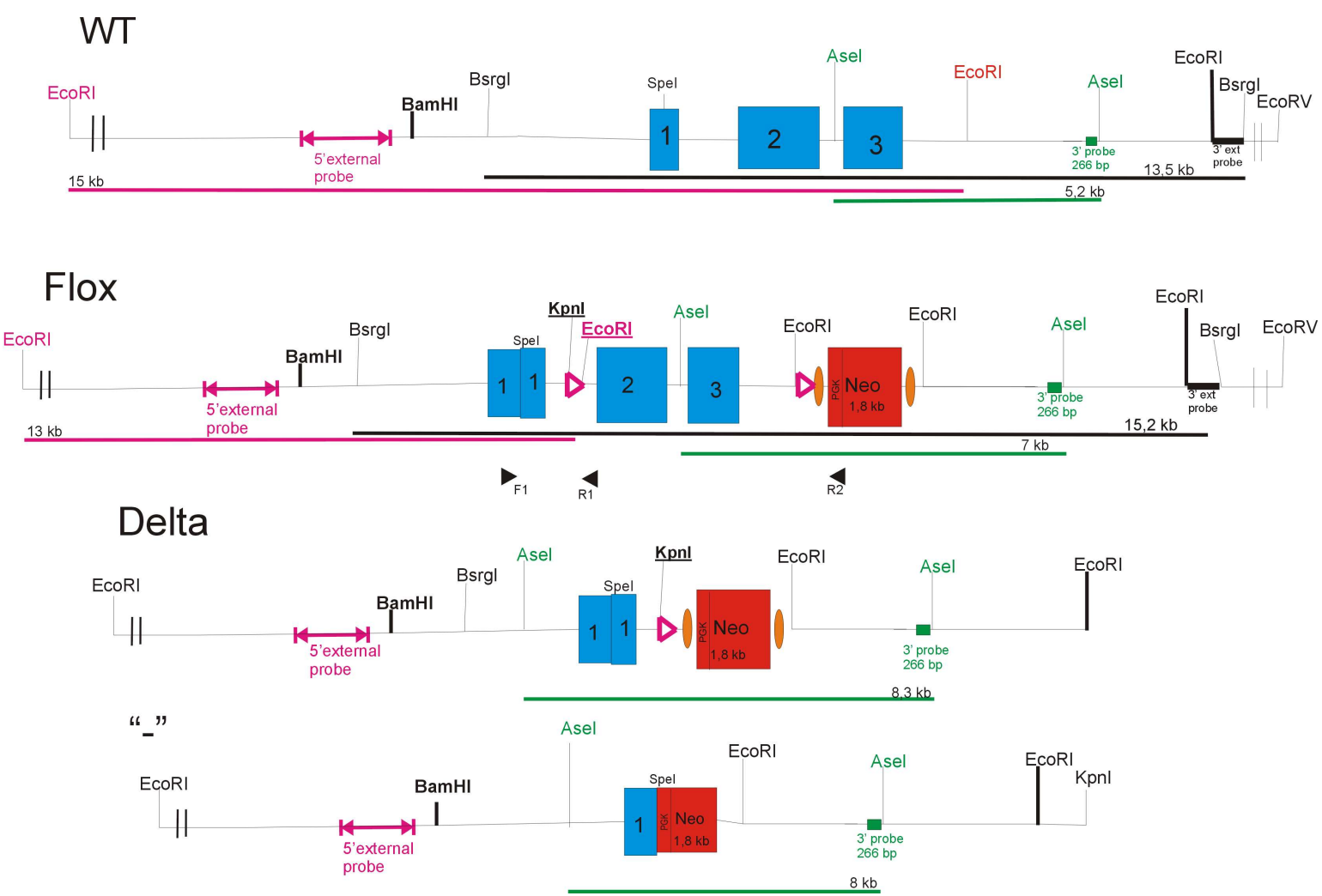

Figure 7. A schematic diagram of conditional knockout (cKO) allele

WT - wild type allele; Flox - conditional knockout allele; Delta - cKO allele after deletion of floxed region between LoxP sites (pink triangles); "_" - classical knockout allele. The hybridization of EcoRI-digested genomic DNA with the 5'external probe results in a 15-kb band for WT and a 13-kb band for the Flox allele (pink color); BsrGI-digested DNA hybridized with 3'ext probe results in 13.5-kb band for WT and 15.2-kb band for Flox allele (black color); bands obtained by hybridization of AseI-digested DNA with the internal probe (3' probe, 266bp) are marked in green color. Primers used in genotyping: F1 = Pelo_F11, $R 1=P e l o \_R 14$ and $R 2=P G K \_c K O \_R l$ are marked by black arrow heads. 
A

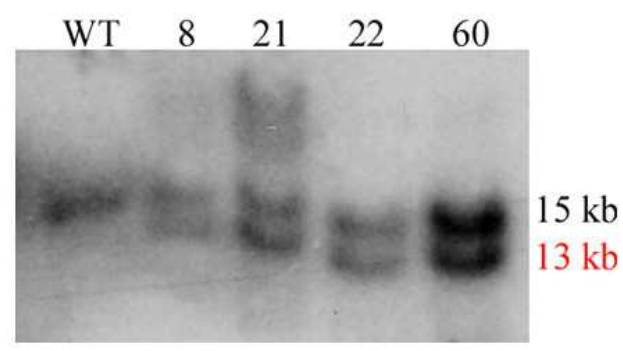

C

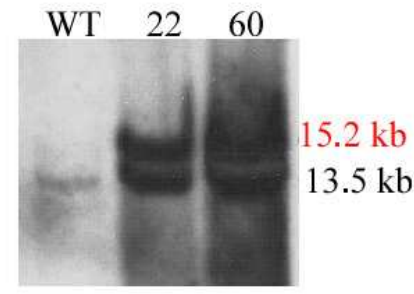

B

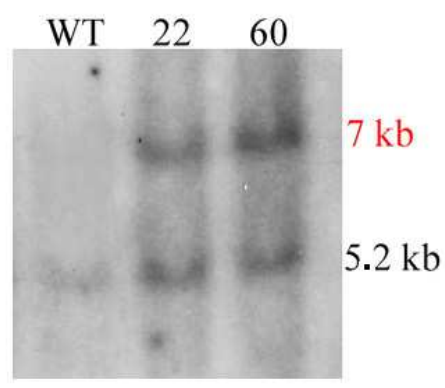

$\mathrm{D}$

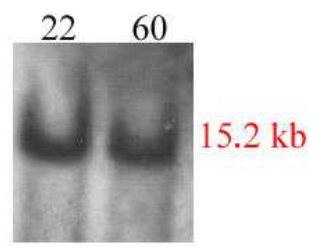

Figure 8. Southern analysis of ESC clones transfected with conditional knockout construct.

$A-D N A$ digested with EcoRI and hybridized with 5' external probe; B - DNA digested with AseI and hybridized with internal probe (3' probe,266bp); C - DNA digested with BsrGI and hybridized with 3' external probe; D - DNA digested with BsrgI and hybridized with Neo probe. Red colour - size of mutant band.

In summary, hybridization of external probes showed correct homologous recombination of the $5^{\prime}$ and $3^{\prime}$ arms of the construct, whereas results obtained from internal and Neo probes confirmed that there was only one integration site of the cKO construct.

\subsubsection{Generation of chimeric mice}

Recombinant ES cells were injected into blastocysts derived from C57Bl/6J mouse strain in Max Planck Institute for experimental medicine in Göttingen. The blastocysts were then transferred into pseudopregnant CD1 females. I obtained 7 chimeric males from clone no. 60, chimerism of which ranged from 20 to $100 \%$, and 4 chimeric males from clone no. 22 with chimerism between 10 and $80 \%$. Two chimeras (90-100\%) from each line were bred with $\mathrm{C} 57 \mathrm{Bl} / 6 \mathrm{~J}$ females. All of them transmitted the $\mathrm{cKO}$ allele to their offsprings. For determination of the genotypes in F1 generation, a set of PCR primers were designed (Fig. 7), which amplify 376 bp-long band for flox allele and $330 \mathrm{bp}$-long fragment for wild type allele (Fig. 9). 


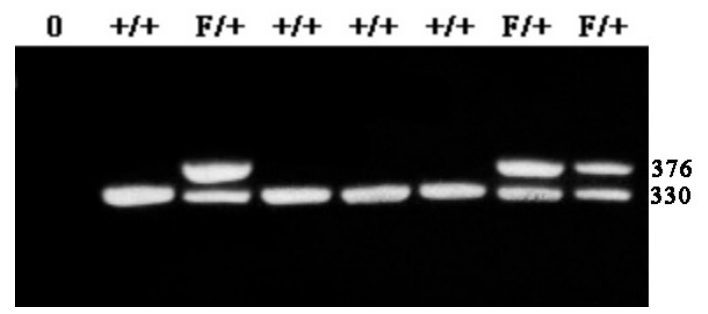

Figure 9. Genotyping PCR for F1 generation of Pelota cKO mice.

$376 \mathrm{bp}$ - flox allele; 330bp - wild-type allele. PCR conditions are presented in chapter 2.2.8.1.

Mice of F1 generation $\left(\mathrm{Pelo}^{\mathrm{F} /+}\right.$ ) displayed no abnormalities - they were healthy and fertile. When bred together $\left({ }^{\mathrm{A}} \mathrm{Pelo}^{\mathrm{F} /+} \mathrm{x}\right.$ $\left.\mathrm{Pelo}^{\mathrm{F} /+}\right)$, they yielded Pelo ${ }^{\mathrm{F} / \mathrm{F}}$ offspring which were viable and fertile as well. These results revealed that the introduction of neomycin cassette and LoxP elements into introns of pelota gene did not disrupt its expression.

\subsubsection{Generation of an ESC line}

For more comprehensive studies of pelota influence on differentiation and cell cycle progression, we generated a Pelo ${ }^{\mathrm{F} /}$ CreERT embryonic stem cell line. To establish the ESC line, blastocysts $(\mathrm{E} 3.5)$ were isolated from Pelo ${ }^{\mathrm{F} /} \mathrm{CreERT}$ females mated with Pelo ${ }^{\mathrm{F} /}$ CreERT males. After 4 days of blastocyst culture, when the proliferating inner cell mass (ICM) caused a break of zona pellucida, one could observe trophoblast cells attached to the bottom and ICM growing on them. Such generated ESCs were genotyped - clone 9 (Pelo ${ }^{\mathrm{F} /-}$ CreERT) and $1\left(\right.$ Pelo $\left.^{\mathrm{F} / \mathrm{F}}\right)$ were chosen for further experiments. To induce Cre-mediated silencing of pelota gene, both clones were treated with $1 \mu \mathrm{M}$ hydroxytamoxifen (OHT) which is more suitable for cultured cells than tamoxifen applied for mice treatment. A genotyping PCR showed that one-day presence of OHT in medium was sufficient to excise the floxed region from the allele of mutant cells (Fig. 10). OHT did not influence viability and differentiation ability of control cells $\left(\mathrm{Pelo}^{\mathrm{F} / \mathrm{F}}\right)$. It proved that applied OHT concentration was not toxic to the cell.

Pelota deletion was also demonstrated by Northern analysis (Fig. 11). Pelota RNA is clearly visible in control and mutant ESCs which were not treated with OHT. After addition of OHT into the medium, pelota expression is stopped in the mutant cells while in control cells lacking recombinase it is not affected. 


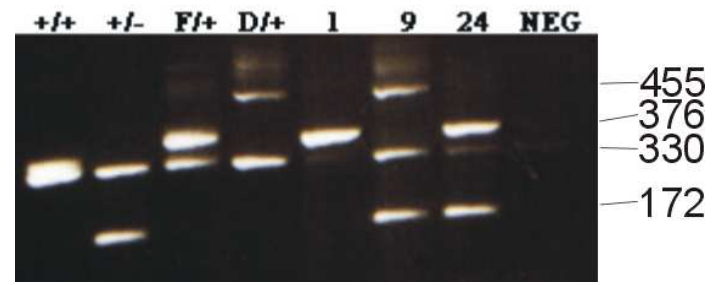

Figure 10. Genotyping PCR for OHT-treated ESCs.

1 - ESC control clone 1;9 - ESC mutant clone 9; 24 - ESC control clone F/- without CreERT; NEG - negative control for PCR. Wild type band visible in ESC lanes comes from feeder layer (mouse embryonic fibroblasts), on which ESCs are cultured. Size of products: " “ band - 172bp; “+” band - 330bp; flox band $(F)-376 b p$; delta band $(D)-$ $455 \mathrm{bp}$

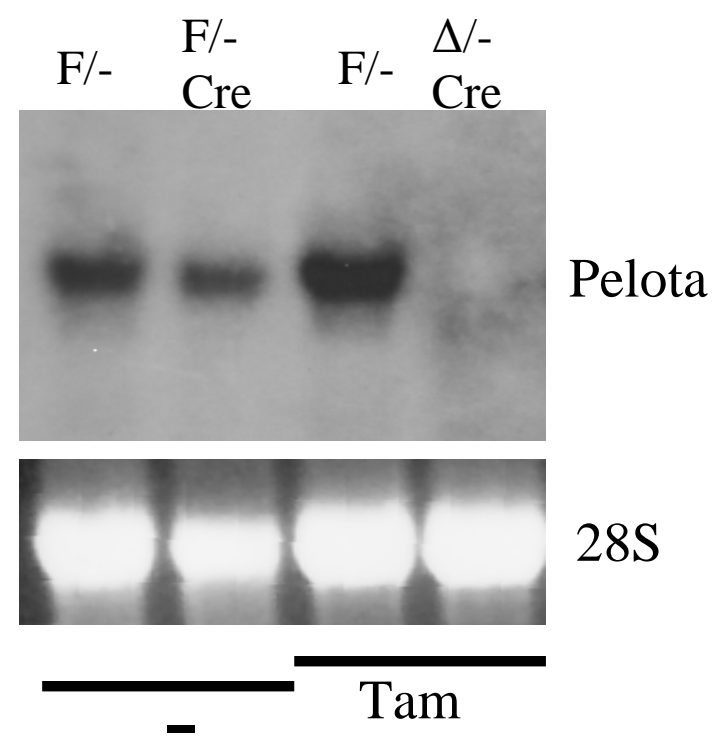

Figure 11. Northern analysis of pelota expression in OHT-treated and untreated ESCs. F/- are control cells because they do not possess CreERT recombinase. First 2 samples are not treated and 2 last are OHT-treated ESCs. The good quality of RNA is demonstrated in the picture of the gel by RNA of $28 S$ subunit.

Pelota-deficient cells did not exhibit any growth impairment - their morphology did not differ from control ESCs. They were successfully preserved in the culture.

\subsubsection{Conditional knockout system- verification of recombination efficiency by generation of cKO/EIIaCre mouse line}

To examine the recombination efficiency of floxed pelota allele and to determine whether the deletion of Pelota during early embryogenesis results in a phenotype similar to that of classical knockout mice, we have introduced a non-inducible EIIaCre recombinase 
allele into the genome of cKO mice (Lakso et al., 1996). The Cre recombinase allele is controlled by adenovirus EIIa promoter which is activated in one-cell stage embryo. Therefore, we expected that floxed pelota allele would be recombinated at zygote stage.

The breeding strategy was as follows: we bred heterozygous $\mathrm{Pelo}^{+/-}$mice with $\mathrm{Pelo}^{+/+}$ EIIaCre $^{\mathrm{T} /-}$ transgenic animals to obtain $\mathrm{Pelo}^{+/-}$EIIaCre which were further bred with Pelo ${ }^{\text {Flox/+ }}$. The mice were genotyped by using two PCRs (Fig. 12) to determine the genotype of pelota locus and the presence of transgenic EIIaCre allele.

A

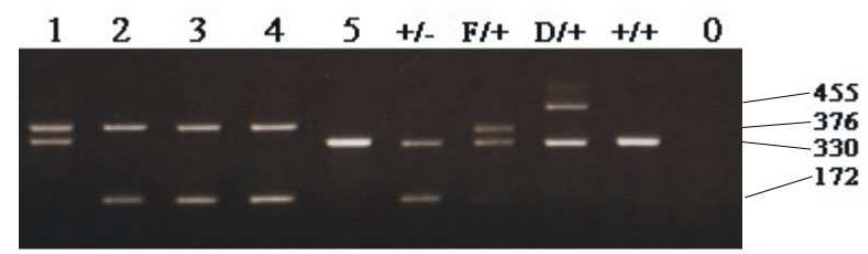

B

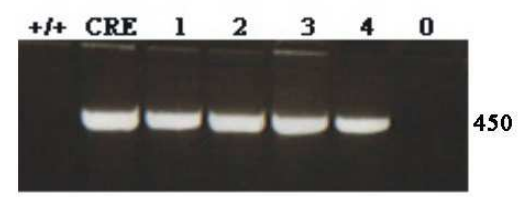

Figure 12. Genotyping PCRs for cKO/EIIa mice

$\boldsymbol{A}$ - flox/-/A PCR for determination of the genotype of pelota locus, B - EIIa PCR

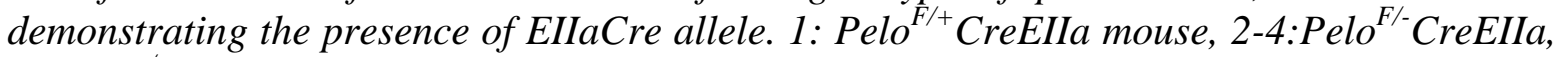
5: Pelo $^{+/+}$. Size of products of flox/-I $\triangle$ PCR: $455 \mathrm{bp}$-deleted allele; $376 \mathrm{bp}-$ flox $(\mathrm{F})$ allele; $330 b p$ - wild-type allele; 172bp - classical KO allele. Size of transgene band: 450bp. Primers were designed in transgene sequence what explains lack of the band in wild-type animal (+/+). PCR conditions are presented in chapter 2.2.8.1.

We predicted that Pelo ${ }^{\Delta /-}$ CreEIIa offsprings would die at early embryonic stage. There were no Pelo ${ }^{\Delta /-}$ EIIaCre animals out of 219 genotyped mice of F1 generation. According to Mendelian ratio, Pelo ${ }^{\Delta /}$ EIIaCre should constitute $12.5 \%$ of all offsprings in the breeding of $\mathrm{Pelo}^{+/-} \mathrm{Cre}^{\mathrm{T} /-}$ and Pelo ${ }^{\mathrm{F} /+}$ (Table 1). Moreover, this genotype was also not found in further generations (180 mice tested).

Table 1. Statistics of genotypes obtained in F1 generation from cKO/EIIaCre mouse line

\begin{tabular}{|c|c|c|c|c|c|c|c|c|}
\hline \multicolumn{8}{|c|}{ Pelo $^{+/-} \mathrm{Cre}^{\mathrm{T} /-} \mathrm{X}$} & $\mathrm{Pelo}^{\mathrm{F} /+}$ \\
\hline F1 generation & $+/+$ & $+/-$ & $\mathrm{F} /+$ & $\mathrm{F} /-$ & $+/+\mathrm{T} /-$ & $+/-\mathrm{T} /-$ & $\Delta /+\mathrm{T} /-$ & $\Delta /-\mathrm{T} /-$ \\
\hline Mendelian ratio & 1 & 1 & 1 & 1 & 1 & 1 & 1 & 1 \\
\hline Mice number (out of 219) & 33 & 29 & 25 & 41 & 36 & 29 & 26 & $\mathbf{0}$ \\
\hline Percentage (\%) & 15.1 & 13.2 & 11.4 & 18.7 & 16.4 & 13.2 & 11.9 & $\mathbf{0}$ \\
\hline
\end{tabular}


The results clearly demonstrated that Cre-mediated recombination efficiently excises pelota-flanked region in one-cell stage of mouse development, i.e. Pelo ${ }^{\Delta /-}$ EIIaCre died during prenatal stages (like Pelo $^{--}$). To obtain more evidence, embryos (E8.5) from breeding of Pelo ${ }^{\Delta /+}$ CreEIIa mice were genotyped. None out of 7 isolated embryos was Pelo ${ }^{\Delta / \Delta}$ EIIaCre. Three deciduas were found empty and degenerated. It indicated that the absorption of dead embryos had occured. These results suggest that Pelo ${ }^{\Delta /}$ CreEIIa have a phenotype similar with classical pelota knockout mice (Adham et al., 2003).

\subsubsection{The role of Pelota in germ cell development - testis-specific cKO/Stra8-Cre mouse line}

To analyze Pelota impact on spermatogenesis, we introduced a Stra8-Cre recombinase allele to the genome of Pelo ${ }^{\mathrm{F} / \mathrm{F}} \mathrm{cKO}$ mice. Expression of Stra8 is germ-cellspecific and has been reported in spermatogonia (Oulad-Abdelghani et al., 1996) and premeiotic germ cells of embryonic ovary (Baltus et al., 2006). According to Stra8 expression, we expected that pelota would be exclusively deleted in spermatogonia and we would be able to verify pelota involvement in self-renewal of germ stem cells.

\subsubsection{Generation of Pelo ${ }^{\mathrm{F} /}$ Stra8-Cre mouse}

Heterozygous $\mathrm{Pelo}^{+/-}$mice were bred with transgenic $\mathrm{Pelo}^{+/+} \mathrm{Stra}_{-}-\mathrm{Cre}^{\mathrm{T} /}$ to obtain Pelo $^{+/}$Stra8-Cre mice, which were further bred with Pelo ${ }^{\mathrm{F} / \mathrm{F}}$ mice. We genotyped the offsprings using flox/-/S PCR amplifying all alternatives of Pelo allele and PCR demonstrating presence/lack of Stra8-Cre in mouse genome (Fig.13). In F2 generation we

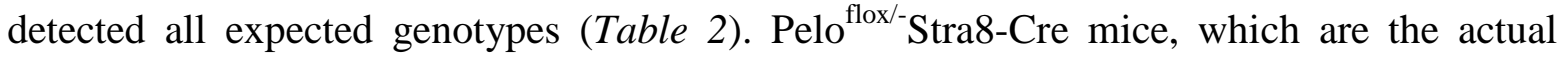
model for study of spermatogenesis in pelo-deficient mice, were also found. It indicates that Pelo ${ }^{\mathrm{F}}$ allele is not recombined in somatic cells. 


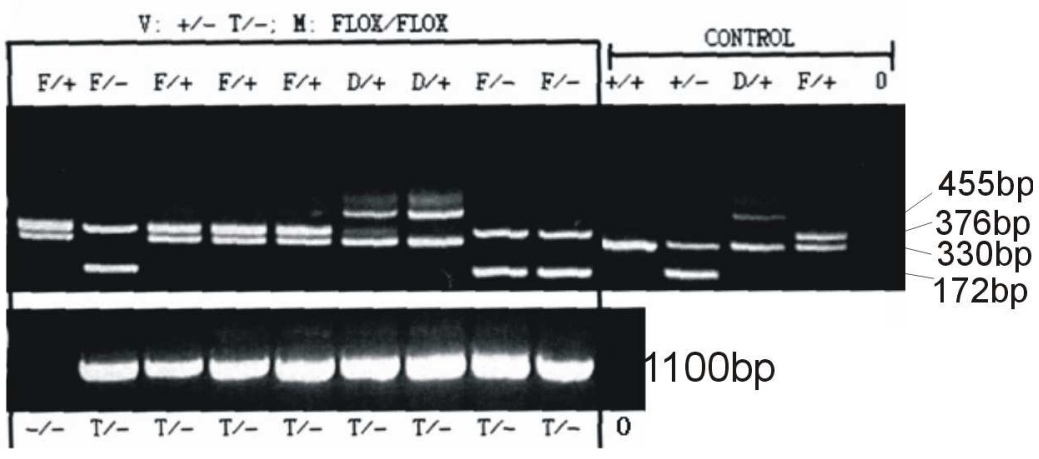

Figure 13. Genotyping PCRs for cKO/Stra8-Cre line.

The figure shows pictures of PCR products loaded on gel. PCR flox/-/4 products are Pelo $\triangle$ (455bp), PeloF (376bp), Pelo+ (330bp), Pelo- (172bp). Transgene-specific band is 1100bp long. Primers were designed in transgene sequence what explains lack of the band in wildtype animal. PCR conditions are presented in chapter 2.2.8.1.

Table 2. Statistics of male genotypes obtained in F2 generation from cKO/Stra8-Cre mouse line

\begin{tabular}{|c|c|c|c|c|}
\hline \multicolumn{5}{|c|}{ Pelo $^{+/-}$Stra8-Cre ${ }^{\mathrm{T} /-} \times$ Pelo $^{\mathrm{F} / \mathrm{F}}$} \\
\hline F2 generation & $\mathrm{F} /+$ & F/- & $\mathrm{F} /+\mathrm{Cre}$ & F/-Cre \\
\hline Mendelian ratio & 1 & 1 & 1 & 1 \\
\hline$\hat{\sigma}$ Number (out of 66) & 14 & 17 & 19 & 16 \\
\hline Percentage $(\%)$ & 21.2 & 25.8 & 28.8 & 24.2 \\
\hline
\end{tabular}

However, by genotyping the mice of this line we found 9 males and 5 females which were Pelo ${ }^{\Delta /+}$ Cre. It suggests that Stra8-Cre-mediated recombination occurs in some somatic cells. Intrestingly, no chimeric Pelo ${ }^{\Delta / \mathrm{F} /}$ Stra8-Cre offspring was detected. To examine the Cre recombination range resulting in pelota deletion, DNA from various tissues of two Pelo ${ }^{\Delta /+}$ Stra8-Cre animals was isolated and genotyped. The mosaic genotype was found in all studied organs (Fig. 14). The result suggests that Cre recombinase under Stra8 promoter is activated during early embryogenesis of some animals and then contributes to pelota excision by Cre-mediated recombination of floxed allele. The absence of Pelo ${ }^{\mathrm{F} / \Delta /} \mathrm{Stra} 8-\mathrm{Cre}$ animals may be caused by early embryonic lethality of this genotype. 


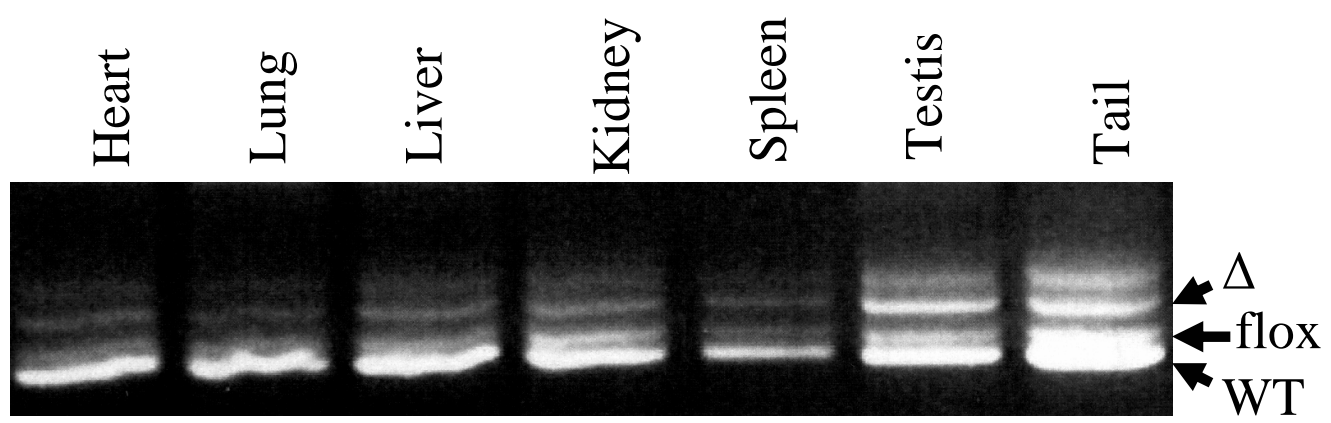

Figure 14. Genotyping of different organs derived from Pelo ${ }^{4 /+}$ Stra8-Cre animal DNA from different organs was isolated by the same method as from tail DNA (chapter 2.2.1.2.) and it was genotyped with PCR flox/-/A.

\subsubsection{Histological analysis of testes during postnatal development}

In order to check if Stra8-Cre-mediated pelota deletion influences spermatogenesis, we isolated testes of 6-week-old males for histological study (Fig. 15). Hematoxilin and eosin $(\mathrm{H} \& \mathrm{E})$ staining revealed that spermatogenesis is impaired in $70 \%$ of seminiferous tubules of Pelo ${ }^{\mathrm{F} /}$ Stra8-Cre. The diameter of the tubules is significantly smaller than in wild type and Leydig cells are hyperproliferated. Germ cell differentiation is arrested at premeiotic stage in most affected tubules where few number of pachytene spermatocytes and round spermatids were observed. Additionally, one could notice numerous vacuoles. In normal tubules of mutant testes, spermatogenesis was found to progress fairly normal to elongated spermatids. 


\section{RESULTS}

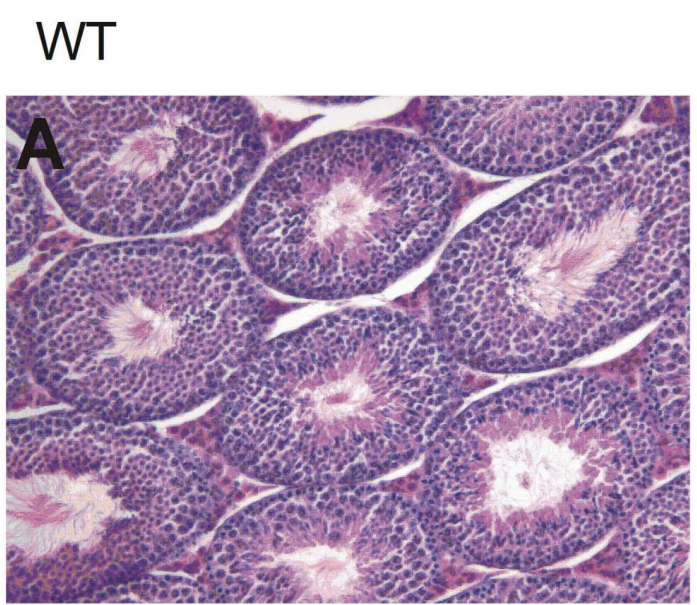

\section{Pelo $^{\mathrm{F} /}$-Stra8-Cre}
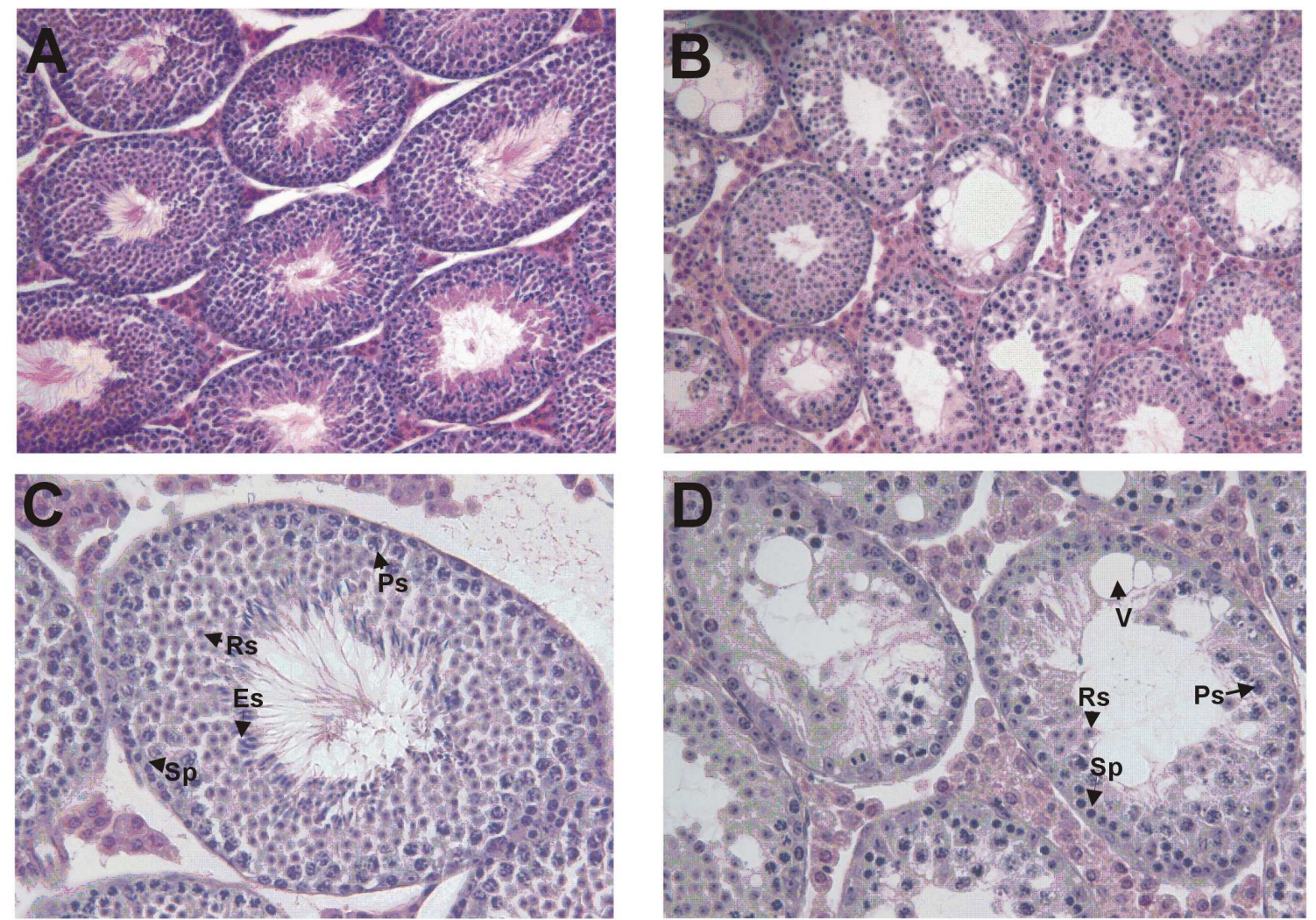

Figure 15. H\&E staining of testis sections from wild-type and Pelo ${ }^{\mathrm{F} / \mathrm{Stra} 8-\mathrm{Cr} \text { - mice. }}$

Testes were isolated from 6-week-old animals of cKO/Stra8-Cre line. A, C-wild-type testis; B, D - Pelo ${ }^{F /}$ Stra8-Cre testis. Sp - spermatogonia; Ps - pachytene spermatocytes; Rs round spermatids; Es - elongates spermatids; $V$-vacuoles. A, $B$ - 10 x magnification; $C, D$ $-20 x$ magnification.

To define the onset of pelota influence on spermatogenesis in Pelo ${ }^{\mathrm{F} /} \mathrm{Stra} 8-\mathrm{Cre}$, we characterized the first wave of germ cell differentiation in testes of wild-type and mutant mice. We isolated testes from 5-, 10-, 15-, 20- and 25-day-old animals, fixed and stained them with hematoxilin and eosin.

Analysis of cross sections of 5- and 10-day-old wild-type and mutant testes revealed no striking differences (Fig.16A-D). At day 10 of spermatogenesis, primary spermatocytes appear. The number of germ cells seems to be slightly reduced compared to the wild type. At day 15, the differentiation reaches the stage of pachytene spermatocytes (Fig. 16E). In mutant testes, we observed a drastic reduction in the number of pachytene spermatocytes in some tubules, while the other tubules displayed the depletion of all meiotic germ cells (Fig. $16 F$ ). Germ cell development results in round spermatids at the day 20 (Fig17A). However, in mutant testes the germ cells were developmentally arrested at the stage of pachytene 


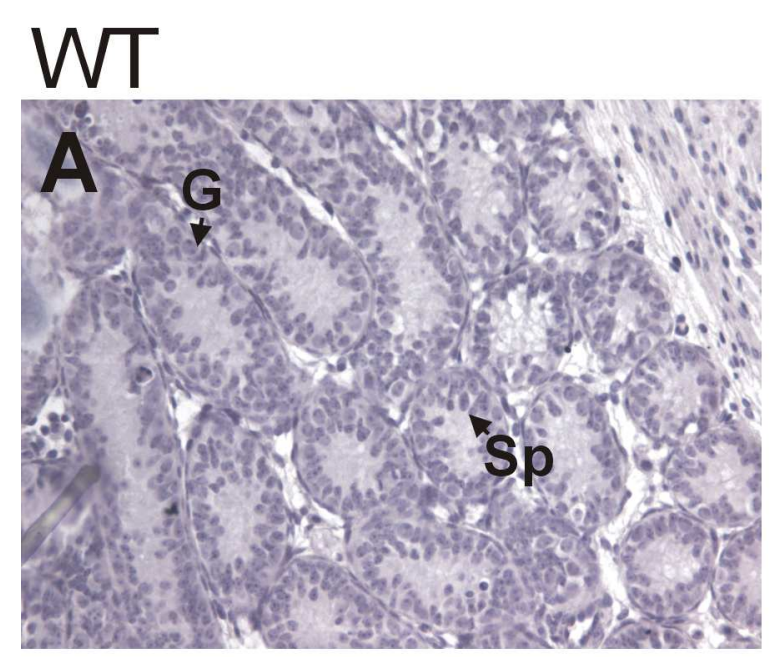

\section{Pelo ${ }^{\mathrm{F}-S t r a 8-C r e}$}
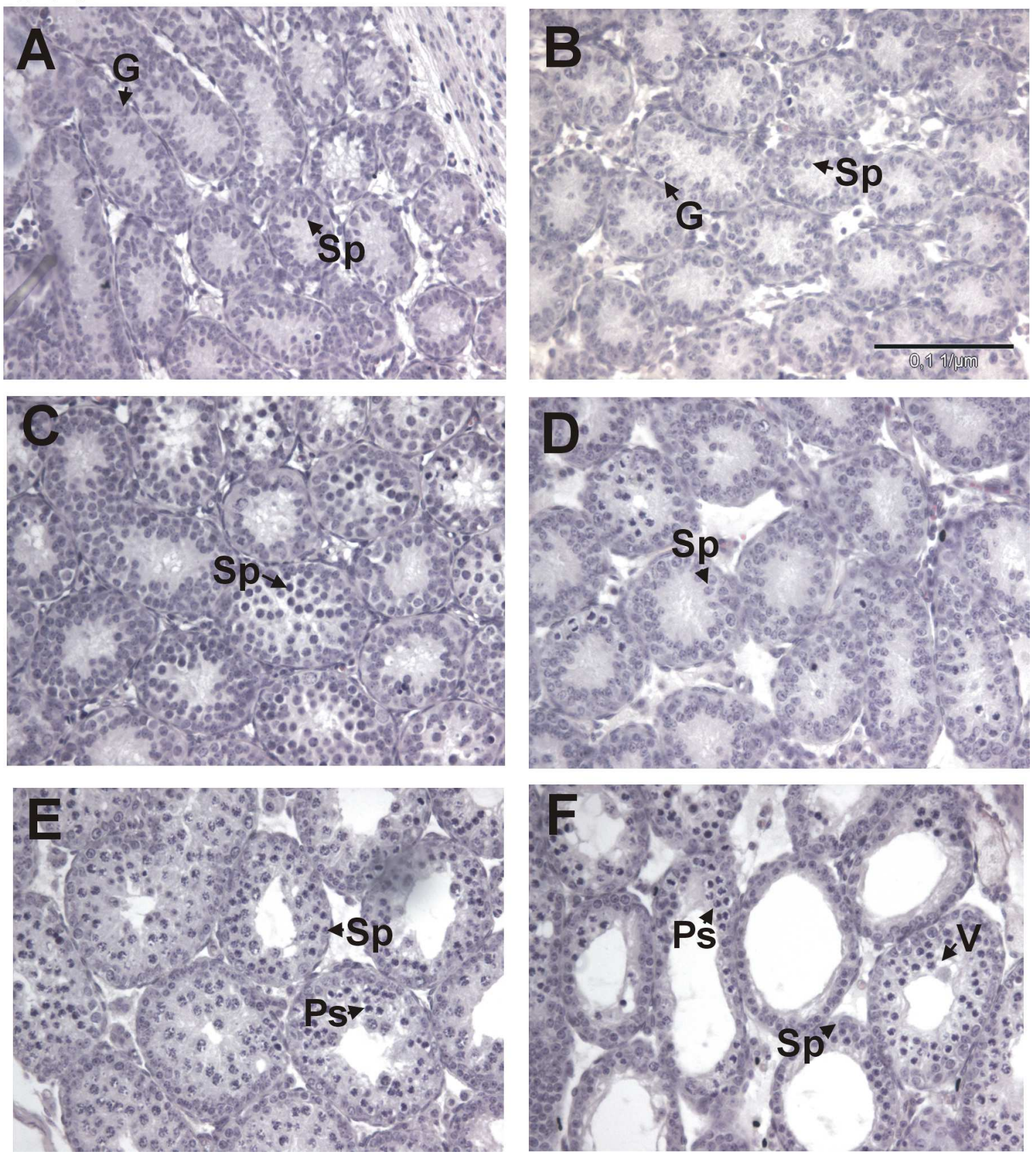

Figure 16. $\mathrm{H} \& \mathrm{E}$ staining of 5-, 10- and 15-day-old testis sections from wild-type and Pelo ${ }^{F /-}$ Stra8-Cre mice.

$A, C, E$ - wild-type testis; B, D, F - Pelo ${ }^{F /}$ Stra8-Cre testis. G - gonocytes; Sp spermatogonia; Ps - pachytene spermatocytes; V-vacuoles. Photos were taken in $20 x$ magnification).

spermatocytes (Fig. 17B). At day 25 the first round of spermiogenesis proceeds and elongated spermatids appear (Fig. 17C). While mutant testes displayed severe depletion of germ cells, pachytene spermatocytes and round spermatids were strongly reduced in number, 
and vacuolization of Sertoli cells was more pronounced (Fig. 17D). These results suggest that spermatogenesis is disrupted at premeiotic and/or early meiotic stages.
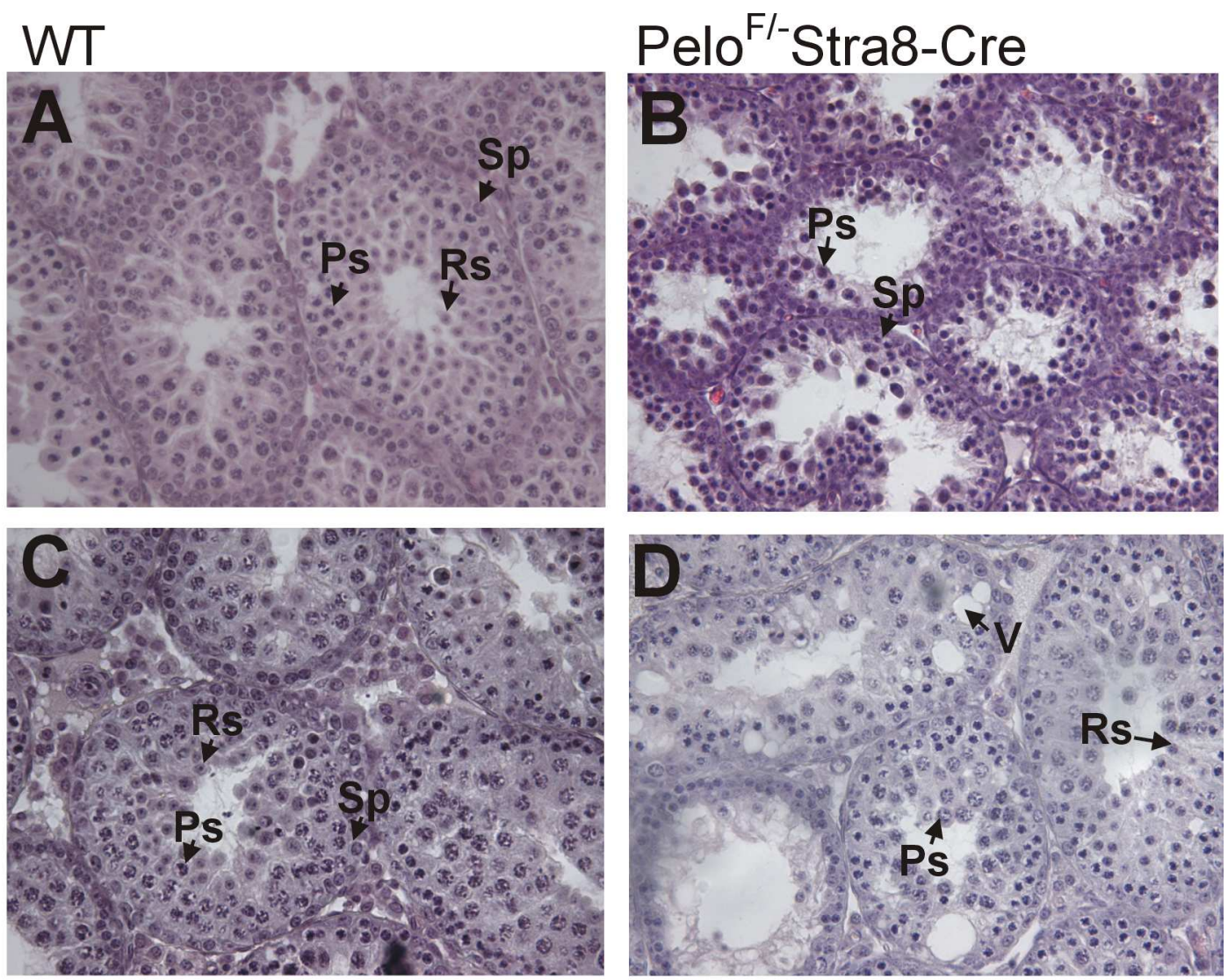

Figure 17. H\&E staining of 20- and 25-day-old testis sections from wild-type and Pelo ${ }^{\text {F/- }}$ Cre mice.

20-day-old testes are presented in picture $A$ and B. 25-day-old testes are shown in picture $C$ and D. A, C-wild-type testis; B, D-Pelo ${ }^{F /}$ Cre testis. Sp - spermatogonia; Ps - pachytene spermatocytes; Rs - round spermatids; V-vacuoles; Gc - monster cells. Photos were taken in $20 x$ magnification.

Due to severe impairment of spermatogenesis and loss of cells in particular tubules, we performed a TUNEL-assay (the terminal deoxynucleotidytransferase-mediated dUTPBiotin nick end labeling) in order to verify if enhanced apoptosis is the reason of germ cell depletion. We examined the apoptosis levels in testes of 5-, 10-, 15-, 20 and 25-day-old mice (Fig. 18). In comparison to control mice (wild-type), Pelo ${ }^{\mathrm{F} /}$ Stra8-Cre did not show any difference in apoptosis level until postnatal day 10. However, starting with day 15 we could observe a significant increase in number of apoptotic cells, most of which seemed to be in the meiotic prophase. Hence, enhanced level of apoptosis may be the cause of germ cell depletion in mutant testes. 


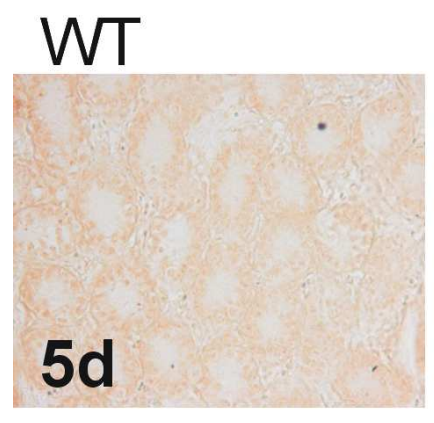

\section{Pelo ${ }^{\mathrm{F} /}$-Stra8-Cre}

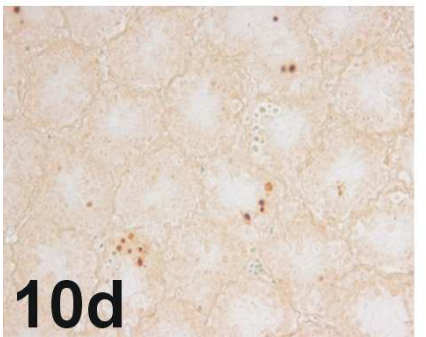

$5 d$

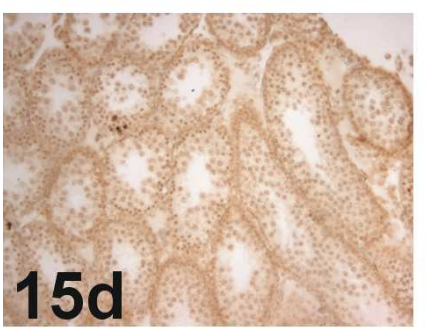

$10 d$
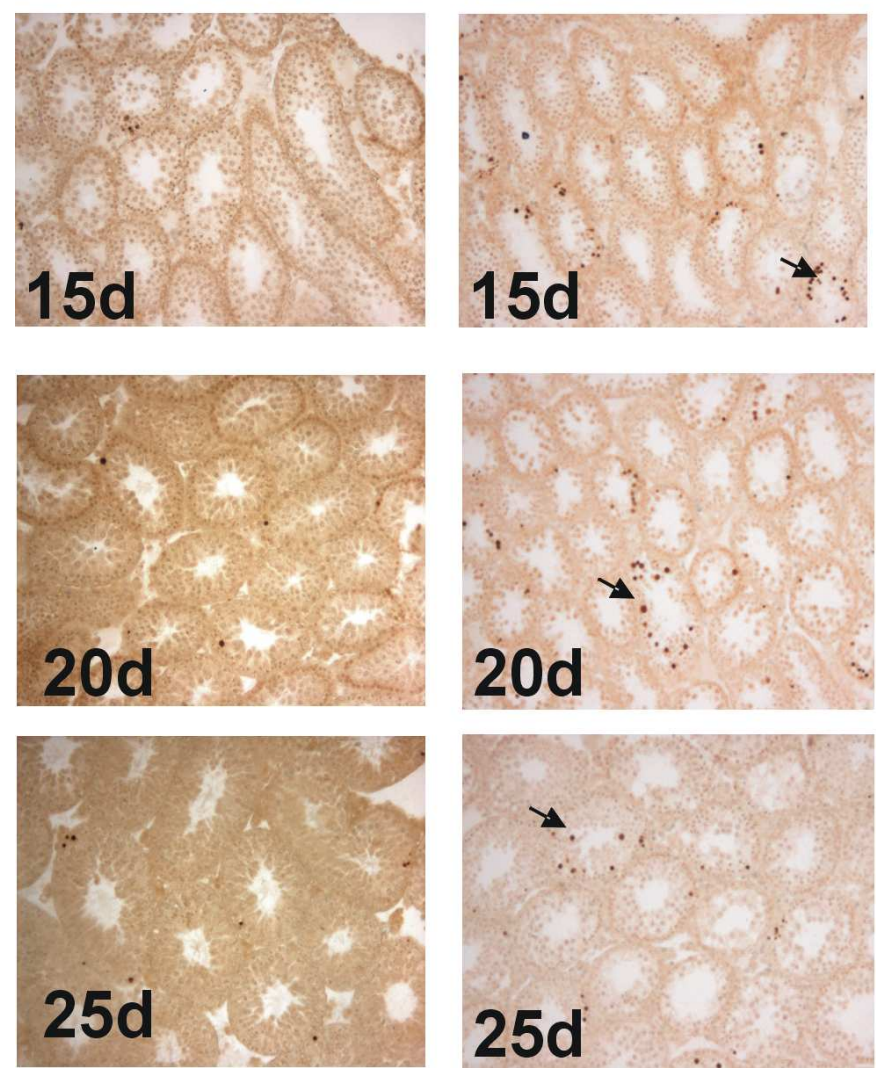

Figure 18. Apoptosis analysis of testis sections from wild-type and and Pelo ${ }^{F /}$ Stra8-Cre mice.

Testes were isolated from 5-, 10-, 15-, 20- and 25-day-old mice. Left panel - wild-type testes; right panel - Pelo ${ }^{\mathrm{F}-}$ Stra8-Cre testes. The arrows indicate apoptotic cells. Photos were taken in $20 x$ magnification. 


\subsubsection{Spermatogenesis of Pelo ${ }^{\mathrm{F} /}$ Stra8-Cre mice is affected at premeiotic stages}

To determine the developmental stage, at which spermatogenesis is arrested in mutant testis, we performed immunohistochemical analysis using premeiotic (Hsp-110, GCNA1) and meiotic (HSPA4L) markers.

HSP110 protein is expressed ubiquitously, but its highest level is observed in gonocytes. Immunohistochemical analysis of 5- and 10-day-old testes with antiHSP110 antibody revealed that the number of HSP110-positive cells exhibits a twofold reduction in tubules of 5-day-old Pelo ${ }^{\mathrm{F} / \mathrm{S}} \mathrm{Stra8}$-Cre mice in comparison to the control (Fig. 19A,B).

\section{WT}
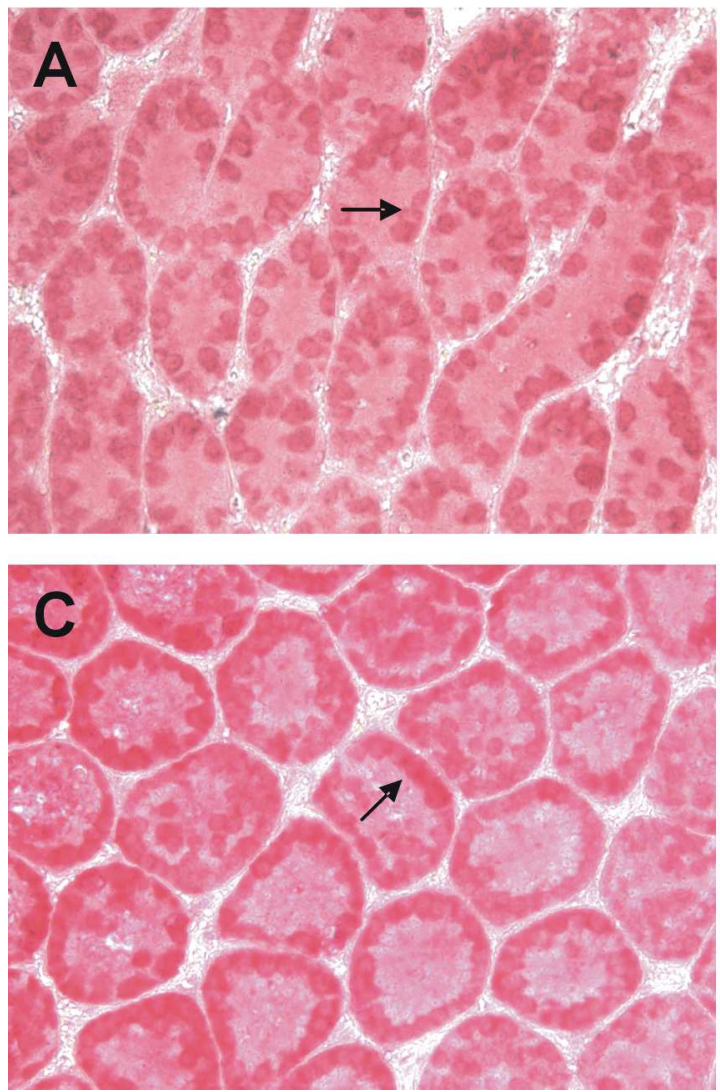

Pelo ${ }^{\mathrm{F} /}$ - Stra8-Cre
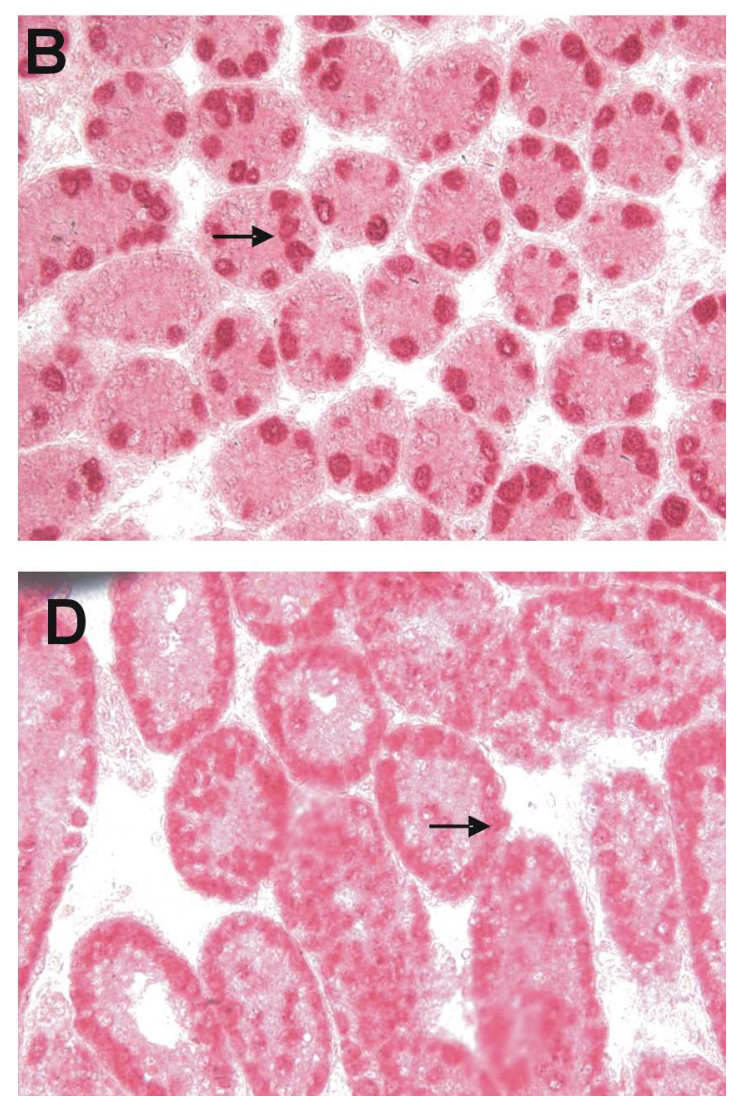

Figure 19. Immunohistochemical analysis of Hsp110 in testis sections from wild-type and Pelo ${ }^{\text {F/ }}$ Stra8-Cre mice at day 5 and 10 of spermatogenesis

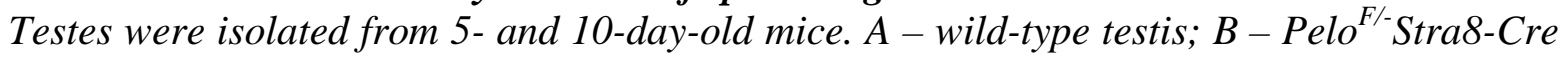
testis. The arrows show spermatogonia. Photos were taken in $20 x$ magnification.

Reduction of germ cells was also visible at day 10, but exact estimation of cell number was impossible at that stage due to staining quality (Fig.19C,D).

The second premeiotic marker that we used, was GCNA1 (germ cell nuclear antigen). It is highly expressed in spermatogonia and primary spermatocytes (Enders and May, 1994). 
We performed GCNA1 staining on 5-, 10- and 15-day-old testis sections of mutant and control mice (Fig. 20,21) to further confirm the premeiotic impairment of spermatogenesis. In 5-day-old testes we could see no significant difference in number of GCNA1-positive cells between the mutant and the conltrol (Fig. 20A-D). Staining was specific for cells localized as spermatogonia in the tubules. However, at the age of 10 day we found app. $24 \%$ of germ cell-depleted tubules in testes of Pelo ${ }^{\mathrm{F} /}$ Stra8-Cre mice $(F i g .20 F, H$ ), where no GCNA1-positive cells could be detected. In the control all seminiferous tubules contained spermatogonia and primary spermatocytes stained with GCNA1 (Fig. 20E, G).

In testes of 15-day-old control mice, GCNA1-positive cells, i.e. spermatogonia and spermatocytes, constituted peripheral multi-cell layer in each tubule (Fig. $21 A, C)$. Mutant testes were composed of reduced number of GCNA1-stained cells. We found a significant increase of seminiferous tubules, which lacked GCNA1-positive germ cells in mutant testes (Fig. 21B, D). 

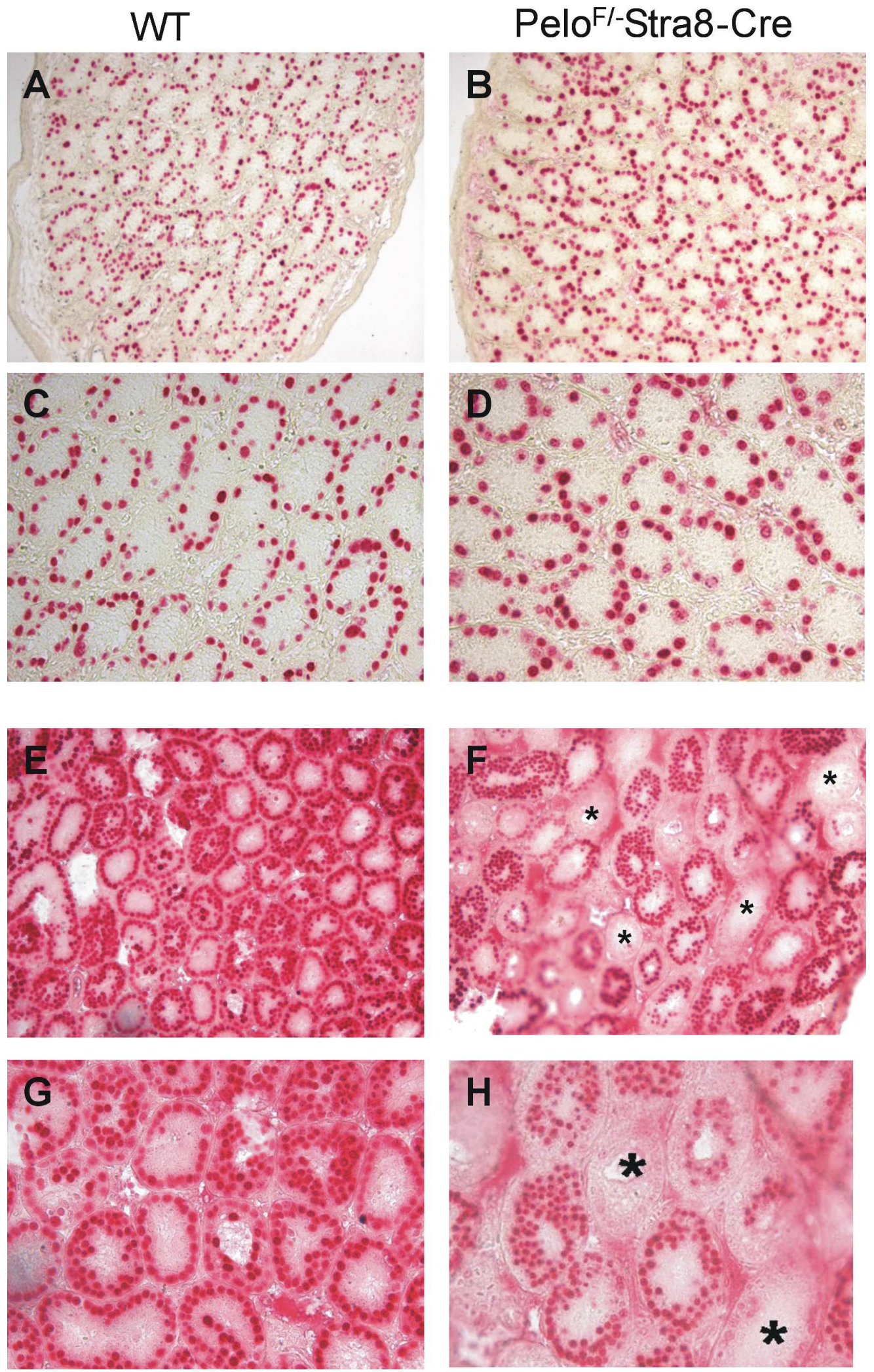

Figure 20. Immunohistochemical analysis of GCNA1 in testis sections from wild-type and Pelo $^{\text {F/- }}$ Cre mice at day 5 and 10 of spermatogenesis.

Testes were isolated from 5- (A-D) and 10-day-old (E-H) mice. Wild-type testes are presented in the left panel $(A, C, E, G)$, whereas Pelo ${ }^{F /}$ Stra8-Cre testes are demonstrated in the right panel $(B, D, F, H)$. Stars stand for tubuli devoid of spermatogonia. Photos were taken in 10 and $20 x$ magnification. 

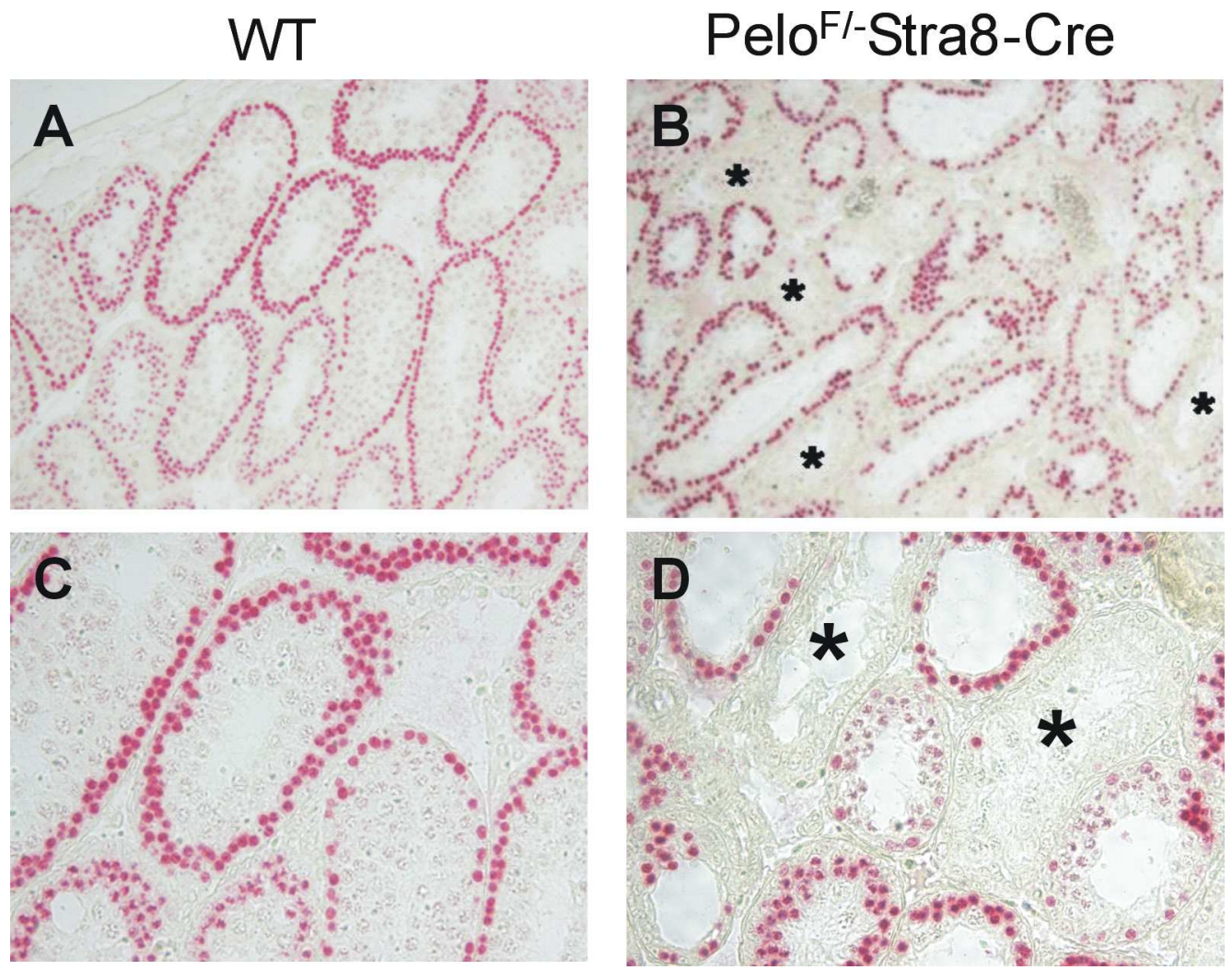

Figure 21. Immunohistochemical analysis of GCNA1 in testis sections from wild-type and

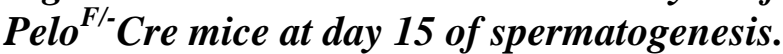

Testes were isolated from 15-day-old mice. A, C-wild-type testis; B, D-Pelo ${ }^{\mathrm{F} /}$-Stra8-Cre testis. Star stands for degraded tubuli. Photos were taken in 10 and $20 x$ magnification.

We used a specific antibody against HSPA4L (heat shock 70kDa protein 4-like /Apg1) for immunohistochemical analysis of testis sections from 15-day-old mice. HSPA4L is expressed from late pachytene spermatocytes and all germ cell stages thereafter (Held et al., 2006). We detected the number of tubules containing HSPA4L-positive cells in mutant testes as compared to wild type is reduced (Fig. 22A,B)

On the basis of these immunohistochemical results, we can assume that PELO depletion results in the arrest of spermatogenesis in the premeiotic stage. 


\section{WT}

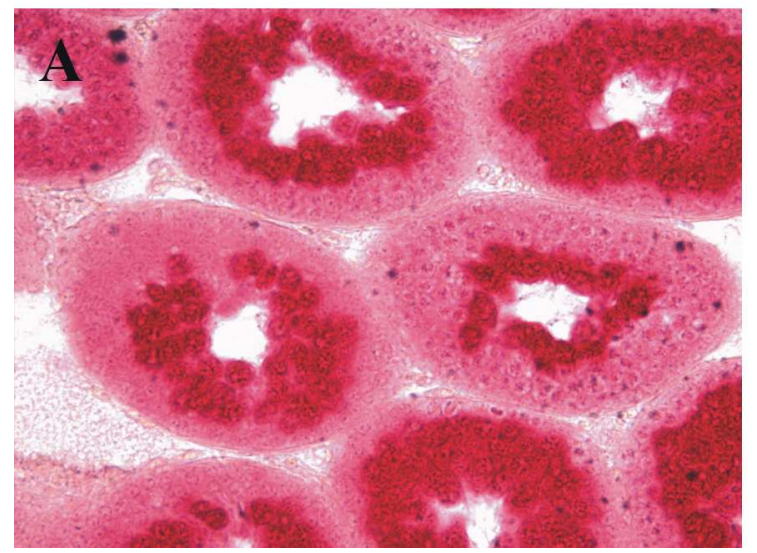

\section{PeloF/-Stra8-Cre}

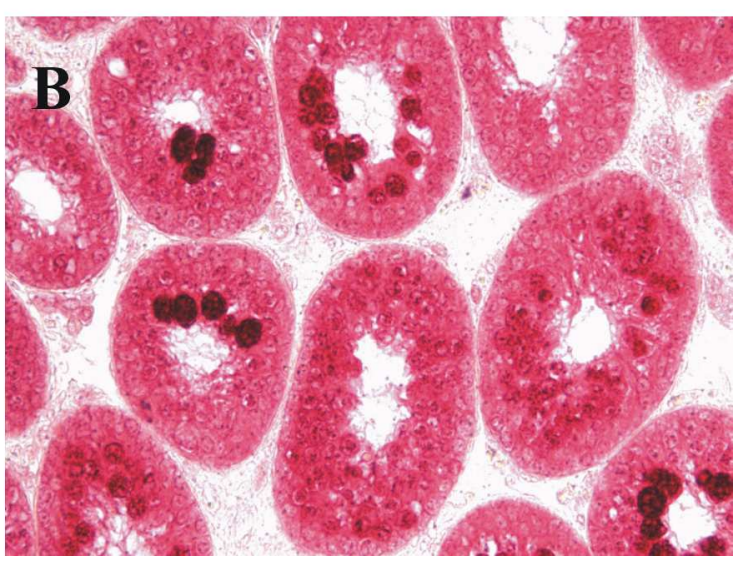

Figure 22. Immunohistochemical analysis of APG1 in testis sections from wild-type and Pelo $^{\text {F/ }}$ Cre mice at day 15 of spermatogenesis.

\subsubsection{Quantitative expresion analysis of premeiotic markers in Pelo ${ }^{\mathrm{F} /}$-Stra8-Cre mice}

For further verification of the germ cell developmental stage disrupted in mutant testes, we examined the expression of various premeiotic molecular markers by quantitative RT PCR (qRT-PCR). We prepared testis cDNA from 5-, 10-, 15- and 20-day-old mice and used it in real time PCR analysis by means of primers specific for genes expressed in undifferentiated spermatogonia (Plzf and Sox3), differentiated spermatogonia (c-Kit) and early meiotic stages (Stra8). The results were standarized to relative expression in reference to expression of housekeeping gene - SDHA (succinate dehydrogenase complex subunit $\underline{\mathrm{A}}$ ). The analysis of the marker expression was performed using 2-3 testes of each stage and each genotype.

Plzf and Sox 3 genes are expressed in undifferentiated spermatogonia (Raverot et al., 2005). The relative expression of both markers was reduced in 5- and 10-day-old mutant testes compared to the control. Except for decreased expression of Plzf gene in 15-day-old mutant testes, there were no significant differences in the transcript level of both markers between mutant and control testes at 15- and 20-day-old testes (Fig. 23).

Analysis of c-Kit, exclusively expressed in differentiated spermatogonia (SchransStassen et al., 1999), revealed no difference in relative expression between mutant and control testes of all studied developmental stages (10-, 15-, 20-day-old) apart from mutant 5day-old testes, where it was reduced (Fig. 24). 

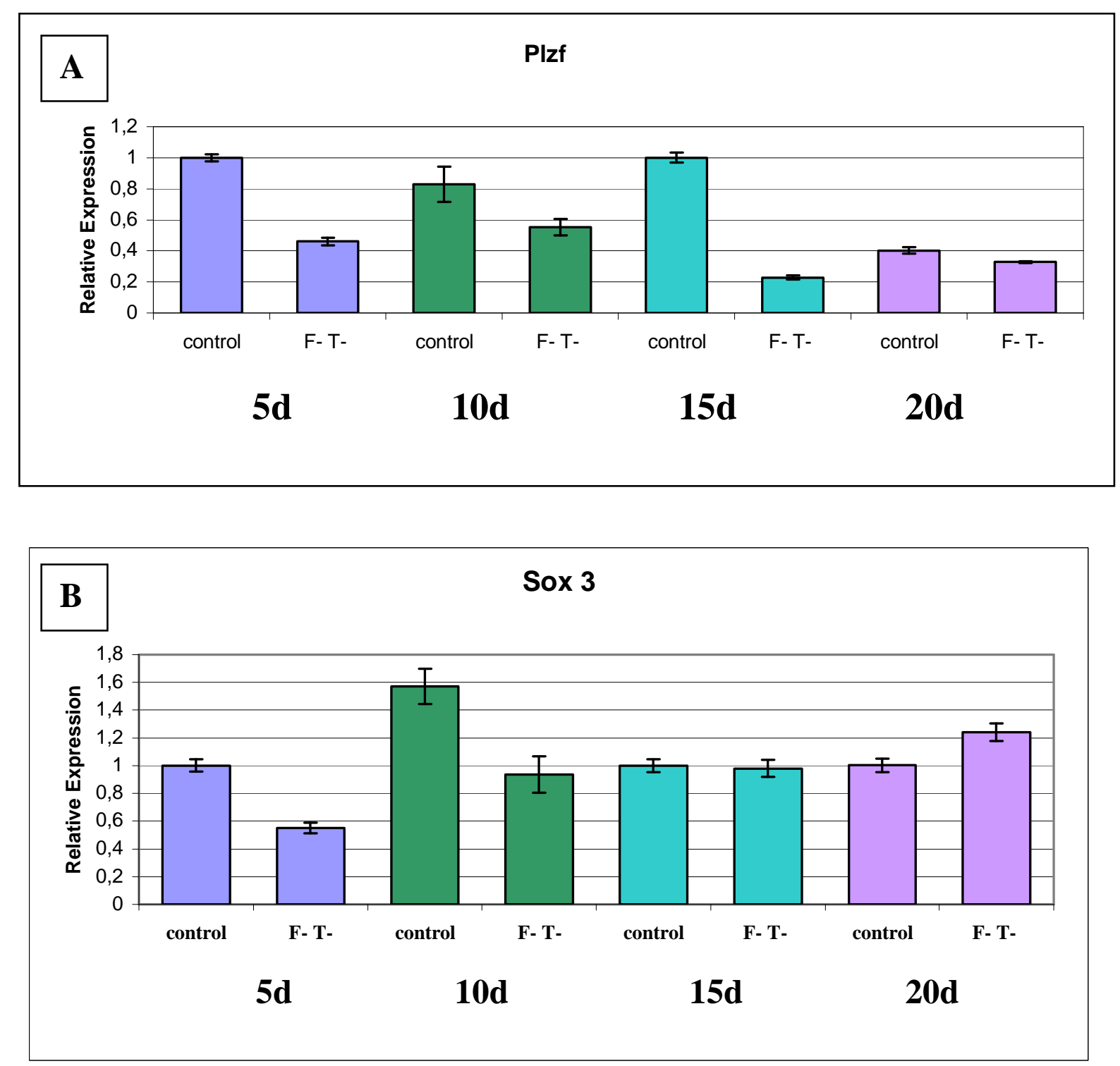

Figure 23. Relative levels of Plzf(A) and Sox3 (B) mRNA expression in testes of Pelo/Stra8-Cre mice during first wave of spermatogenesis.

Values represent relative level of Plzf and Sox3 in testes of 5-, 10-, 15- and 20-day-old animals $(5 d, 10 d, 15 d, 20 d)$. Expression levels were normalised to the expression of endogenous control (Sdha). 2-3 biological replicates were used for each stage and genotype. 


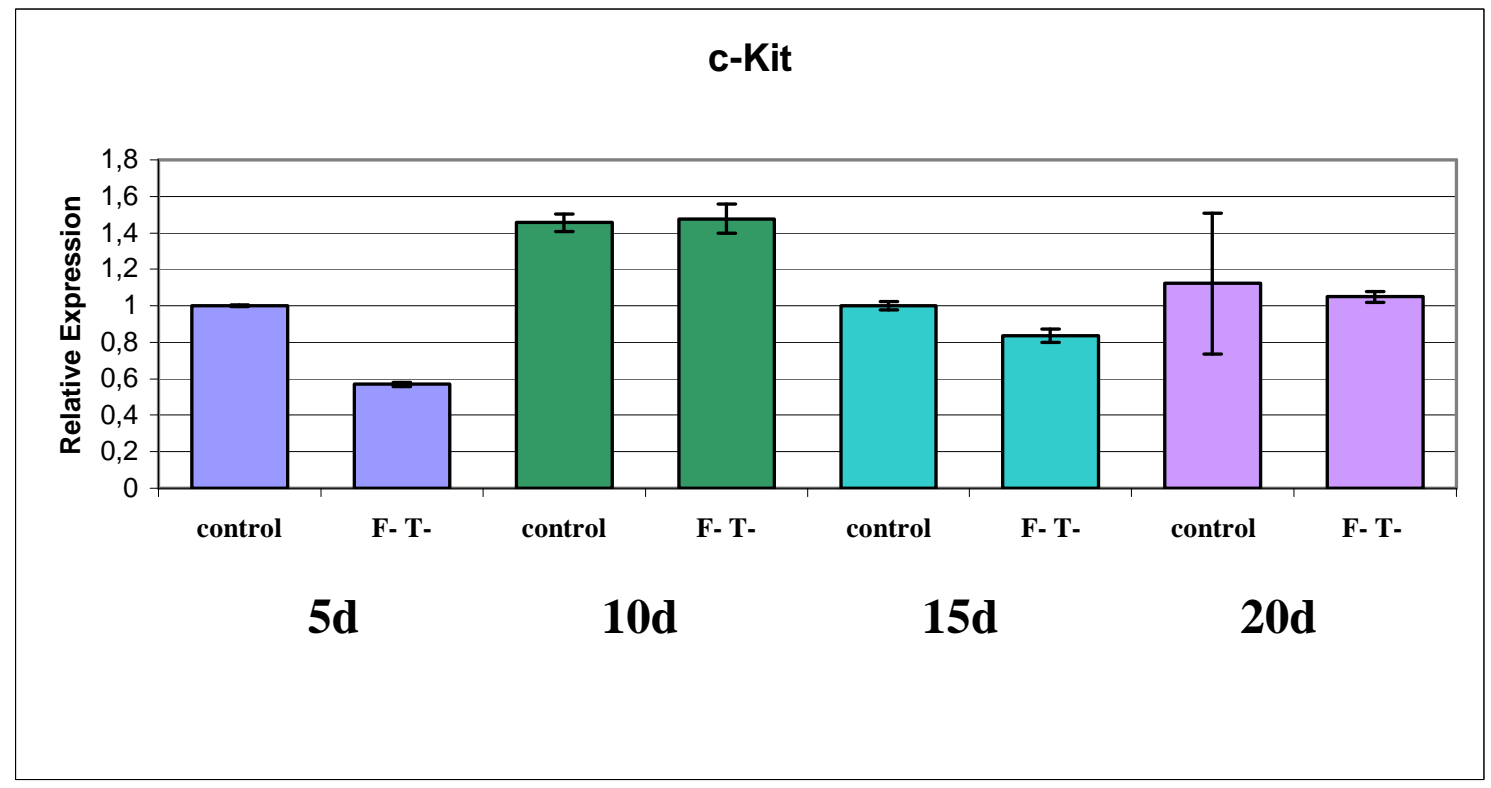

Figure 24. Relative levels of c-Kit mRNA expression in testes of Pelo/Stra8-Cre mice during first wave of spermatogenesis.

Values represent relative levels of c-Kit in testes of 5-, 10-, 15- and 20-day-old animals (5d, $10 d, 15 d, 20 d)$. Expression levels were normalised to the expression of endogenous control (Sdha). 2-3 biological replicates were used for each stage and genotype.

Dazl, Ddx4 and Stra8 genes are specifically expressed in spermatogonia and early primary spermatocytes (Ruggiu et al., 1997; Toyooka et al., 2000; Zhou et al., 2008). Analysis of the expression profile during postnatal development showed that expression of these genes was relatively low in 5-day-old wild-type and mutant testes. In day 10, when the first wave of spermatogenesis progresses to leptotene spermatocytes in wild-type testes, a drastic increase in mRNA levels of all three genes was observed in mutant as well as in wild-type testes. However, in mutants it was significantly lower. At days 15 and 20 the expression level is sharply decreased in both genotypes (Fig. 25). The evident reduction in mRNA level of Dazl, Ddx4 and Stra8 led us to assumption that leptotene is a first stage that is affected during the first wave of spermatogenesis in Pelo ${ }^{\mathrm{F} /}$ Stra8-Cre mice. 

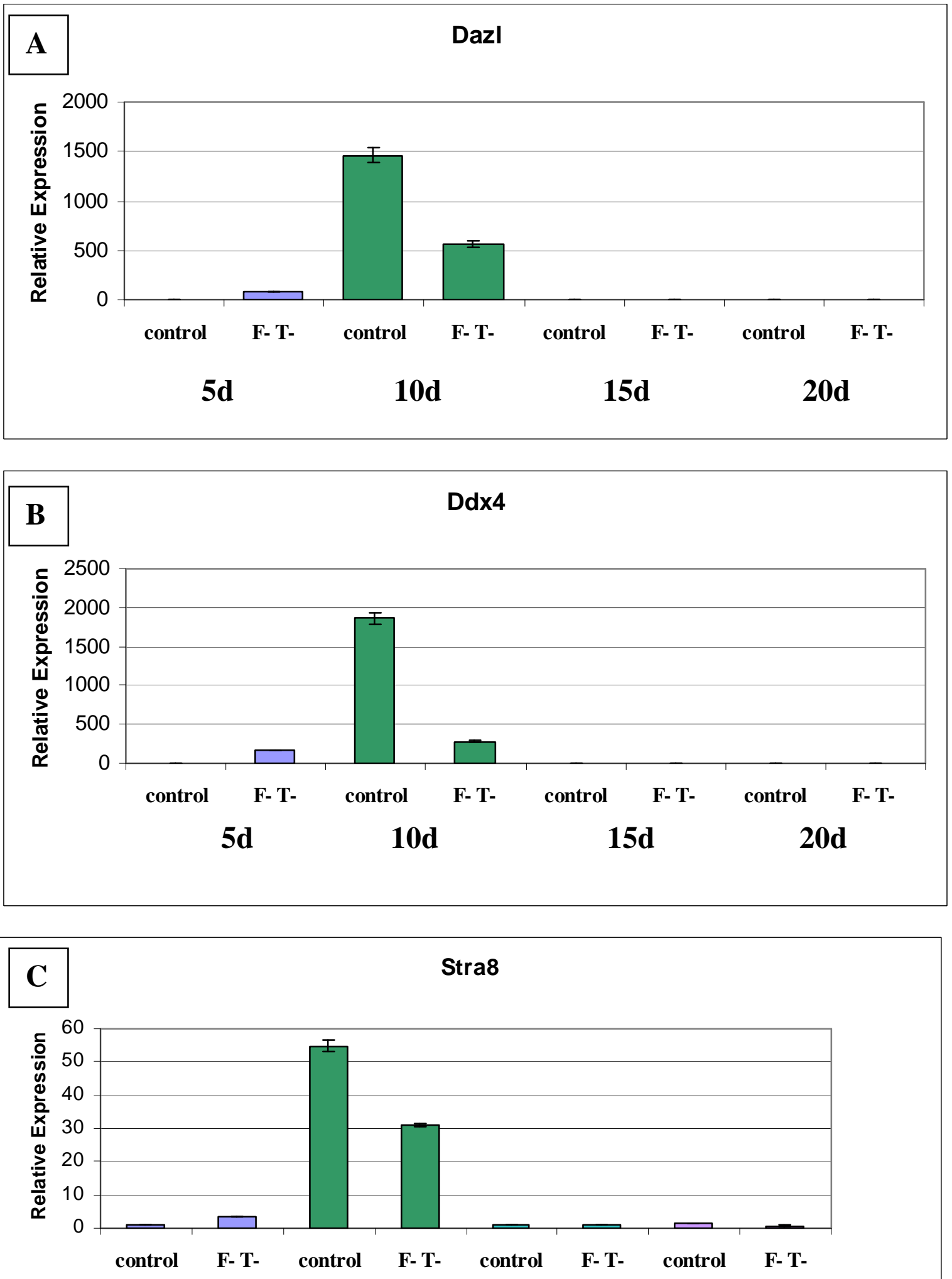

$\begin{array}{llll}5 d & 10 d & 15 d & 20 d\end{array}$

Figure 25. Relative levels of Dazl (A), Ddx4 (B) and Stra8 (C) mRNA expression in testes of Pelo/Stra8-Cre mice during first wave of spermatogenesis. 
Values represent relative level of Dazl and Ddx4 in testes of 5-, 10-, 15- and 20-day-old animals $(5 d, 10 d, 15 d, 20 d)$. Expression levels were normalised to the expression of endogenous control (Sdha). 2-3 biological replicates were used for each stage and genotype.

\subsubsection{Analysis of Pelo ${ }^{\mathrm{F} /}$-Stra8-Cre fertility}

The histological and molecular analysis of mutant testes suggests spermatogenesis impairment at early stages (premeiotic germ cells). However, germ cell differentiation progresses normally in some seminiferous tubules of mutant testes. To study the consequences of the impairment on fertility of mutant mice, at the age of 8 weeks three males and three females Pelo ${ }^{\mathrm{F} /} \mathrm{Stra} 8-\mathrm{Cre}$ were bred with wild-type animals. The number of offsprings was counted and is presented below (Table 3).

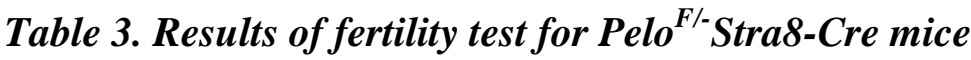

\begin{tabular}{|c|c|c|c|}
\hline Pelo $^{\mathrm{F} /-}$ Stra8-Cre & $\begin{array}{c}\text { Litter size } \\
\text { (mean) }\end{array}$ & Litter number & $\begin{array}{c}\text { General number of } \\
\text { offsprings }\end{array}$ \\
\hline$\hat{0}$ & 9.2 & 9 & 83 \\
\hline 우 & 12.4 & 8 & 99 \\
\hline
\end{tabular}

The fertility test showed that examined animals were fertile and there was no decrease in amount of offsprings in single litter. The mean litter size of mutant females was comparable with wild-type mice which deliver 14 offspring on average. Whereas mutant males produced a slightly reduced number of offsprings.

\subsubsection{Tamoxifen-dependent pelota deletion in cKO/CreERT mouse line}

To study pelota function in postnatal develpment of mammals, we have generated a system for spatiotemporal inactivation of floxed pelota allele. We introduced ubiquitously expressed Rosa26_CreERT knock-in allele to the genome of Pelo ${ }^{\mathrm{F} / \mathrm{F}}$ and Pelo ${ }^{\mathrm{F} /}$ mice. The CreERT recombinase is also ubiquitously expressed, but is not translocated to nucleus. The migration occurs upon application of tamoxifen (TAM), which binds to mutated estrogen receptor (ERT) binding site, fused with Cre recombinase. The system allows for excision of 
the floxed pelota allele in various tissues and cultured cells after administration of tamoxifen to animals or hydroxytamoxifen (OHT) to the cells. In absence of the substance, the recombinase is not able to be transported into the nucleus what disables its function. This mouse model allows us to study pelota's role in proliferation and differentiation events during mouse development.

To generate the cKO/CreERT line, we mated heterozygous $\mathrm{Pelo}^{+/-}$mice with transgenic Pelo ${ }^{+/+}$CreERT mice to obtain $\mathrm{Pelo}^{+/}$CreERT. Such mice were further bred either with Pelo $^{\mathrm{F} /+}$ or with Pelo ${ }^{\mathrm{F} / \mathrm{F}}$. From those crossings we achieved the actual genotype, i.e. Pelo ${ }^{\mathrm{F} /}$ CreERT, which after tamoxifen application will yield Pelo ${ }^{\Delta /-} \mathrm{CreERT}$. Two types of PCR were used for determination of the genotypes: flox/-/ $\triangle$ PCR which amplify wild-type $(+)$, knockout (-), flox $(\mathrm{F})$ and recombined $(\Delta)$ alleles (Fig. 12A) and CreERT PCR for Cre recombinase allele (Fig. 26).

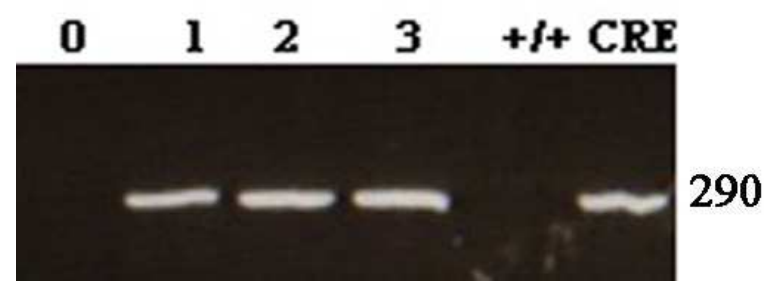

Figure 26. Genotyping PCR for CreERT recombinase.

The figure presents the genotyping of 3 CreERT-positive mice (1-3) where transgenic allele (290bp) was detected. Primers are designed in transgene sequence what explains lack of the band in wild-type animal. PCR conditions are presented in chapter 2.2.8.1.

Pelo $^{\mathrm{F} / \mathrm{F}}$ CreERT and Pelo ${ }^{\mathrm{F} /}$ CreERT after TAM-treatment will be mentioned as mutant mice (Pelo ${ }^{\Delta / \Delta}$ CreERT and Pelo ${ }^{\Delta /-}$ CreERT, respectively). For the control we used mice either with Pelo wild-type allele $\left(\mathrm{Pelo}^{\mathrm{F} /+} \mathrm{CreERT}\right.$ or $\mathrm{Pelo}^{+/-} \mathrm{CreERT}$ ) or without CreERT recombinase $\left(\right.$ Pelo $^{\mathrm{F} / \mathrm{F}}, \mathrm{Pelo}^{\mathrm{F} /-}$ and $\left.\mathrm{Pelo}^{+/-}\right)$.

\subsubsection{TAM treatment of Pelo ${ }^{\mathrm{F} /}{ }^{-}$CreERT mice}

Originally, TAM treatment was applied $(0.5 \mathrm{mg} / 30 \mathrm{~g})$ to adult mutant males $(\mathrm{n}=8)$, adult mutant females (3) and control mice $(n=5)$ by intraperitoneal injections for 5 subsequent days. After two weeks from last TAM application, one male was taken for histological analysis. However, all analyzed tissues were morphologically similar to the control. The Cre-mediated Pelo deletion had appeared, but was incomplete (data not shown). The mice did not exhibit any apparent disorder. 
Due to the fact that Pelota was shown to be involved in cell division (Castrillon et al., 1993; Ebenhart and Wasserman, 1995; Xi et al., 2005) we have decided to treat young animals which still are in the phase of somatic growth. Therefore, 15-day-old mice were injected with TAM for 5 days. 2 days after last application of tamoxifen, we weighed the mice for next 9 days (Fig. 27A). The data indicate shown that Pelo ${ }^{\Delta / \Delta}$ CreERT animals exhibit growth impairment what might be correlated with mitotic cell division disorder.

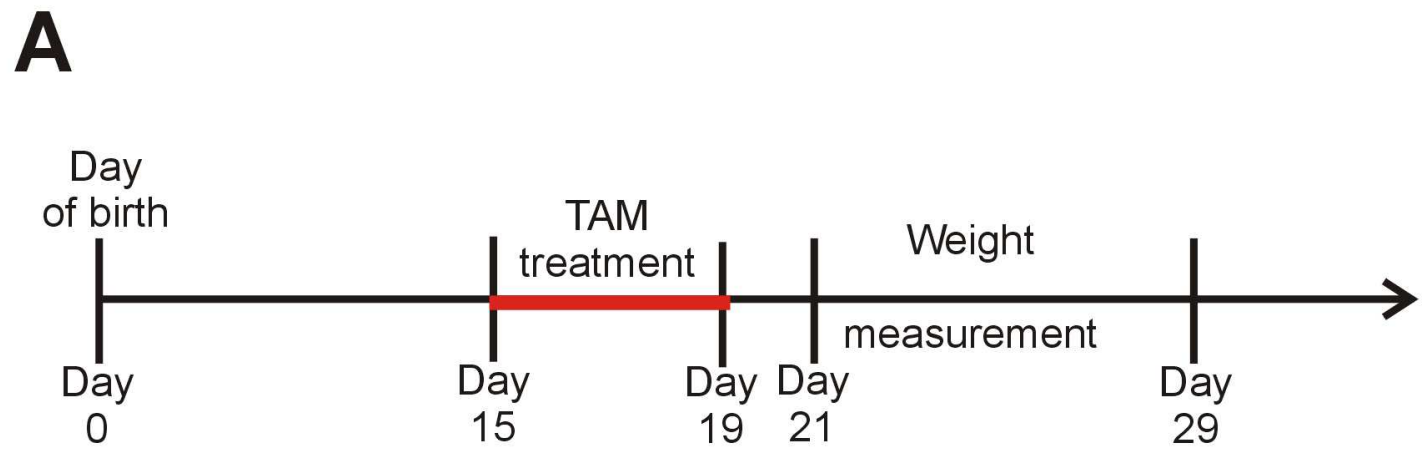

B Weight of TAM-treated mice

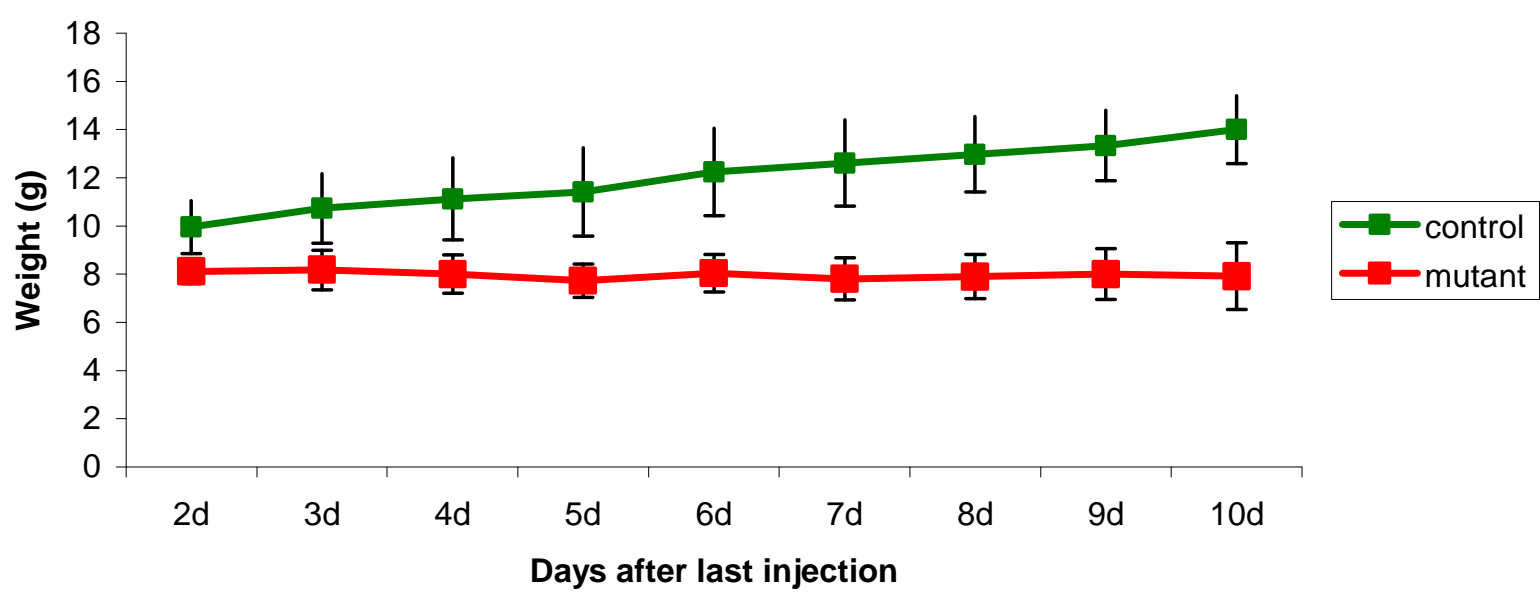

Figure 27. Weight gaining of mice treated with TAM at the age of 15 days.

The mice were treated for 5 days and the weight measurement was started 2 days after last injection and lasted for 9 days (A). The data were collected from 6 mutant (Pelo ${ }^{4 / 4}$ CreERT or Pelo ${ }^{\Delta /-}$ CreERT) and 11 control animals $(B)$.

To verify whether the observed phenotype results from recombination of floxed pelota allele, DNA from various organs of mutant mice was isolated and genotyped (Fig. 28). It turned out that TAM-induced pelota deletion occurs in all examined tissues at high extent. Partial deletion was detected in heart, lung, stomach and kidney. Only brain is hardly affected what can be caused by blood-brain barrier blocking tamoxifen transport. 


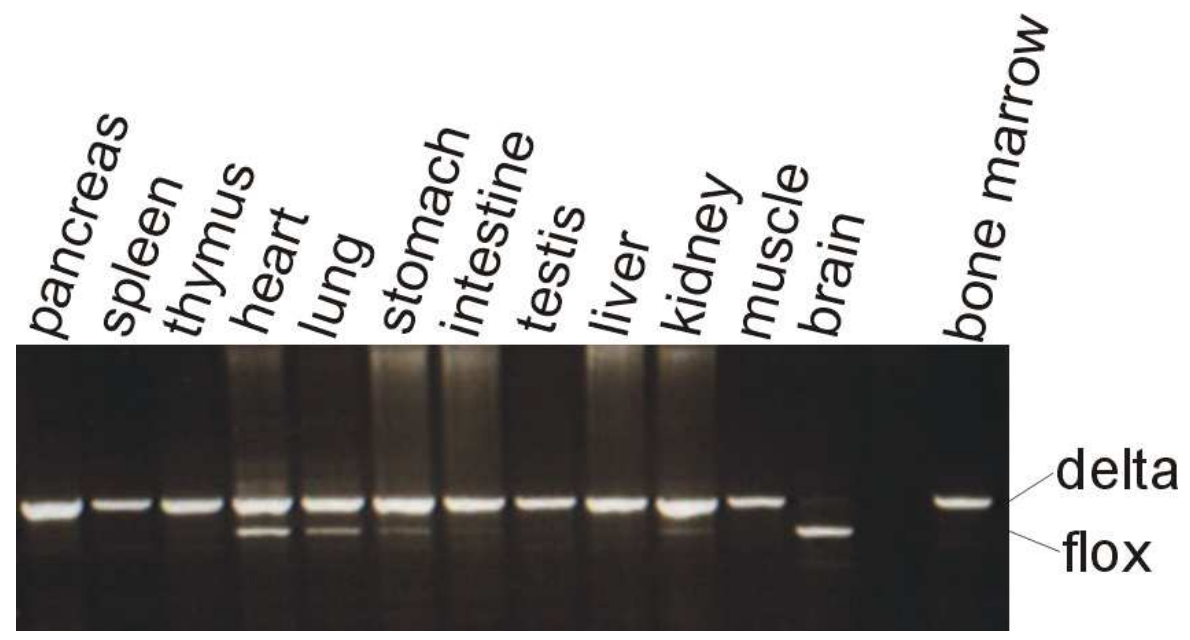

Figure 28. Genotyping PCR of organs from Pelo ${ }^{4 /-}$ CreERT mouse

Size of products: delta - 455bp; flox - 376bp. PCR conditions are presented in chapter 2.2.8.1.

Approximately $50 \%$ of mutant animals died within 3 weeks after the treatment. It suggests that effective pelota ablation is a severe disturbance in mouse physiology. Nonetheless, $50 \%$ of Pelo ${ }^{\Delta /-}$ CreERT mice were able to survive, so that we could study their phenotype in detail.

\subsubsection{Effects of pelota deletion in Pelo ${ }^{\mathrm{N} /}$ CreERT animals}

One month after TAM-application, some symptoms were found in mutant mice. Apart from their reduced weight, Pelo ${ }^{\Delta /}$ CreERT mice have begun to loose hair in the neck area and nose, their eyes have become dry (Fig. 29). Additionally, their tails have looked raspy with peeling skin. In the course of the time, the bare skin developed erosive lesions in the neck, nose and around the mouth. In contrast, control mice remain healthy although they have been kept together with mutants in the same cages. It ruled out the possibility that tamoxifen is toxic as well as any contagious factor is responsible for the phenotype. 


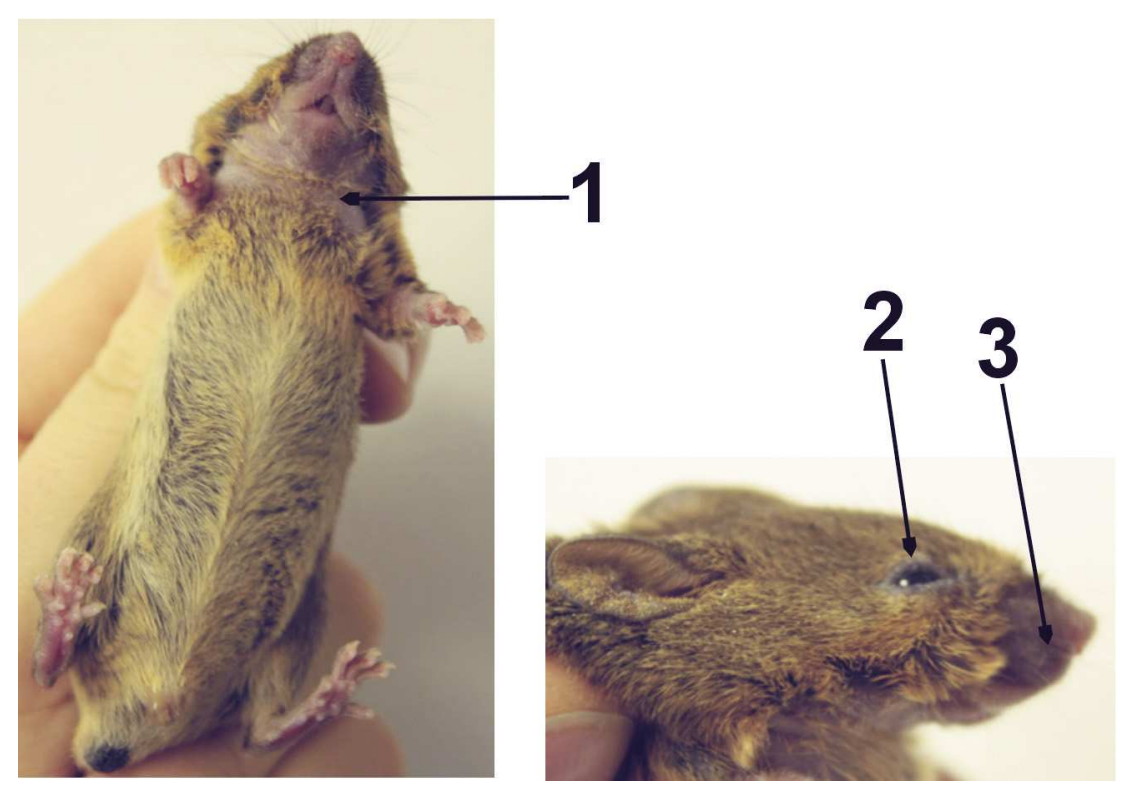

Figure 29. Apparent symptoms of pelota deletion in Pelo ${ }^{4 /-}$ CreERT mouse. 1 - loss of hair in neck area; 2 -dry eyes; 3 - hairless and swollen nose.

Dissection of mutant mice 2-3 months after TAM-treatment revealed that their thymus and testes are extremely reduced. Histological analysis of diverse tissues of Pelo ${ }^{\Delta /-}$ CreERT has disclosed some abnormalities. H\&E staining of skeletal muscle has shown that diameter of skeletal cells is decreased in mutant mice in comparison to the control, but the number of cells seems to be unaffected (Fig. 30). This reduction in size is probably associated with growth retardation of mutant animals. 

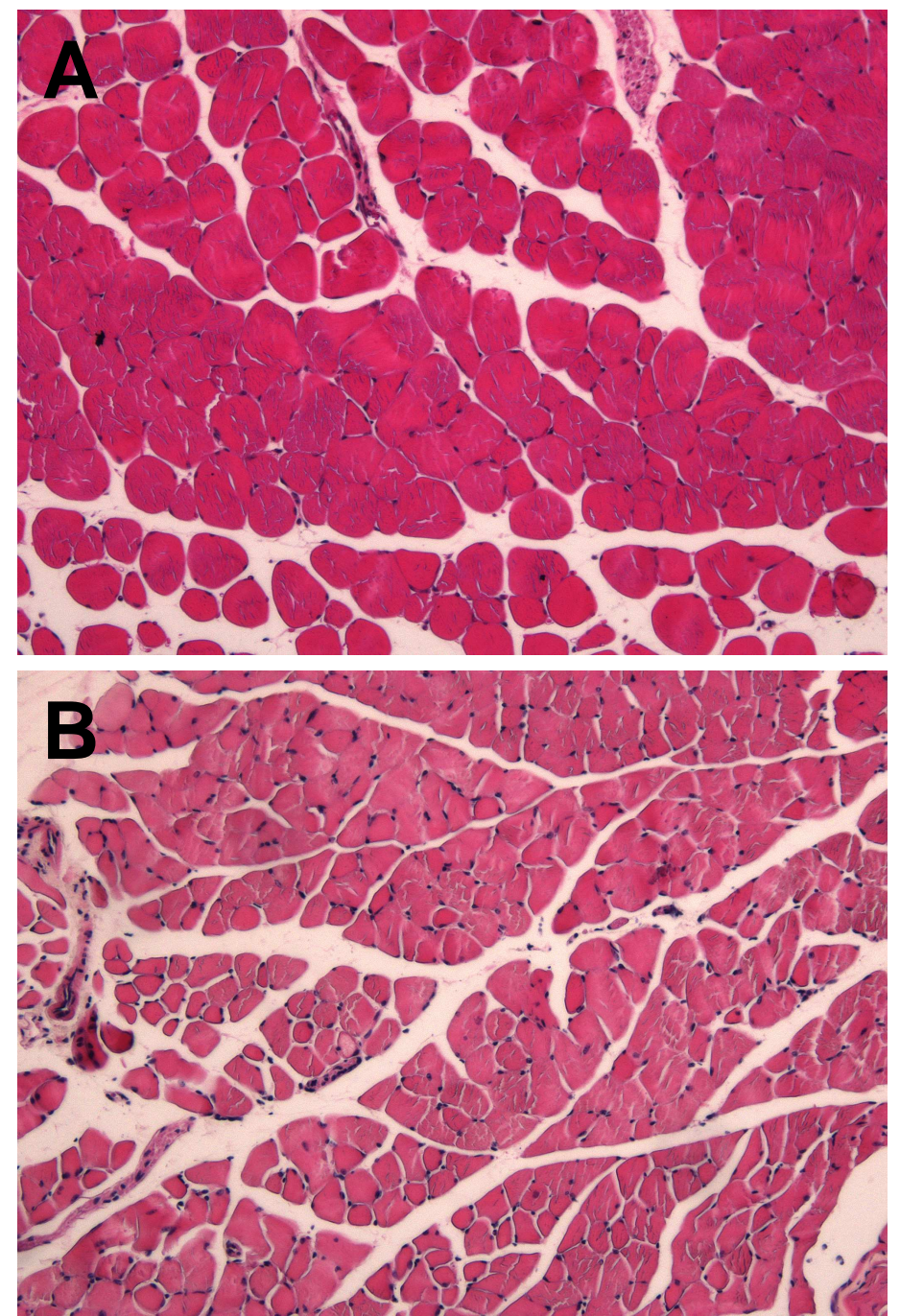

Figure 30. H\&E staining of skeletal muscles isolated from Pelo ${ }^{4 /-}$ CreERT

$A$ - wild-type muscles; $B$ - mutant muscles. Photos were taken under $10 x$ magnification.

Histological analysis of testes revealed a severe effect of pelota depletion. In 2month-old wild-type testes we could observe all stages of spermatogenesis, i.e. spermatogonia, primary spermatocytes, round spermatids, elongated spermatids and spermatozoa (Fig. 31A). However, in mutant testes 2 months after TAM treatment spermatogenesis was completely arrested. In seminiferous tubules, one could find only Sertoli cells which fill out the whole lumen. Tubules were reduced in size, so it caused increase of Leydig cells number (Fig. 31B).

This phenotype appears already in mutant testes 2 weeks after TAM treatment (at the age of 30 days) what suggests that pelota plays a critical role in a first round of spermatogenesis. 

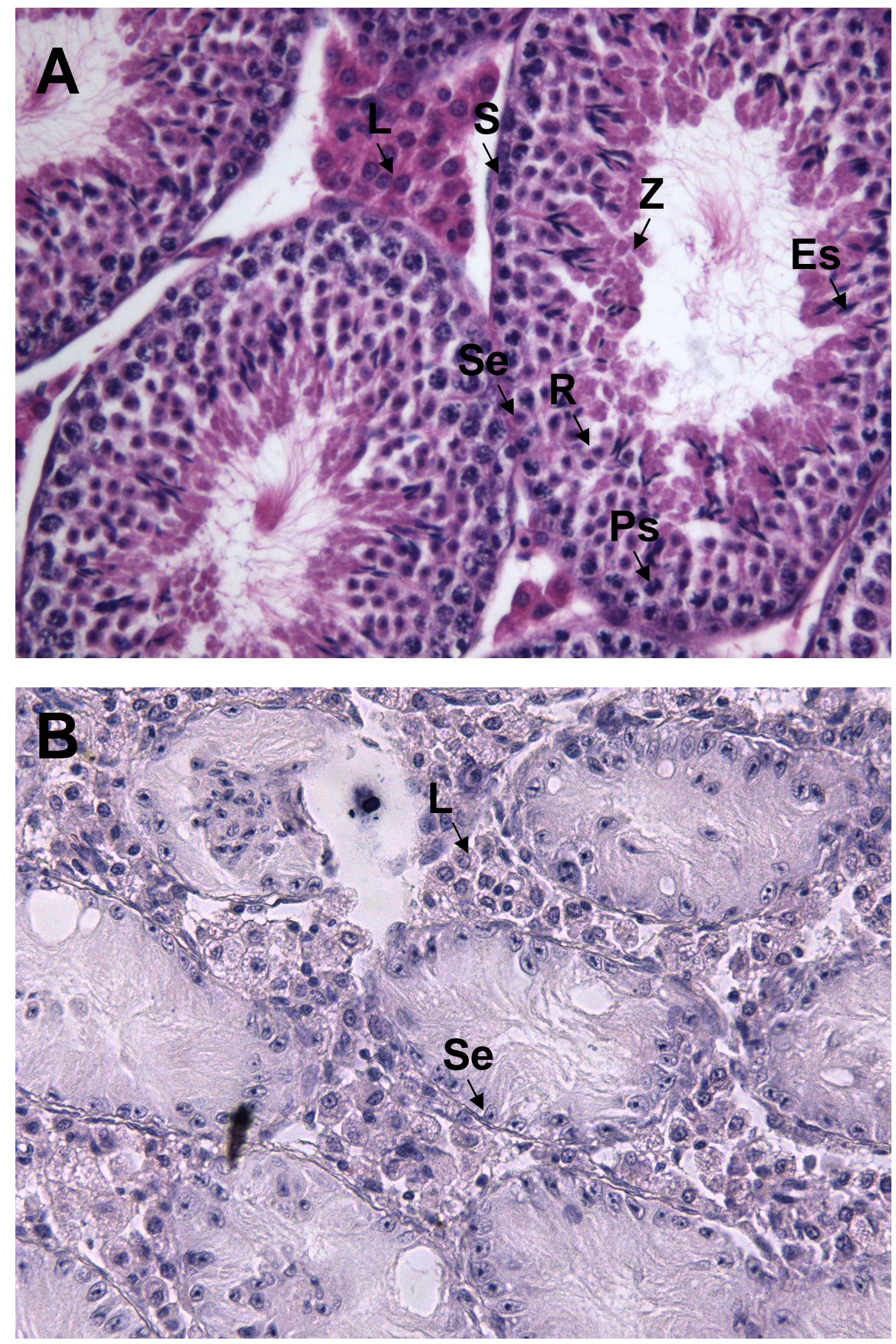

Figure 31. H\&E staining of testes isolated from Pelo ${ }^{4 / 4} \mathrm{CreERT}$ and wild- type mice. A-wild type; $B$ - mutant. Abbreviations: $L$-Leydig cells; $S$-spermatogonia; Ps - primary spermatocytes; Rs - round spermatids; Es - elongated spermatids; Z - spermatozoa; Se Sertoli cells. Photos were taken under $20 x$ magnification.

A piece of bare skin from neck area was isolated and stained with H\&E. In wild type, the epidermis is relatively thin in comparison to dermis (Fig. 32A). Epidermis consists of keratinocytes - cells which are arranged in 5 layers. The most outer layers are composed of flattened cells which have no nuclei. However, in the skin of the mutant we could observe hypertrophia of keratinocytes (hyperkeratosis) which infiltrate the dermis. The keratinocytes 

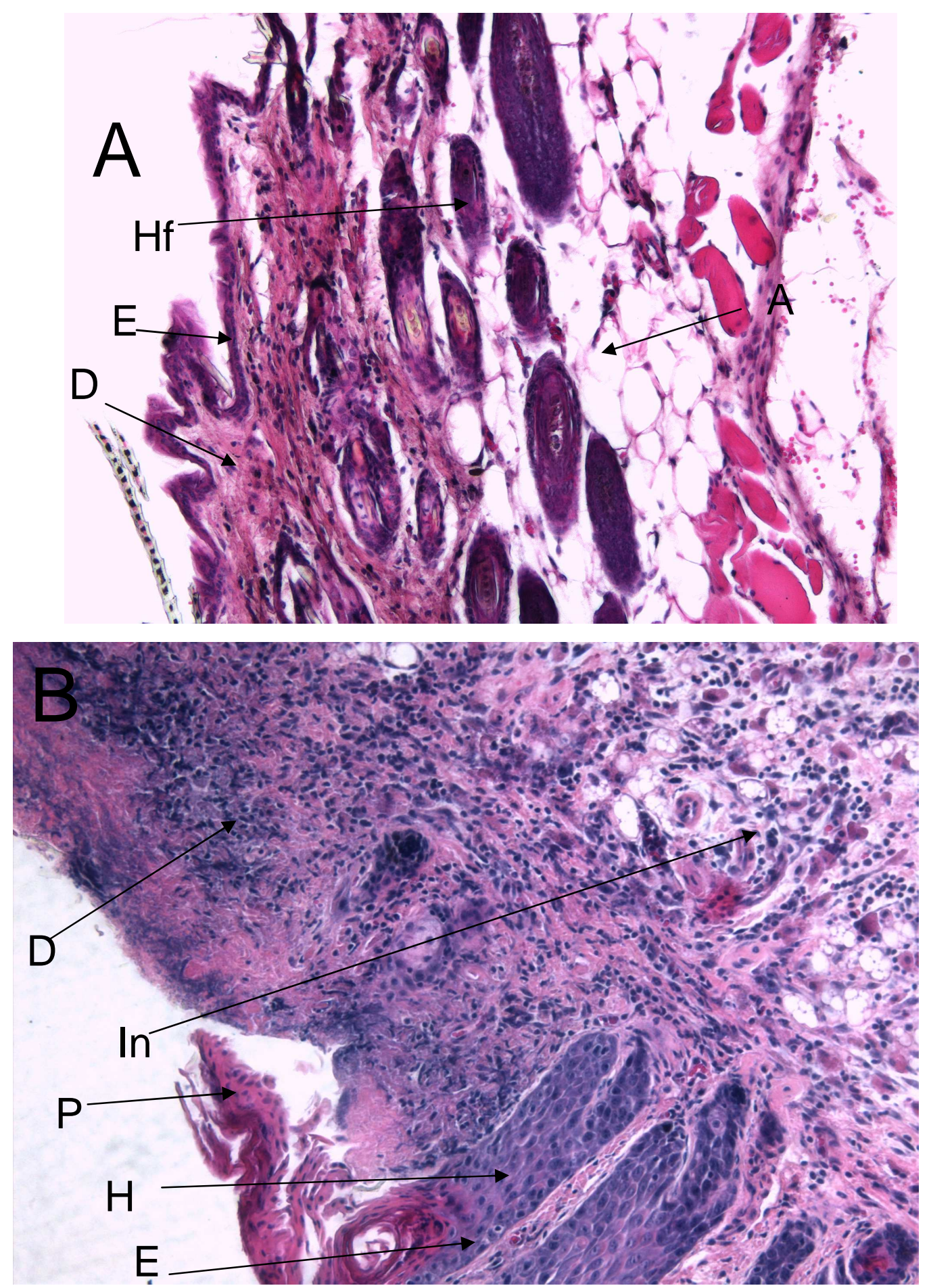

Figure 32. Disorders observed in Pelo ${ }^{4 /-}$ CreERT skin structure

Skin was isolated from control (A) and Pelo ${ }^{4 /-}$ CreERT mouse (B). Hf-hair follicle (A); Eepidermis; $D$ - dermis; $A$ - adipocytes $(A) ; \quad I n$ - inflammatory region $(B) ; \quad P$ parakeratosis(B); $H$ - hyperkeratosis $(B)$.

from outer layer were found to possess nuclei (parakeratosis) - this process is common for diseases related to excessive proliferation of epithelium. Additionally, 
symptoms of a chronic inflammatory response appear in deeper layers of the skin. Histological studies of kidney also revealed lymphocyte-rich inflammatory cell infiltration (data not shown).

Other tissues of the mutant mice (such as spleen, liver, stomach, heart, intestine, ovary) were also studied, but they did not display such a pronounced phenotype. The effect of pelota deletion on different organs still requires thorough studies. The impaired development of thymus beside these histological observations implies putative defects in the immune system of Pelo ${ }^{\Delta / \Delta}$ mice.

The thymus is an organ where thymocytes mature into $\mathrm{T}$ cells, which respond to foreign antigens, but do not recognize self-antigens (Goldrath and Bevan, 1999; Miller, 2002; Starr et al., 2003). We suspected that pelota depletion affects the maturation of $\mathrm{T}$ cells. Therefore, we have analyzed cell surface markers for $\mathrm{B}$ and $\mathrm{T}$ cells isolated from thymus (Table 4.) and spleen (Table 5.) of mutants $(\mathrm{n}=4)$ and controls $(\mathrm{n}=4)$ using flow cytometry. The thymus and spleen cells were prepared and stained with fluorescence-conjugated monoclonal antibodies, which recognize different cell surface markers (Materials \& methods, 2.2.17.). The analyzed cell number was $11 \pm 4 \times 10^{7}$ for control thymus and $11 \pm 5 \mathrm{x}$ $10^{7}$ for control spleen. The amount of mutant cells was reduced to $0.8 \pm 0.7 \times 10^{7}$ in thymus, and $5.5 \pm 2.5 \times 10^{7}$ in spleen.

We have found a strongly reduced level of $\mathrm{CD} 4^{+} \mathrm{CD} 8^{+}$double positive, $\mathrm{CD} 4^{+} \mathrm{CD} 8^{-}$, $\mathrm{CD}^{+} \mathrm{CD}^{-}$single positive and $\mathrm{CD} 3$-positive cells ( $\mathrm{T}$ lymphocytes). The number of doublenegative $\left(\mathrm{CD}^{-} \mathrm{CD}^{-}\right)$cells, i.e. thymocyte progenitors derived from hematopoietic stem cells, was 6-fold increased in all mutants. It is extremely noticeable in mutant 2' (Table 4.), where these cells constituted a vast majority of tested cell population. The decrease of differentiating and mature stages of $\mathrm{T}$ cells indicate that after Pelota protein is deleted, the further differentiation of thymocytes is disrupted and the stage of double negative cells is accumulated. It explains high susceptibility to infections of all mutant mice. 
Table 4. The number of $T$ cells (various developmental stages) in thymus of TAM-treated animals (Pelo ${ }^{\Delta / 4}$ CreERT and Pelo ${ }^{\Delta /-}$ CreERT)

The animals treated with TAM at the age of 6 weeks were analysed 1 month after treatment. The mice which were injected at the age of 15 days, were examined 2 weeks after treatment. The thymus of mutant 3' was strongly reduced and the amount of isolated cells was insufficient for FACS analysis.

\begin{tabular}{|c|c|c|c|c|c|}
\hline \multirow{3}{*}{$\frac{\text { Organ }}{\text { Age of treated mice }}$} & \multicolumn{5}{|c|}{ THYMUS } \\
\hline & \multicolumn{2}{|c|}{6 weeks } & \multicolumn{3}{|c|}{15 days } \\
\hline & Control & Mutant & Control & ${ }_{1}, \mathrm{Mu}$ & \\
\hline DN (double-negative $\mathrm{CD}^{-} \mathrm{CD}^{-}$cells) & 4.78 & 30.59 & $11.1 \pm 0.6$ & 15.46 & 98.83 \\
\hline $\mathrm{CD}^{+} \mathrm{CD}^{+}$(differentiating thymocytes) & 76.71 & 34.86 & $60.5 \pm 1.6$ & 77.67 & 0.64 \\
\hline $\begin{array}{l}\mathrm{CD} 4^{+} \mathrm{CD} 8^{-} \mathrm{SP} \\
\text { (differentiating thymocytes) }\end{array}$ & 11.91 & 28.11 & $16.94 \pm 0.06$ & 2.75 & 0.18 \\
\hline $\begin{array}{l}\mathrm{CD}^{+} \mathrm{CD} 4{ }^{-} \mathrm{SP} \\
\text { (differentiating thymocytes) }\end{array}$ & 5.41 & 3.39 & $11.3 \pm 1$ & 4.06 & $\mathbf{0}$ \\
\hline $\mathrm{CD}^{+}(\mathrm{T}$ cells $)$ & 18.08 & 11.19 & $31.81 \pm 6.2$ & 7.19 & 0.56 \\
\hline
\end{tabular}

Examination of B cells derived from spleen demonstrated that CD19- and B220positive cells (B lymphocytes) in Pelo ${ }^{\Delta /-}$ CreERT animals are also reduced in number (Table 5.) as compared to the controls. CD19 and B220 (CD45) are cell surface markers specific for mature B cells. In some mutant mice we have found a slight increase in number of $\mathrm{CD} 4^{+} \mathrm{CD} 25^{+}$cells, which recognize autoantigens. This might suggest that mice exhibit autoimmune disorder, but it requires further studies. We detected higher number of CD25 cells, which are indicators of inflammatory state of the organism as well as NK cells $\left(\mathrm{DX}^{+}-\right.$ positive), which were increased. The amount of $\mathrm{T}$ cells, detected in spleen, was variable depending on the individuals. 
Table 5. The number of B and T cells in spleen of TAM-treated animals

The animals treated with TAM at the age of 6 weeks were analysed 1 month after treatment. The mice which were injected at the age of 15 days, were examined 2 weeks after treatment. NK cells - natural killer cells.

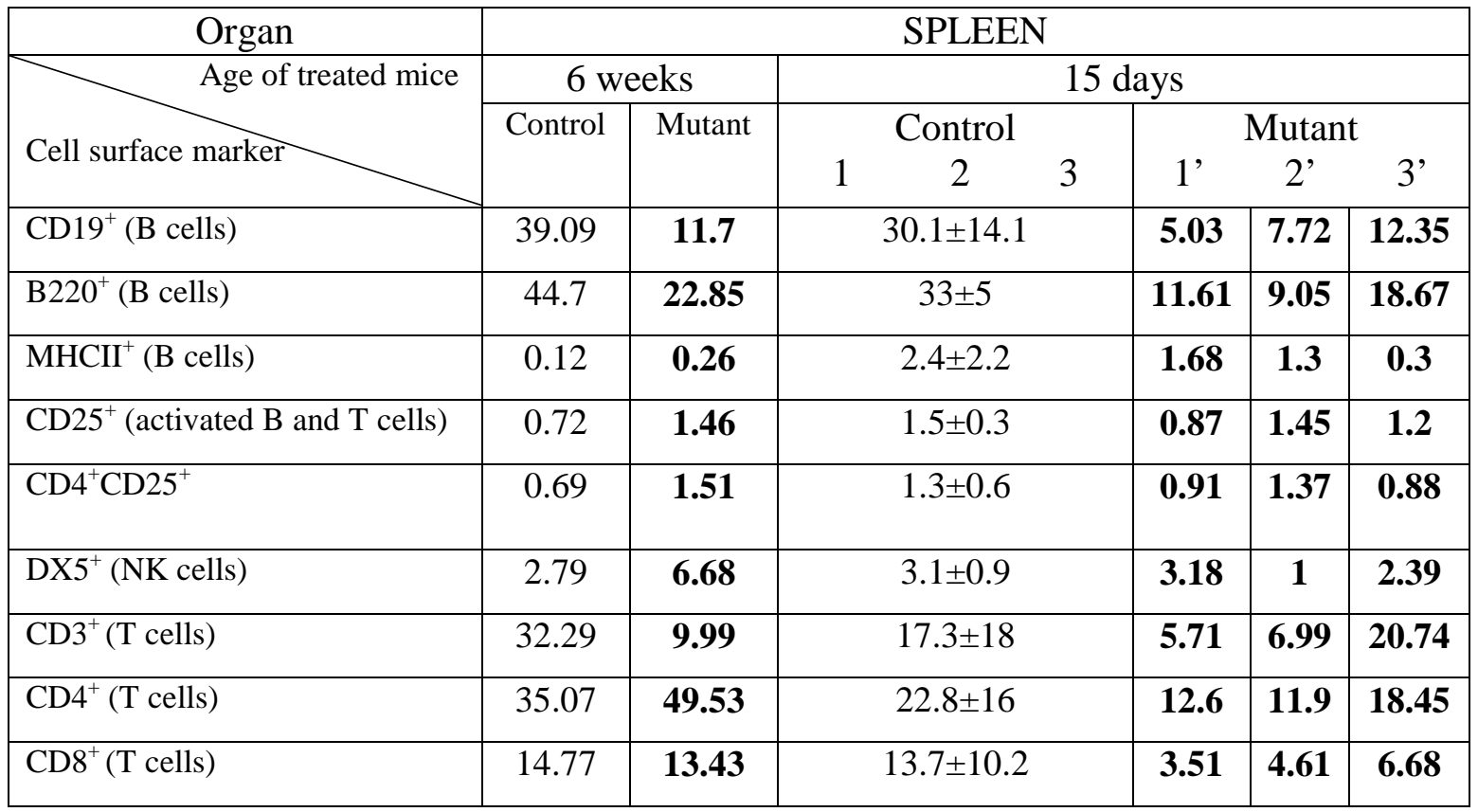

\subsubsection{Pelota-deficient ESC line - functional characterization}

To study pelota function on a molecular level, we generated a ESC line with flox allele and tamoxifen-activated CreERT recombinase. For all experiments described we used Pelo $^{\mathrm{F} / \mathrm{F}}$ cells treated with $\mathrm{OHT}$ as a control.

To study if pelota deficiency enhances direction of cells to programmed cell death, we performed the annexin-7AAD assay. For control, we used Pelo ${ }^{\mathrm{F} /}$ cells either untreated or treated with OHT and untreated mutant cells (Pelo ${ }^{\mathrm{F} /}$ CreERT). Using FACS analysis, we examined early (annexin V staining) and late (7-AAD staining) apoptosis levels in the culture (Fig. 33). The percentage of viable cells (NOT STAINED, Fig. 33) was predominant in comparison to apoptotic cells. The experiment showed that the number of either dead or apoptotic cells was not increased upon pelota deletion. It demonstrates that pelota deficiency does not influence the proliferation and viability of ES cells. 


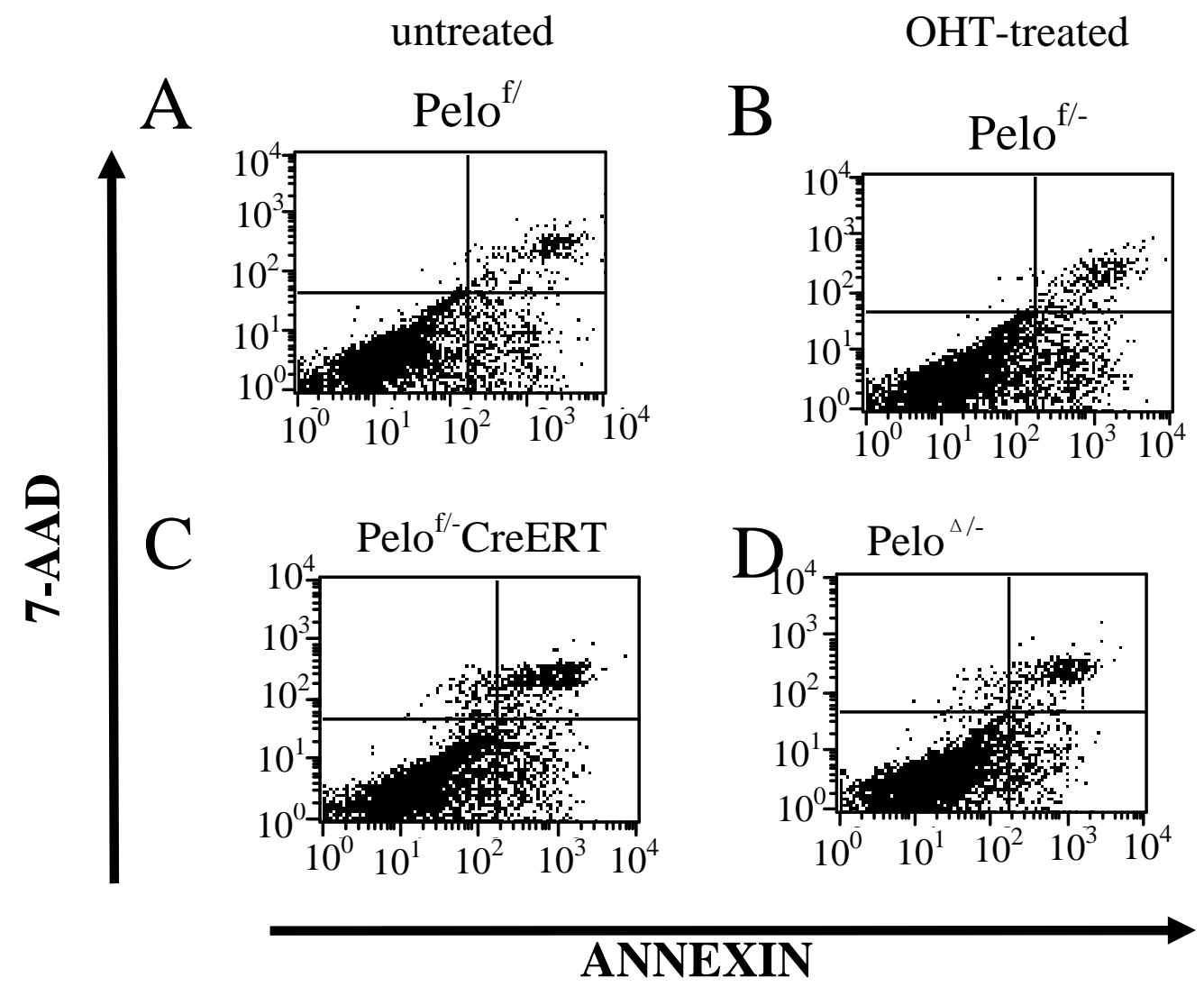

$\mathbf{F}$

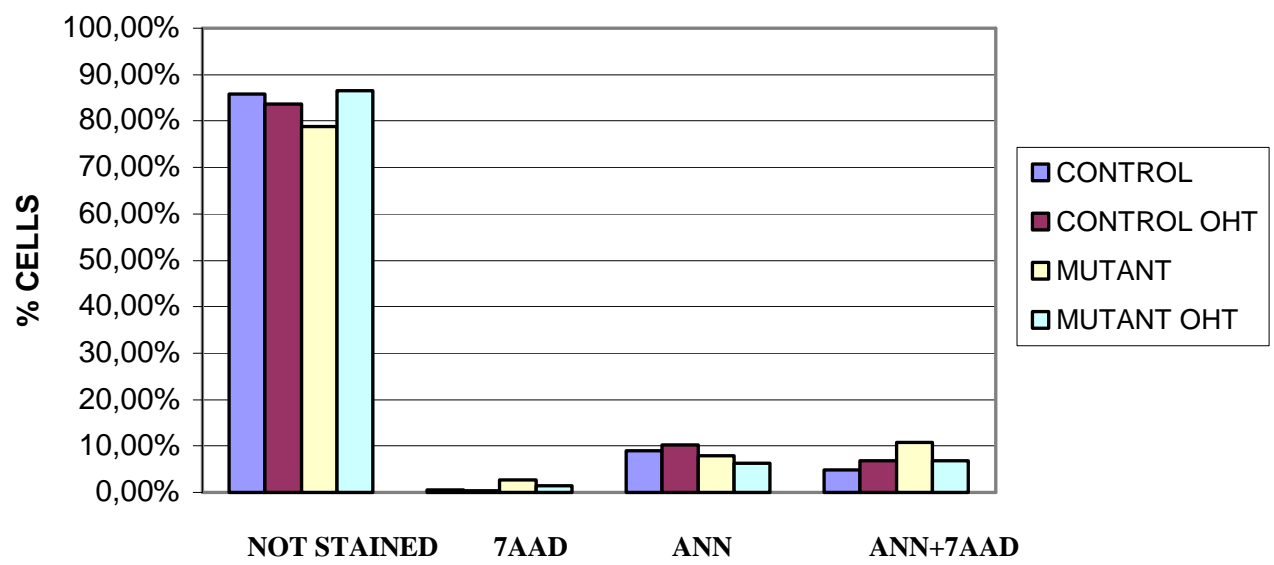

Figure 33. Flow cytometric analysis of apoptosis level in mutant cells treated with OHT and untreated

FITC-Annexin V/7AAD flow cytometry of an untreated control $(\boldsymbol{A})$ and mutant $(\boldsymbol{C}) . O H T$ treated cells are presented in $\boldsymbol{B}$ (control) and $\boldsymbol{D}$ (mutant). The lower left quadrant shows viable cells, which exclude 7AAD and are negative for FITC-Annexin $V$ binding. The upper right quadrant contains the nonviable necrotic cells positive for $7 A A D$ and annexin binding. The lower right quadrant represents the apoptotic cells, FITC-Annexin V positive and 7AAD negative, demonstrating cytoplasmic membrane integrity. The graph $(\boldsymbol{F})$ indicates percentage of all kinds of cells. NOT STAINED - viable cells; 7AAD - single-stained with 
$7 A A D$ (necrotic cells); ANN - single-stained with annexin (apoptotic cells); ANN+7AAD double-stained with annexin and $7 A A D$.

Lack of prominent effect of pelota ablation on proliferation and viability of ESCs led us to check the role of pelota protein in differentiation. Therefore, the cells were cultured in conditions that induce the differentiation process. ESCs were trypsinized, plated on bacteria dishes and left in suspension in the absence of LIF for 10 days. Under these conditions ES cells aggregated and formed embryoid bodies (EBs), in which cells differentiated into the three germ layers - endoderm, mesoderm and ectoderm. We did not observe any differences in morphology between mutant and control cells. EBs were thereafter trypsinized, plated on gelatin-coated dishes and cultured in ESC medium without LIF. We could observe a striking difference in morphology between mutant and control cells. The control cells were differentiated, whereas pelota-deficient cells formed two types of cells spread on the plate: differentiated ones attached to the bottom and ESC-like colonies growing over them. To confirm pluripotent character of the mutant cells, we stained them with alkaline phosphatase (AP), which is an enzyme specific for pluripotent cells. Pelo ${ }^{\Delta /-}$ CreERT colonies were APpositive (Fig. 34B).
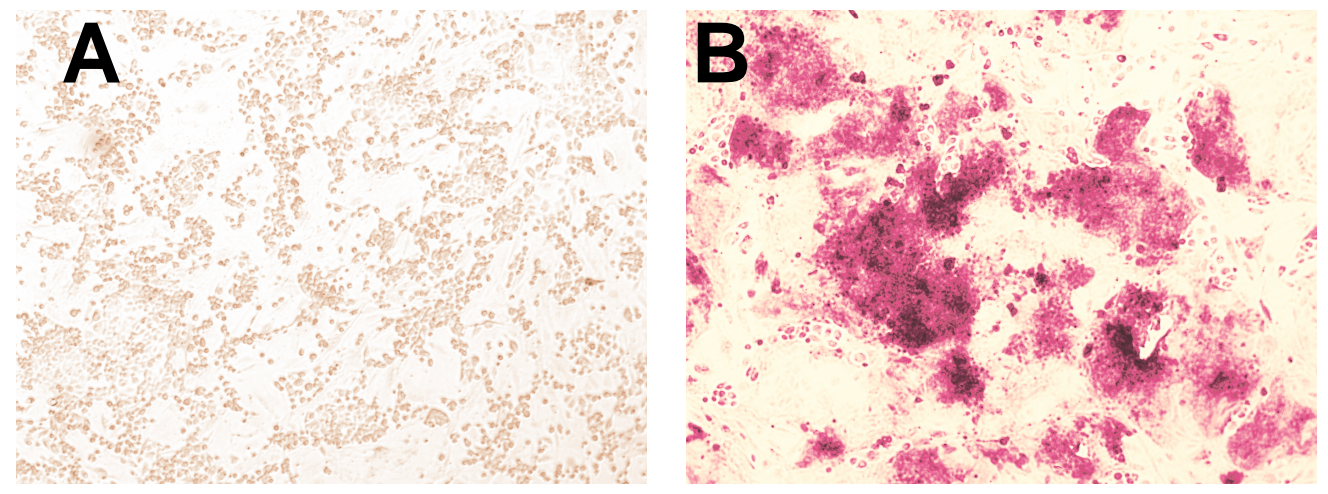

Figure 34. Alkaline phosphatase staining of replated EB-like structures from Pelo ${ }^{4 /-}$ CreERT and wild-type cells.

EBs after 10 days of differentiation were trypsinized and plated on gelatine. A - wild type; $B$ - mutant cells.

Further confirmation of pluripotent nature of mutant EBs was determined by expression analysis of essential molecular marker for pluripotency - Oct4 gene, which is downregulated as soon as the cell begins to differentiate. Western blot analysis showed that Oct4 protein is normally expressed in undifferentiated cells (ES1 and ES9), but it was also present in Pelo ${ }^{\Delta /-}$ EBs in contrary to control EBs (Fig. 35). 


\section{ES 1 ES 9 EB 1 EB 9

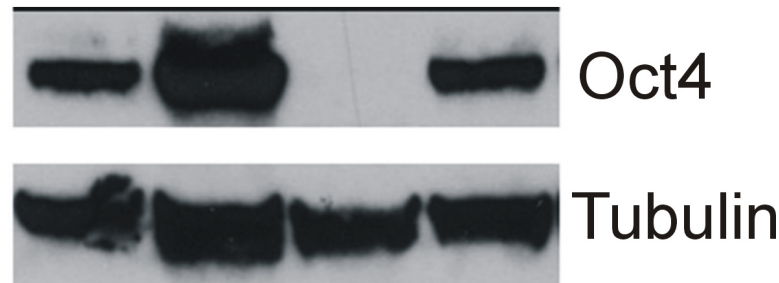

Figure 35. Western blot analysis of Oct4 expression in differentiated and undifferentiated cKO/CreERT cells.

Picture shows Oct4 protein in undifferentiated mutant (ES9) and control (ES1) cells; differentiated mutant (EB9) and control (EB1) cells.

For further demonstration of Oct4 expression in Pelo ${ }^{\Delta /-}$ EBs, we performed immunohistochemical staining of EBs, which were cultured for 18 days in medium without LIF. The experiment proved that Oct4 protein was still expressed in the mutant cells (Fig. 36). Nonetheless, we could find few positive cells also in the control (Table 6). There were $21.2 \%$ of positive and partially positive cells in the control type, whereas in the mutant such colonies constituted $45.9 \%$ of all counted colonies. These data show that Pelo ${ }^{\Delta /-}$ cells failed to differentiate at higher extent than the control. 


\section{RESULTS}

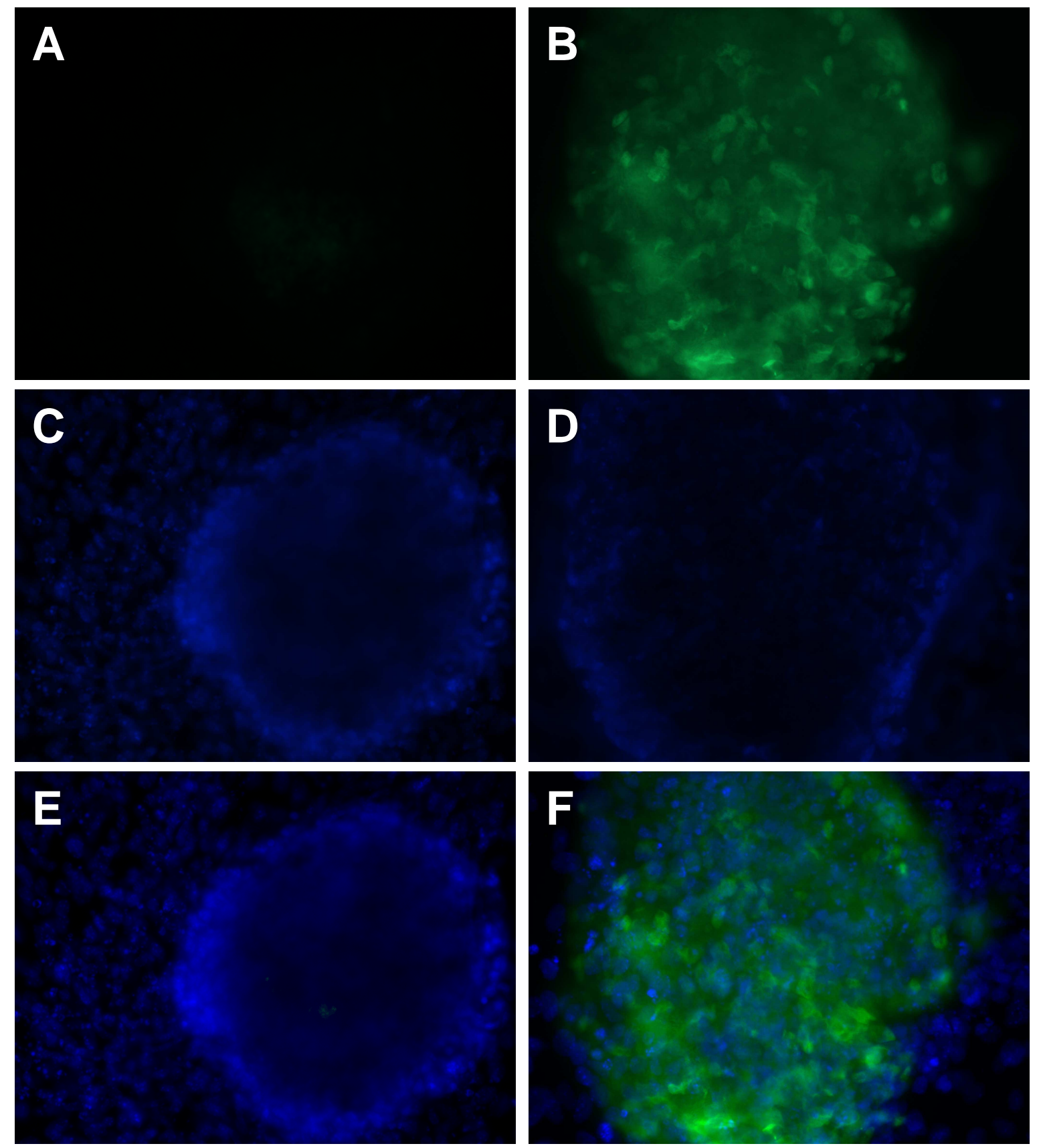

Figure 36. Immunohistochemical analysis of Oct4 expression in differentiated mutant cells

The cells were cultured for 18 days without LIF and then stained with antiOct4 antibody and mounted in medium containing DAPI. A, C, E-control cells; B, D, F-mutant cells. The photos were taken in green fluorescence for visualization of Oct4 and blue-for DAPI. 
Table 6. Statistcs for Oct4-positive cells after differentiation.

Cells were plated on 4-chamber slides. The calculations are done for each chamber of the slides with control and mutant cells.

\begin{tabular}{|c|c|c|c|c|c|c|}
\hline \multirow{2}{*}{$\begin{array}{l}\text { Sort of cell } \\
\text { aggregate }\end{array}$} & \multicolumn{3}{|c|}{ Control } & \multicolumn{3}{|c|}{ Pelo $^{\Delta /}$ CreERT } \\
\hline & $\begin{array}{c}\text { Oct4- } \\
\text { positive }\end{array}$ & $\begin{array}{c}\text { Oct4- } \\
\text { negative }\end{array}$ & $\begin{array}{l}\text { Partially } \\
\text { positive }\end{array}$ & $\begin{array}{c}\text { Oct4- } \\
\text { positive }\end{array}$ & $\begin{array}{c}\text { Oct4- } \\
\text { negative }\end{array}$ & $\begin{array}{l}\text { Partially } \\
\text { positive }\end{array}$ \\
\hline $\begin{array}{l}\text { No. of aggregates in } \\
\text { first chamber }\end{array}$ & \multirow[t]{2}{*}{$\begin{array}{c}0 \\
0 \%\end{array}$} & \multirow[t]{2}{*}{$\begin{array}{c}21 \\
11.7 \%\end{array}$} & \multirow[t]{2}{*}{$\begin{array}{c}2 \\
1.1 \%\end{array}$} & \multirow[t]{2}{*}{$\begin{array}{l}3 \\
1.5 \%\end{array}$} & \multirow[t]{2}{*}{$\begin{array}{c}21 \\
10.8 \%\end{array}$} & \multirow[t]{2}{*}{$\begin{array}{c}8 \\
4.1 \%\end{array}$} \\
\hline$\%$ of aggregates & & & & & & \\
\hline $\begin{array}{c}\text { No. of aggregates in } \\
\text { second chamber }\end{array}$ & \multirow[t]{2}{*}{$\begin{array}{c}3 \\
1.7 \%\end{array}$} & \multirow[t]{2}{*}{$\begin{array}{c}12 \\
6.7 \%\end{array}$} & \multirow[t]{2}{*}{$\begin{array}{c}3 \\
1.7 \%\end{array}$} & \multirow[t]{2}{*}{$\begin{array}{c}1 \\
0.5 \%\end{array}$} & \multirow[t]{2}{*}{$\begin{array}{c}29 \\
14.9 \%\end{array}$} & \multirow[t]{2}{*}{$\begin{array}{c}14 \\
7.2 \%\end{array}$} \\
\hline$\%$ of aggregates & & & & & & \\
\hline $\begin{array}{c}\text { No. of aggregates in } \\
\text { third chamber }\end{array}$ & \multirow[t]{2}{*}{$\begin{array}{c}1 \\
0.6 \%\end{array}$} & \multirow[t]{2}{*}{$\begin{array}{c}69 \\
38.5 \%\end{array}$} & \multirow[t]{2}{*}{$\begin{array}{c}19 \\
10.6 \%\end{array}$} & \multirow[t]{2}{*}{$\begin{array}{c}5 \\
2.6 \%\end{array}$} & \multirow[t]{2}{*}{$\begin{array}{c}40 \\
20.6 \%\end{array}$} & \multirow[t]{2}{*}{$\begin{array}{c}28 \\
14.4 \%\end{array}$} \\
\hline$\%$ of aggregates & & & & & & \\
\hline $\begin{array}{l}\text { No. of aggregates in } \\
\text { forth chamber }\end{array}$ & \multirow[t]{2}{*}{$\begin{array}{c}0 \\
0 \%\end{array}$} & \multirow[t]{2}{*}{$\begin{array}{c}39 \\
21.8 \%\end{array}$} & \multirow[t]{2}{*}{$\begin{array}{c}10 \\
5.6 \%\end{array}$} & \multirow[t]{2}{*}{$\begin{array}{c}8 \\
4.1 \%\end{array}$} & \multirow[t]{2}{*}{$\begin{array}{c}15 \\
7.7 \%\end{array}$} & \multirow[t]{2}{*}{$\begin{array}{c}22 \\
11.3 \%\end{array}$} \\
\hline \% of aggregates & & & & & & \\
\hline $\begin{array}{c}\text { No. of aggregates in } \\
\text { general }\end{array}$ & \multirow[t]{2}{*}{$\begin{array}{c}4 \\
2.2 \%\end{array}$} & \multirow[t]{2}{*}{$\begin{array}{c}141 \\
78.8 \%\end{array}$} & \multirow[t]{2}{*}{$\begin{array}{c}34 \\
19 \%\end{array}$} & \multirow[t]{2}{*}{$\begin{array}{c}17 \\
8.8 \%\end{array}$} & \multirow[t]{2}{*}{$\begin{array}{c}105 \\
54.1 \%\end{array}$} & \multirow[t]{2}{*}{$\begin{array}{c}72 \\
37.1 \%\end{array}$} \\
\hline $\begin{array}{c}\text { \% of aggregates } \\
\text { in general }\end{array}$ & & & & & & \\
\hline
\end{tabular}

We have then examined the expression of miR-290 cluster - set of microRNAs specifically expressed in pluripotent cells. In wild-type cells, miR-290 was downregulated upon differentiation and loss of pluripotency. However, in pelota-deficient EBs the amount of those small regulative RNAs was upregulated (Fig. 37).

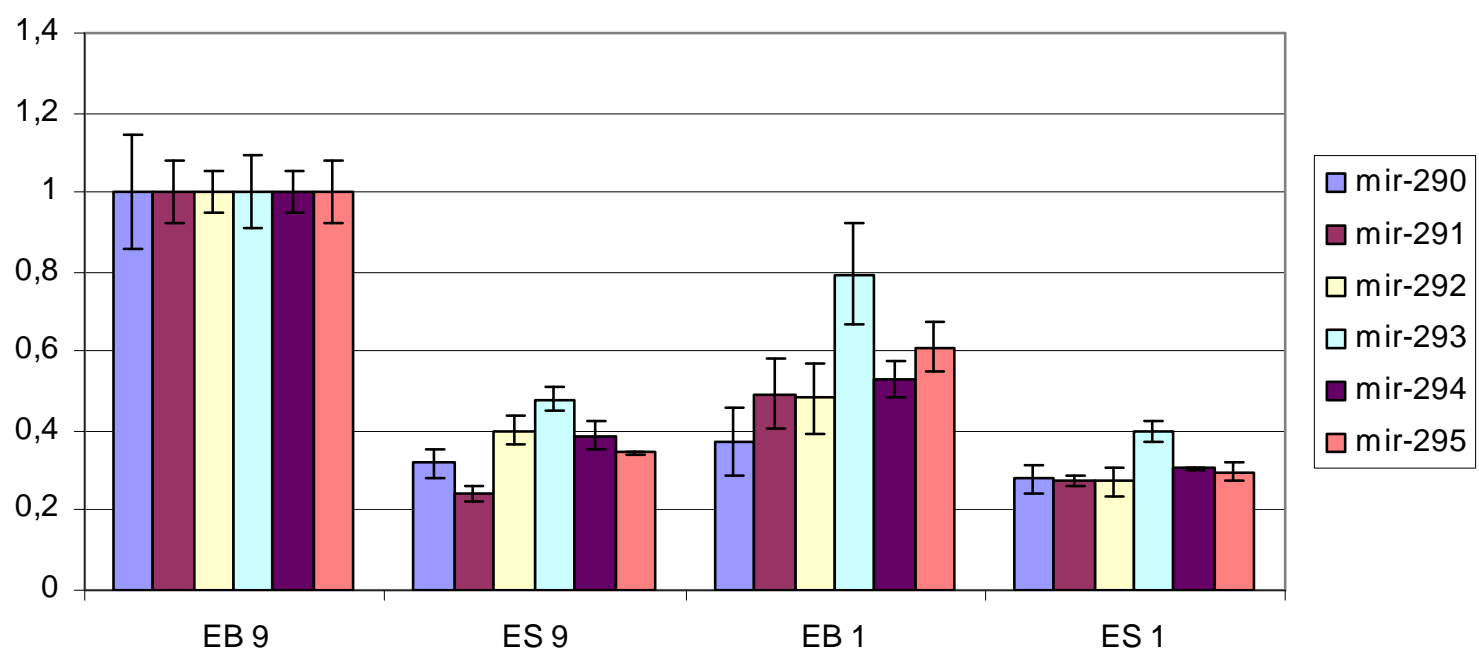

Figure 37. Relative levels of miR-290 cluster expression in Pelo ${ }^{\Delta /-}$ ES cells and embryoid bodies. 
Values represent relative levels of microRNAs of miR-290 cluster in undifferentiated control (ES1) and mutant (ES9) ES cell and differentiated cells: the control (EB1) and the mutant (EB9). Expression levels were normalised to the expression of endogenous control (Sdha). 2 technical replicates were done for each microRNA and each cell type. The different colours of bars stand for different microRNAs of miR-290 cluster-explained in the right table.

Results presented above, indicate that the mutant EBs are indeed pluripotent and their differentiation is somehow disrupted. To shed more light on differentiation process in Pelo ${ }^{\Delta /-}$ CreERT cells, we determined the potential of mutant ESCs for neuronal differentiation (Fig. 38). The experiment did not show any difference between mutant and control cells in their ability to form neurons. In both cases one could observe neuronal cells which were confirmed by immunohistochemical staining with neuron-specific markers $-\beta 3$ tubulin (TUJ) and tyrosine hydroxylase (TH). As shown in Figure 38, TUJ- and TH-positive cells were found in both cell lines. However, the number of mutant cells, which formed neurons seems to be decreased in comparison to control.
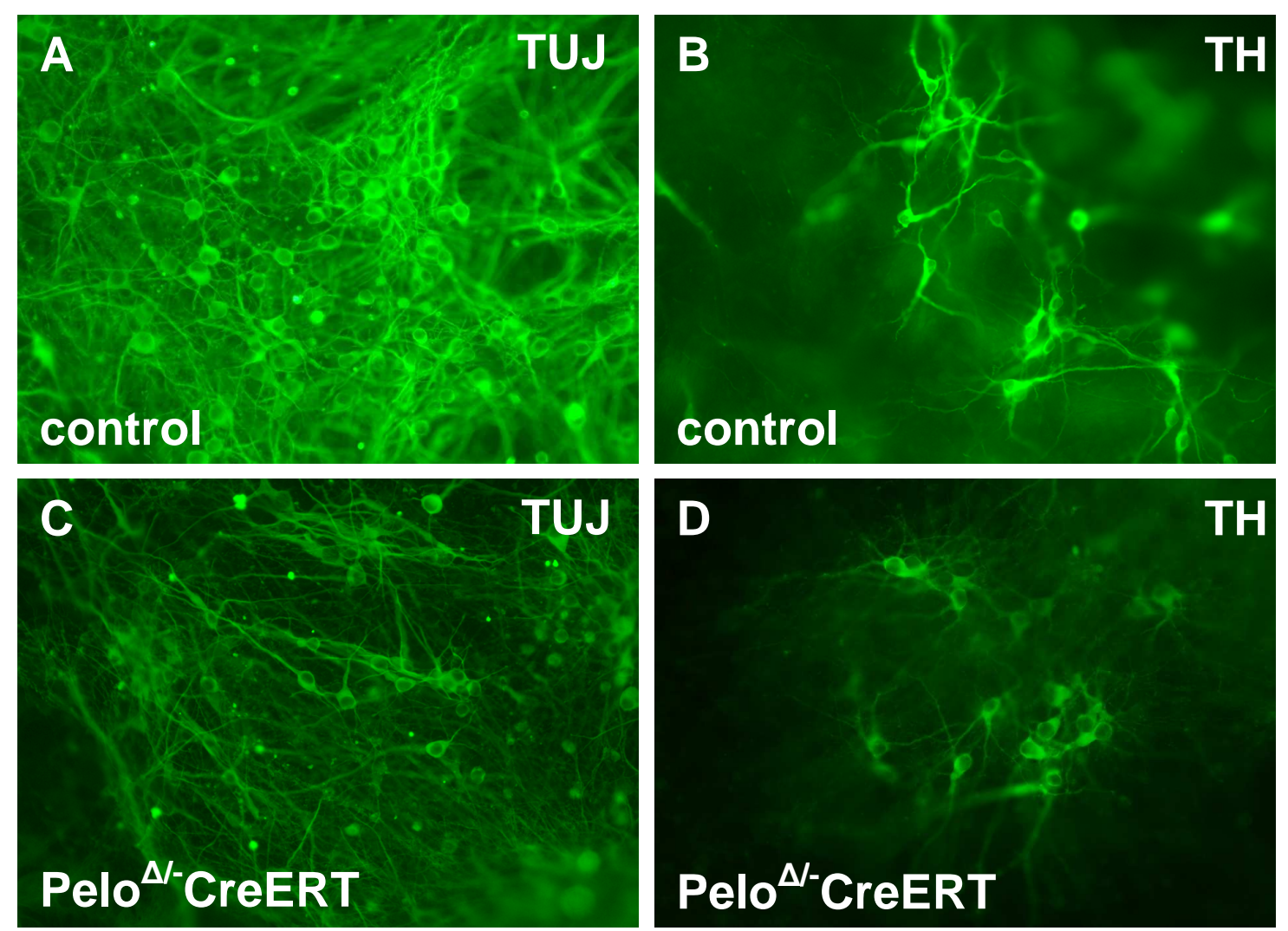

Figure 38. Neural differentiation of mutant and control cells.

The control $(A, B)$ and mutant $(C, D)$ cells were stained with two neuron-specific antibodies: $\beta 3$-tubulin (TUJ) and tyrosine hydroxylase (TH) and visualized by green fluorescence (FITC). 
For investigation of endodermal and mesodermal differentiation ability of mutant cells, we determined the expression level of early and late molecular markers for mesoderm and endoderm development. Eomesodermin is expressed early during mesodermal differentiation (Izumi et al. 2007), whereas vimentin is suggested to be neccesary in advanced stages of mesoderm formation (Rius and Aller, 1992). The expression level of eomesodermin was higher in 10-day-old Pelo ${ }^{\Delta /-}$ CreERT EBs than in control EBs (Fig. 39A), whereas the vimentin was expressed in mutant EBs on a very low level in contrast to the control (Fig. 39B). The data suggest that mesoderm formation is arrested at early stages in Pelo ${ }^{\Delta /-}$ CreERT cells. The high expression of vimentin in control EBs suggests that the cells have reached the late stage of mesodermal differentiation, while in the mutant cells the expression of vimentin has not yet been activated due to early-stage arrest. To verify this assumption, the expression level of both markers must be examined in 3-, 5- and 10-day-old EBs.

\section{$\mathbf{A}$}

\section{EOMESODERMIN}
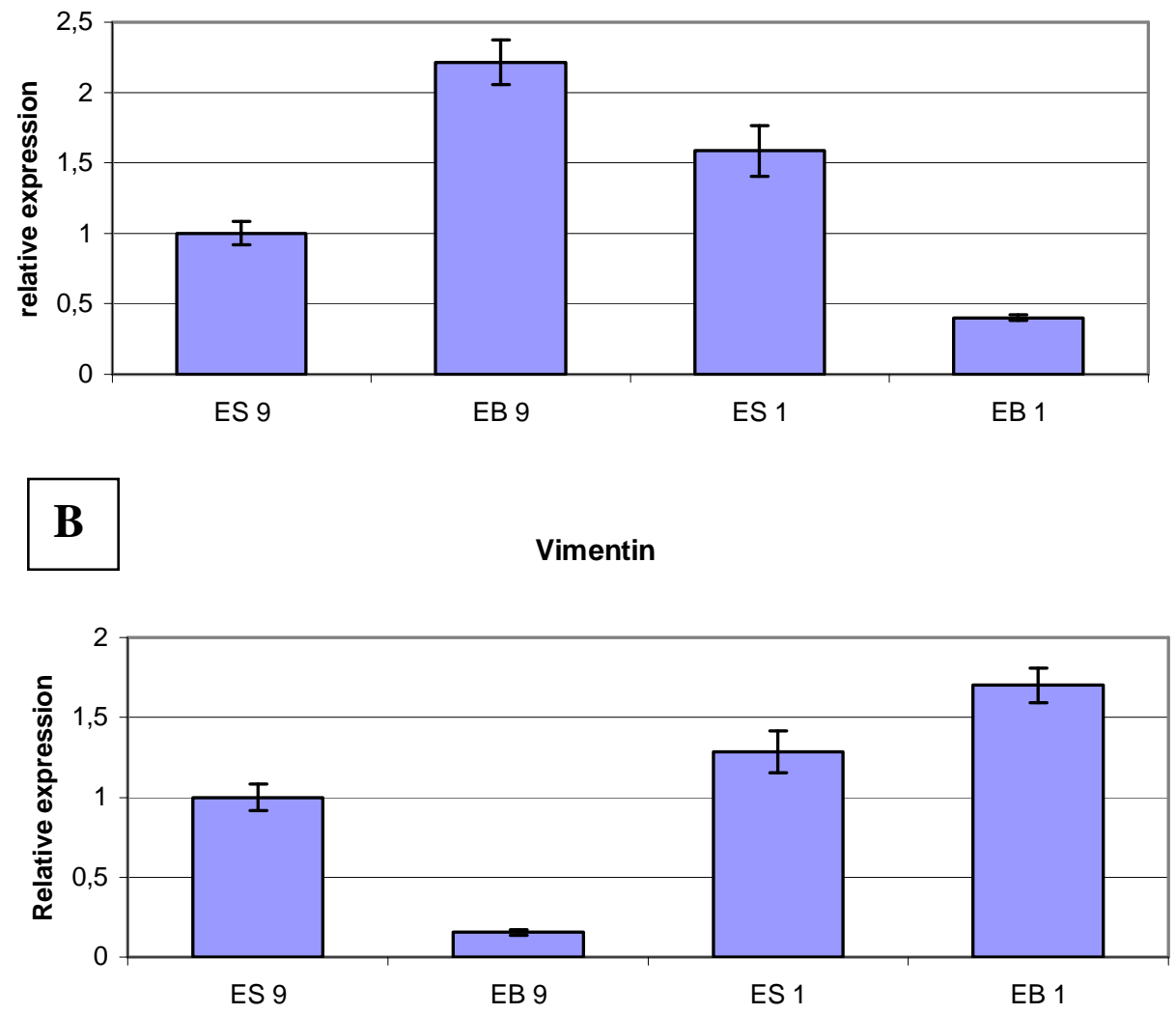

Figure 39. Eexpression profiles of early $(A)$ and late $(B)$ mesodermal markers. Values represent relative level of eomesodermin and vimentin in 10-day-old mutant (EB9) and control (EB1) EBs and was compared to the expression in undifferentiated mutant (EB9) 
and control (EB1) ES cells. Expression levels were normalised to the expression of endogenous control (Sdha). 2 biological replicates were done for each cell type.

Sox7 and Hnf4 are expressed at early and late stages of endodermal differentiation, respectively (Futaki et al., 2004; Duncan et al., 1997). The expression analysis of these markers in 10-day-old EBs revealed that Sox7 expression level does not differ significantly between Pelo ${ }^{\Delta /-}$ CreERT and control EBs and is similar to the level in undifferentiated cells (Fig. 40A). Late endodermal marker (Hnf4) exhibits high expression level in 10-day-old control EBs, whereas in undifferentiated cells it is downregulated. In mutant EBs the amount

\section{A}

Sox7

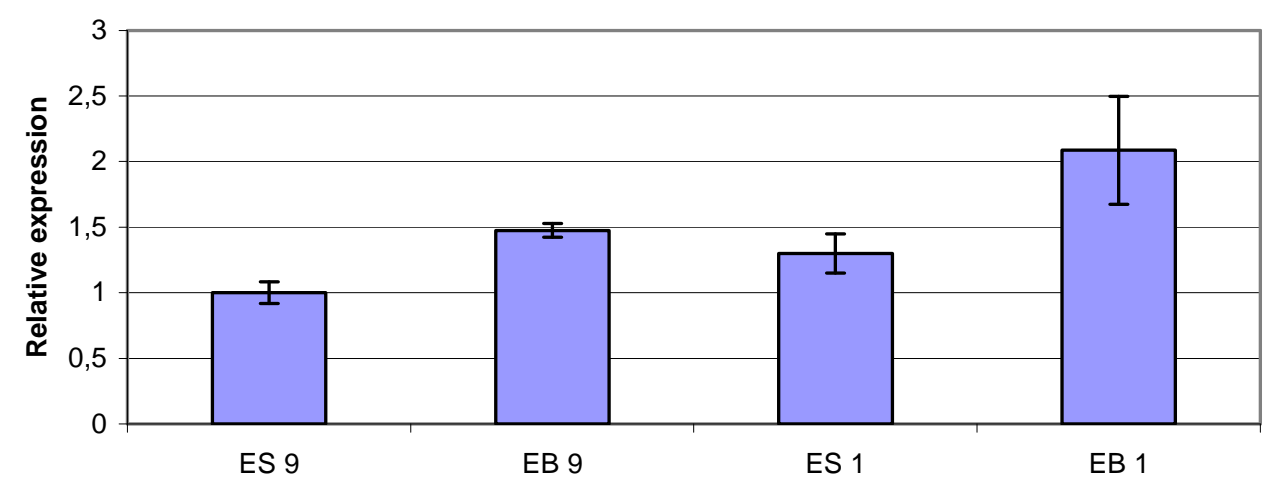

B

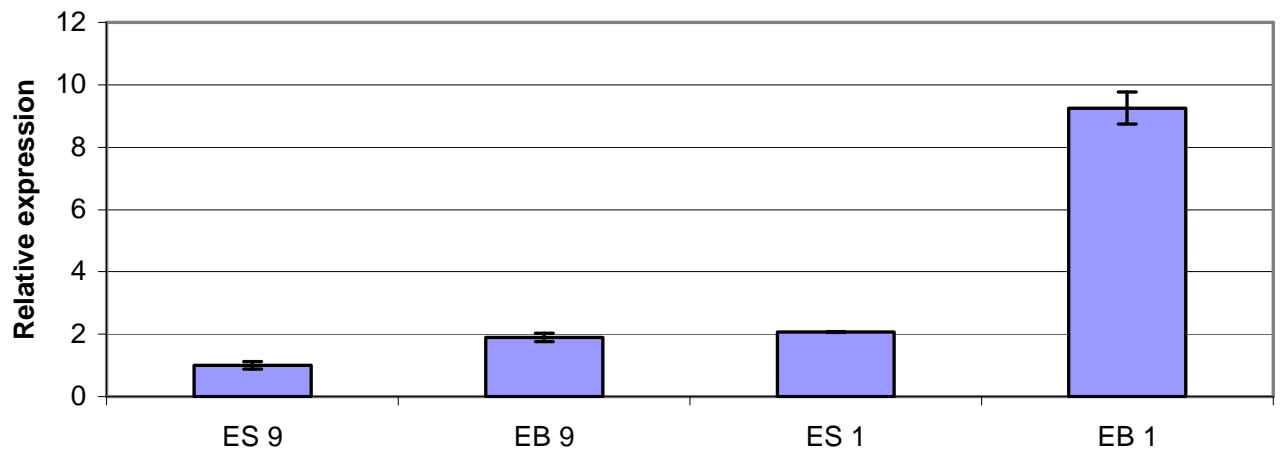

Figure 40. Eexpression profiles of early $(A)$ and late $(B)$ endodermal markers.

Values represent relative level of Sox7 and Hnf4 in 10-day-old mutant (EB9) and control (EB1) EBs and was compared to the expression in undifferentiated mutant (EB9) and control (EB1) ES cells. Expression levels were normalised to the expression of endogenous control (Sdha). 2 biological replicates were done for each cell type.

of Hnf4 transcript is reduced to the level detected in undifferentiated cells. The data suggest that mutant cells fail to form endoderm. Unchanged Sox7 expression may result 
from progression to later stages of differentiation, whereas downregulation of Hnf4 may be due to arrest in middle stages of endoderm formation. To evaluate this hypothesis, the expression level of both markers must be done in 3-, 5- and 10-day-old embryoid bodies.

\subsection{Transgenic mice overexpressing Pelota}

An alternaltive way for demonstration of pelota function in germ cells is a transgenic mouse model. In reference to pelota studies in Drosophila ovary (Xi et al., 2005), where depletion of pelota was found to cause loss of self-renewal of germ cells, we suspected that spermatogenesis in mouse testis could be affected as well.

To examine this hypothesis, we studied the phenotype of pelota transgenic animals which had been generated in the institute (Buyandelger, 2006). We analyzed four transgenic lines - two Adam lines (1 and 9) and two Eva lines (1 and 6).

A pelota transgenic allele in Adam lines contains human pelota cDNA under ubiquitin $\mathrm{C}$ promoter. The transgene $\left(\mathrm{Pelo}^{\mathrm{T}}\right.$ ) is specifically expressed in testes (Buyandelger, 2006).

Eva lines possess a transgenic allele composed of human pelota cDNA under the control of the elongation factor $1 \alpha$ promoter. EvaL1 line was shown to exhibit testis-specific Pelo $^{T}$, whereas the expression of Pelo ${ }^{T}$ in EvaL6 was detected in all studied tissues (Buyandelger, 2006). It was impossible to analyze the expression pattern of the transgene on protein level, because transgenic PELO protein did not possess any epitope tag (e.g. c-myc) and was therefore undistinguishable from endogenous Pelota protein. Therefore, the studies concerning expression were done on the level of RNA.

\subsubsection{Testis-specific transgenic lines}

Despite different promoters in Adam and Eva lines, the mice of lines AdamL1, AdamL9 and EvaL1 showed transgene expression restricted to testes. Fertility of males in all lines was not affected, i.e. the mice gave viable offsprings and avarage litter size was comparable to wild type FVB strain: $9 \pm 2$ animals. We decided to generate lines of homozygous Pelo ${ }^{T}$ mice. To establish homozygous lines $\left(\right.$ Pelo $\left.^{\mathrm{T} / \mathrm{T}}\right)$, we mated Pelo $^{\mathrm{T}}$ mice from F1 generation together. Subsequently, F2 mice were bred with wild type in order to distinguish between Pelo ${ }^{\mathrm{T}}$ and Pelo ${ }^{\mathrm{T} / \mathrm{T}}$ mice (Fig. 41). 


\section{Option l:}

Pelo ${ }^{\text {pos }}$

\section{Option II:}

$$
\text { Pelo }{ }^{\text {pos }}
$$

\section{F1: Pelo only

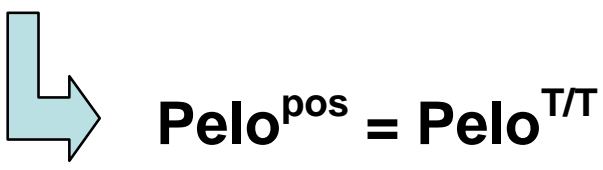 \\ Pelo $^{\text {pos }}=$ Pelo $^{\text {T/T }}$}

Figure 41. Scheme of test breedings to identify the homozygous and hemizygous transgenic mice.

Pelo $^{\text {pos }}$ stands for mouse that is positive for transgene, whereas Pelo ${ }^{+++}$is a wild type without transgene. Such genotype estimation was done on the basis of at least 2 litters for each positive mouse.

We were able to establish homozygous lines for AdamL1 and AdamL9, whereas test breedings did not reveal any Pelo ${ }^{\mathrm{T} / \mathrm{T}}$ mouse of line EvaL1. Histological analysis of testes isolated from F2 animals of all those three lines demonstrated that pelota overexpression did not influence spermatogenesis in any of the lines (Fig. 42). We detected all spermatogenic stages in seminiferous tubules of AdamL1, AdamL9 and EvaL1 animals. 

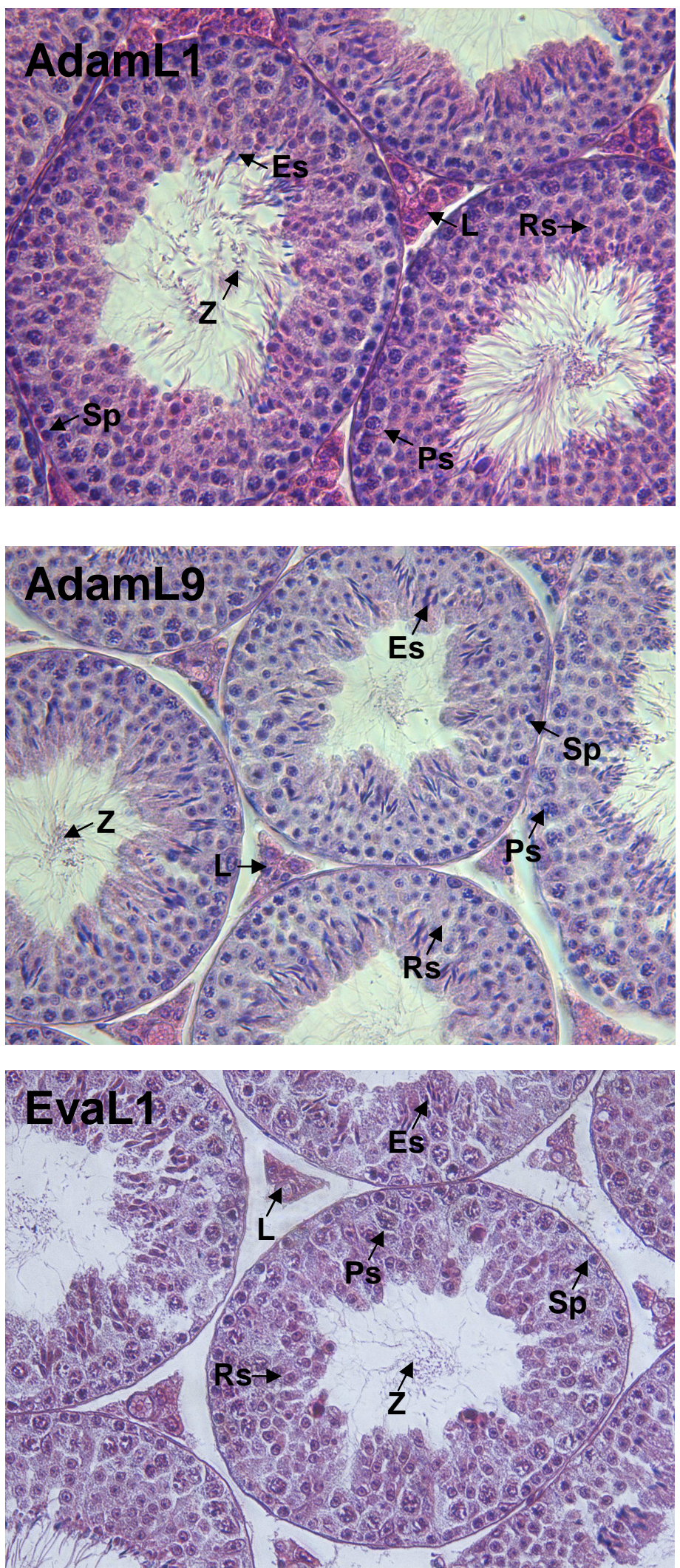

Figure 42. H\&E staining of adult testes isolated from AdamL1, AdamL9 and EvaL1.

$S p$ - spermatogonia; Ps - pachytene spermatocytes; Rs - round spermatids; Z Spermatozoa; L-Leydig cells. The photos were done in 20x magnification. 
The absence of Pelo ${ }^{\mathrm{T} / \mathrm{T}}$ mice in F2 generation of EvaL1 line led us to assume that the insertion of transgenic allele in the genome might have disrupted a gene, which plays a crucial role during embryogenesis. To determine the integration site of the transgene in EvaL1 genome, we used GenomeWalker Kit (Materials \& methods, 2.2.3), which allowed us to identify the genomic sequence adjacent to 3 'end of transgenic pelota allele. It turned out that pelota construct was recombined into the intronic region of Ror1 (receptor tyrosine kinase-like orphan receptor 1) gene located on chromosome 4 . We were able to define the exact integration site of $3^{\prime}$ end of the construct. To confirm the integration site, three primers were designed (Fig. 43). Two of them were located around the integration site and one was located on 3'end of transgenic construct. The set of these primers was used for genotyping of EvaL1 animals.

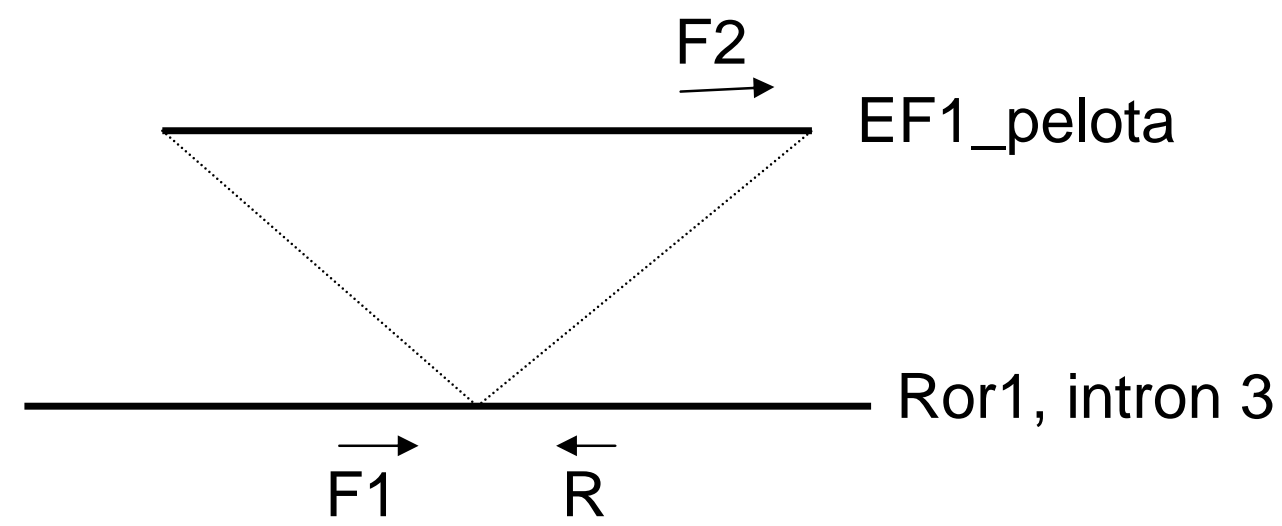

Figure 43. Scheme of pelota construct integration site

The figure presents integration of pelota transgenic allele (EF1_pelota) in the sequence of Rorl gene, in the intron 3. The arrows show primers which are used for genotyping of

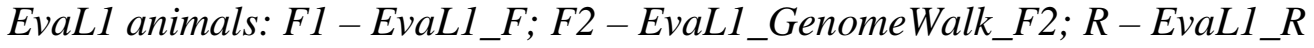

The PCR assay performed by means of designed primers confirmed that determination of integration site was correct. We obtained the expected bands either for wild-type allele or for introduced transgenic allele (Fig. 44). It demonstrates that all offsprings obtained from breedings between transgenic mice, were wild-type or heterozygous. Neither of them was Pelo ${ }^{\mathrm{T} / \mathrm{T}}$. 


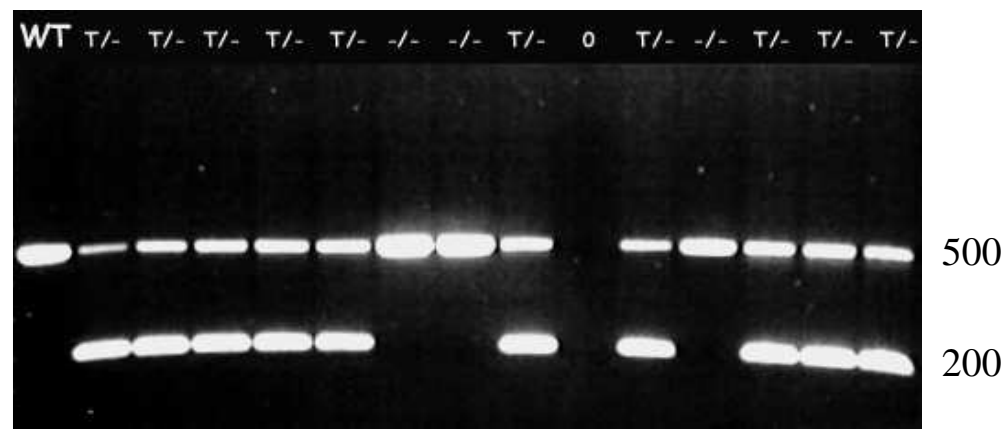

Figure 44. Genotyping PCR for integration site in EvaL1 line

Wild-type band stands for intron 3 frogment of Rorl gene without pelota construct integration amplified by $F 1$ and R primers (Fig. 43), while transgenic allele is amplified by $F 2$ and $R$.

To determine whether the Pelo ${ }^{\mathrm{T} / \mathrm{T}}$ mice die during embryogenesis, we genotyped embryos at E15.5 and E17.5 stages. We found Pelo ${ }^{\mathrm{T} / \mathrm{T}}$ mice in both stages. Analysis of neonatal offsprings derived from crosses of heterozygous Pelo ${ }^{\mathrm{T}}$ mice revealed that Pelo $^{\mathrm{T} / \mathrm{T}}$ newborns died within 24 hour after birth (Table 7.).

Table 7. Genotype statistics of newborns which died within 24 hours after birth.

\begin{tabular}{|c|c|c|c|}
\hline Parents genotype & \multicolumn{2}{|c|}{ Pelo $^{T}$} & $\mathrm{lo}^{\mathrm{T}}$ \\
\hline Newborns genotype & Pelo $^{-/-}$ & Pelo $^{T}$ & Pelo $^{T / T}$ \\
\hline No. of newborns & 17 & 28 & 14 \\
\hline $\begin{array}{l}\text { No. of newborns } \\
\text { which died within } \\
24 \mathrm{~h}\end{array}$ & 1 & 5 & 14 \\
\hline
\end{tabular}

It could be possible that during recombination process a part of intron/exon sequence was deleted and Ror1 was disrupted. To prove this hypothesis, Western analysis of proteins isolated from kidneys of Pelo ${ }^{\mathrm{T} / \mathrm{T}}$, Pelo $^{\mathrm{T}}$ and Pelo $^{-/-}$embryos was performed using polyclonal anti-ROR1 antibody. As shown in Figure 45., the ROR1-specific $105 \mathrm{kDa}$ band was detected. The protein was present either in wild-type or in Pelo $^{\mathrm{T}}$ kidney-protein extracts, whereas in Pelo ${ }^{\mathrm{T} / \mathrm{T}}$ embryos it was undetectable. 

$-1-$
$\mathrm{T} /-$
$\mathrm{T} / \mathrm{T}$
$\mathrm{T} /-$
$\mathrm{T} /-$
$\mathrm{T} / \mathrm{T}$

\section{ROR1}

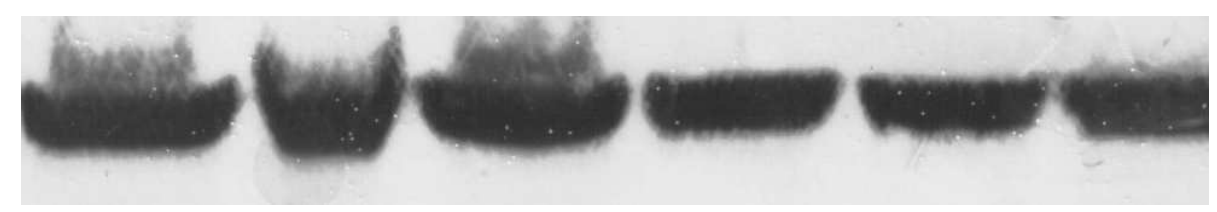

a-tubulin

Figure 45. Western analysis for ROR1 protein in EvaL1 mice.

The upper photo presents staining with anti-RORl antibody which detects the ROR1 protein in size of $105 \mathrm{kDa}$. Antibody staining with anti-tubulin (lower photo) demonstrates tubulin protein of $51 \mathrm{kDa}$ which characterizes the quality of proteins used for RORI staining.

Lack of ROR1 protein confirmed accidental disruption of this gene by recombination of pelota transgene into Ror1 locus. Ror1 knockout phenotype was published (Nomi et al., 2001). It was reported that Ror $1^{-/-}$newborns had respiratory problems and died within 24 hours after birth. After observation of EvaL1 newborns, we obtained convergent results.

\subsubsection{EvaL6 as a rescue for pelota knockout mice}

To study the consequence of Pelo-overexpression on embryonic and germ cell development, our group generated a transgenic mouse line that ubiquitously overexpressed Pelota protein. EvaL6 line was generated by the introduction of the transgenic pelota under EF1 promoter into the wild-type mouse genome (Buyandelger, 2006). The ubiquitous expression of Pelo ${ }^{T}$ in EvaL6 mice did not influence mouse viability and fertilty. We generated a homozygous EvaL6 line like described above (Fig. 41). The line did not exhibit any apparent phenotype.

These transgenic animals were used to solve the question whether the embryonic lethality of Pelo-deficient mice is due to inactivation of pelota gene or because of position effect resulting from manipulation of pelota locus and consequent change in expression of neighbouring genes.

To verify these possibilities, we introduced the transgenic Pelo allele into the genome of Pelo ${ }^{-/-}$mice (Fig. 46) and proved the ability of Pelo ${ }^{\mathrm{T}}$ to rescue the embryonic lethality of $\mathrm{Pelo}^{-/-}$mice. 


\section{Pelo $^{+-} \quad x \quad$ Pelo $^{\text {T/T }}$ \\ F1: Pelo $^{+/-T} \quad x \quad$ Pelo $^{+/-T}$ \\ F2: $\quad \underline{\text { Pelo }^{-/-T}}$}

Figure 46. Strategy of breeding for generation of rescue mouse

Generated Pelo $^{-/-}$Pelo $^{\mathrm{T}}$ rescue mice are healthy (Fig. 47) what provides evidence that pelota transgenic allele is properly constructed. Moreover, its expression under EF1 promoter is efficient to substitute endogenous Pelota protein and mimic its function in living animal. It confirmed close evolutionary relation between human and murine Pelota protein.

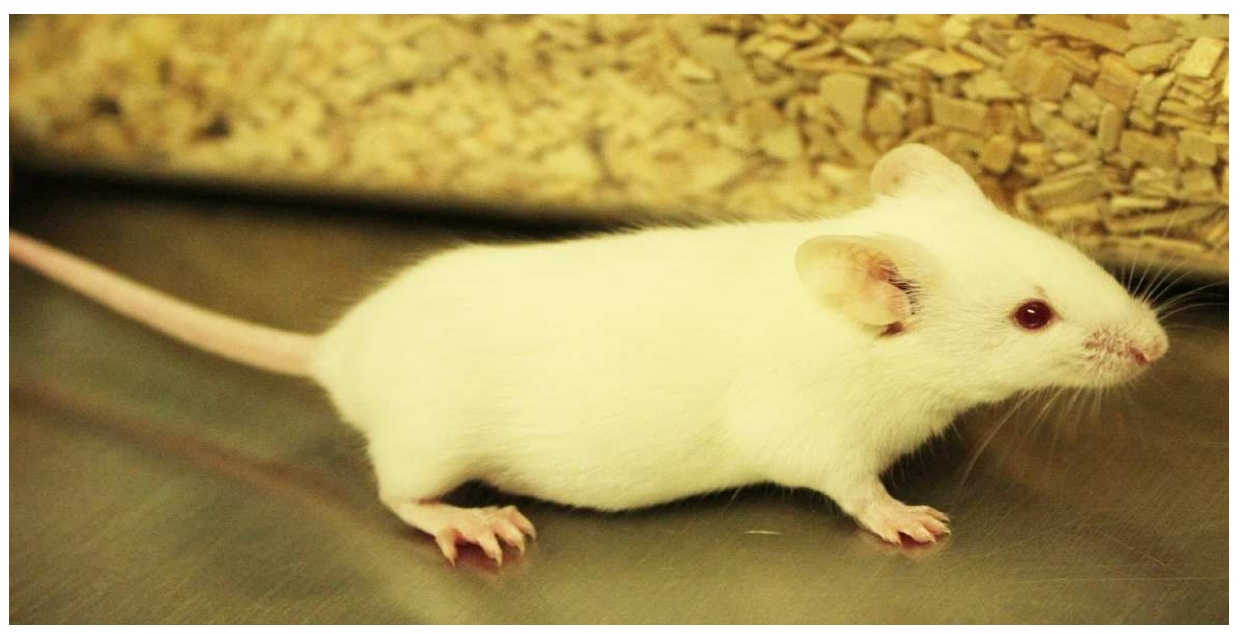

Figure 47. Rescue mouse: Pelo $^{-/-}$Pelo ${ }^{T}$ male

Table 8 demonstrates the genotype statistics of breedings between $\mathrm{Pelo}^{+/ \mathrm{T}}$ mice, which yielded Pelo ${ }^{-/ T}$ mice. All rescue mice were viable. Their fertility was studied in test breedings. One $\mathrm{Pelo}^{-/-\mathrm{T}}$ female has already delivered 8 offsprings, while no progeny was obtained from any Pelo $^{-/-\mathrm{T}}$ male within 2-month breedings. It indicates that transgenic Pelota protein is also capable of retaining germ cell differentiation and functionality at least in ovaries. 
Table 8. Statistical frequency of expected genotypes derived from breedings producing rescue mice

\begin{tabular}{|c|c|c|c|c|c|c|}
\hline \multicolumn{7}{|c|}{ Pelo $^{+/-T}$ x Pelo $^{+/-T}$} \\
\hline F1 generation & $+/+$ & $+/-$ & $-/-$ & $+/+\mathrm{T}$ & $+/-\mathrm{T}$ & $-/-\mathrm{T}$ \\
\hline Mendelian ratio & 1 & 1 & 1 & 1 & 1 & 1 \\
\hline Mice number (out of 52) & 8 & 14 & 0 & 5 & 19 & 6 \\
\hline
\end{tabular}




\subsection{Brief overview of the results}

In 2003 pelota function was analyzed in pelota knockout mouse (Adham et al., 2003). The phenotype of homozygous mutants $\left(\mathrm{Pelo}^{-/}\right)$is lethal during early stages of embryogenesis (E7.5). Pelo $^{-/-}$blastocysts fail to expand in growth after 4-day culture. It was hypothesized that inner cell mass displays the defect rather in cell proliferation than in differentiation. The putative role of pelota in differentiation was demonstrated in Drosophila ovary, where it is involved in self-renewal of germ stem cells (Xi et al., 2005).

To investigate the function of murine PELO in cell cycle/differentiation, we generated a conditional knockout mouse. On the level of RNA, we demonstrated that tamoxifen-induced recombination of floxed Pelo allele was complete in generated Pelo ${ }^{\mathrm{F} /-}$ CreERT ESC line (Fig. 11). The procedure was also very efficient in the mouse model, where we detected almost complete deletion of the floxed allele (Fig. 29).

The histological analysis showed that spermatogenesis was completely disrupted - all stages of germ cells were absent, only Sertoli cells could be found (Fig. 31). For evaluation of PELO effect on spermatogenesis progression, we generated testis-specific knockout mice (Pelo ${ }^{\mathrm{F} /}$ Stra8-Cre), where deletion of floxed Pelo region occurs in accordance with Stra8 promoter-derived Cre recombinase expression (chapter 3.1.6.). The immunohistochemical analysis of mutant testes unveiled lack of spermatogenic progression since day 15, when meiotic division starts. The quantitative analysis of premeiotic markers revealed that expression of Stra8, Dazl and Ddx4 in 10-day-old testes was alike - all three markers exhibited a drastic increase of transcript level at that time in the control, but in mutant testes we observed twofold reduction (Fig. 25, 26, chapter 3.1.6.4.). In case of Plzf, Sox3 and cKit, there was no dramatic discrepancy between control and mutant, despite the slight reduction at day 5. It indicates that there was no clear effect of PELO depletion at the stage of either undifferentiated (Plzf and Sox3) or differentiated (c-Kit) spermatogonia. It suggests that the phenotype appeared with onset of spermatogonial differentiation, that is with entry to meiotic division. In addition, we found mosaic mice ( $\left.\mathrm{Pelo}^{\mathrm{F} / \Delta /-} \mathrm{Stra} 8-\mathrm{Cre}\right)$, which displayed incomplete Pelo allele recombination in various somatic tissues, including kidney, liver, heart, spleen, lungs. It indicates that Stra8 expression is transactivated early in embryogenesis. However, we did not find Pelo ${ }^{\Delta /-}$ Stra8-Cre mice, what means that this genotype is lethal during embryogenesis, similar to pelota classical knockout. 


\section{DISSCUSSION}

Handling the well-functioning conditional knockout mouse model, we were able to verify why Pelo null blastocysts were unable to produce the ESC line. We generated Pelo ${ }^{\mathrm{F} /-}$ CreERT ESC line, where we successfully deleted Pelo (the cell genotype become Pelo ${ }^{\Delta /-}$ CreERT) by CreERT recombination (Fig. 10). The null cells did not show any proliferative disorder and were well preserved in culture. They also did not exhibit an increased level of programmed cell death. Therefore, we analyzed the differentiation capability of mutant ES cells. The Pelo ${ }^{\Delta /-}$ CreERT ES cells turned out to be defective in generating embryoid body structures. The cells showed sustained Oct4 expression and upregulated expression of miR290 cluster - family of microRNA which is characteristic for pluripotent ES cells (Houbaviy et al., 2003, 2005). To investigate in which germ layer the differentiation failure occurs, we used the mutant cells for neuronal differentiation. The experiment resulted in differentiation of neuronal cells in vitro. This indicates that the process of generating ectoderm is unaffected (Fig. 38). For analysis of mesoderm and endoderm lineages, we performed quantitative RT PCR by means of early and late markers for both germ layers. In mutant cells subjected to EB formation, the level of early mesodermal marker (eomesoderin, Fig. 39A) was significantly higher that in control EBs, and expression of a late marker (vimentin, Fig. 39B) was strongly reduced. Whereas the early marker for endodermal development (Sox7) did not show any difference between mutant and control, the late marker (Hnf4) was drastically downregulated in mutant cells. From these results we assume that pelotadeficient cells are defective in mesoderm and endoderm formation. To prove our hypothesis we studied differentiation of adult stem cells, i.e. hematopoietic stem cells and spermatogonial stem cells, which are convenient models in the mouse due to continuous differentiation process along the life span of the animal and due to their mesodermal origin.

The analysis of $\mathrm{B}$ and $\mathrm{T}$ cells isolated from spleen and thymus demonstrated the reduction in number of both kinds of cells. Additionally, in case of $\mathrm{T}$ cells we detected a strong increase of double negative cells $\left(\mathrm{CD}^{-} \mathrm{CD} 8^{-}\right)$, which are developmental precursors of mature $\mathrm{T}$ cells. However, the following developmental stages, that are double positive $\left(\mathrm{CD} 4^{+} \mathrm{CD} 8^{+}\right)$, single positive $\left(\mathrm{CD} 4^{+} \mathrm{CD} 8^{-}\right.$or $\left.\mathrm{CD} 8^{+} \mathrm{CD} 4^{-}\right)$and mature $\mathrm{T}$ cells $\left(\mathrm{CD} 3^{+}\right)$were reduced in number (Table 4.). This clearly shows the developmental arrest of $\mathrm{T}$ cells. However, proliferation of precursor cells was not affected.

To show that mortality of classical knockout mice results from pelota inactivation, we crossed Pelo ${ }^{+-}$mice with transgenic Pelo ${ }^{T}$ mice (chapter 3.2.2), which rescued the lethal phenotype. It clearly demonstrates that the lethality originated from pelota inactivation, and it was not the position effect after introduction of the allele into the genome. 


\section{DISSCUSSION}

In addition, we analyzed transgenic mice which overexpress PELO in testis-specific manner. However, we did not detect any disorder in spermatogenesis. The mice were fertile. This can suggest that PELO protein is subjected to accurate posttranslational regulation in the cell and the excessive amounts of the protein are removed.

\subsection{Embryonic stem cell fate shift from pluripotent to differentiated state}

Embryonic stem cells are derived from the inner cell mass of the blastocyst (E3.5 in murine embryogenesis) and are capable of giving rise to all three germ layers, what constitutes their pluripotency. The important feature of ES cells is their ability to self-renew, which requires a complex transcriptional profile (Zhou et al., 2006). Some factors were identified to contribute to the pluripotency maintenance, including Oct4, Sox 2 and Nanog. The shift of the cell fate to differentiation causes downregulation of the pluripotent markers. For instance, in the cells induced to mesoderm formation, Oct4 is not expressed (Yeom et al., 1996; Yoshimizu et al., 1999).Depletion of the main pluripotent markers stands for the loss of pluripotency. Oct-4-deficient embryos die at blastocyst stage due to loss of pluripotent cells composing inner cell mass (Nichols et al., 1998; Niwa et al. 2000). Sox2-targeted deletion causes a lethal phenotype at peri-implantation stage of embryogenesis. In contrast to Oct4-null mutants, Sox $2^{-/-}$embryos develop the inner cell mass, but they fail to maintain epiblast cells which are essential for further differentiation of extraembryonic tissues (Avilion et al., 2003). Nanog-deficient ES cells differentiate into extraembryonic endoderm lineage, losing pluripotency (Mitsui et al., 2003). Preservation of pluripotency requires also silencing of genes which are responsible for differentiation initiation. Such inactivation is implemented by means of epigenetic regulation, i.e. chromatin remodeling, histone modifications and DNA methylation (Boyer et al., 2006; Lee et al., 2006). However, the genes of pluripotent markers are also subjected to epigenetic regulation. Such regulation by methylation was reported for Oct4 (Hattori et al., 2004) and Nanog promoters (Deb-Rinker et al., 2005). It was unveiled that Nucleosome Remodeling and histone Deacetylation (NuRD) complex (Xue et al., 1998) is recruited at promoter sequences of the pluripotent markers and is responsible for epigenetic modifications and silencing of the gene expression (Wade et al., 1999; Lan et al., 2002; Crook et al., 2006; Kaji et al., 2006).

The NuRD complex is composed of methyl-binding-domain-related protein 2 and 3 (MBD2/3), histone-binding proteins, chromatin remodeling ATPases, zinc-fingers proteins and histone deacetylases, which form together orchestrated apparatus for epigenetic 


\section{DISSCUSSION}

modifications (Crook et al., 2006). MBD2 and 3 were identified as core components of NuRD complex (Ng et al., 1999; Zhang et al., 1999). However, it was found that they are mutually exclusive. They reside in two NuRD complexes with distinct core-subunit compositions: MBD2/NuRD and MBD3/NuRD (Le Guezennec et al., 2006). The results of knockout studies for MBD2 and MBD3 indicate that they play nonoverlapping roles in mouse development. Deletion of MBD2 results in relatively mild defects in transcriptional silencing of methylated promoters. The MBD2-knockout mice are viable - this demonstrates that MBD2 is not crucial for mouse development. Unlike MBD2, the deletion of MBD3 causes embryonic lethality (Hendrich et al., 2001).

Due to the fact that it was impossible to establish an ES cell line from Mbd $3^{-/-}$ blastocysts, Kaji et al. (2006) generated an ESC line with floxed Mbd3 ${ }^{\mathrm{F} /-}$ allele. After MBD3 deletion, the mutant ES cells were unable to repress transcription of Pramel6 and Pramel7 genes highly expressed in preimplantation stages, and Dppa3 which is an early marker of primordial germ cells. When the $\mathrm{Mbd}^{-/-} \mathrm{ES}$ cells were subjected to differentiation conditions, they displayed persistent expression of pluripotent markers (Oct4, Nanog, Rex1). In addition, they failed to express differentiation markers for all developmental lineages (endoderm, mesoderm and ectoderm), except for primitive ectoderm marker Fgf5 at day 3 of differentiation. However, the cells were unable to downregulate the Fgf5 expression at later stages of differentiation as compared with control cells. This suggests that ectodermal differentiation can start, but is arrested at early stage (Kaji et al., 2006). Our results demonstrate that PELO protein inactivation leads to analogous phenotype.

Similarly to $\mathrm{Mbd}^{-/-}$, Pelo ${ }^{\Delta /-}$ ES cells stay pluripotent in differentiation conditions, what was confirmed by alkaline phosphatase staining and sustained Oct4 expression. Analysis of differentiation markers shows that $\mathrm{Pelo}^{\Delta /-}$ and $\mathrm{Mbd}^{-/-} \mathrm{ES}$ cells subjected to embryoid body formation exhibit a differentiation arrest in either all developmental lineages $\left(\mathrm{Mbd}^{-{ }^{-}}\right)$or mesoderm and endoderm $\left(\mathrm{Pelo}^{\Delta /-}\right)$. Interestingly, both mutant cell lines seem to display primitive cell fate shift to differentiation into one germ layer: ectoderm $\left(\mathrm{Mbd}^{-{ }^{-}}\right)$or mesoderm $\left(\right.$ Pelo $\left.^{\Delta /-}\right)$. However, the increased mRNA levels of early differentiation markers and decreased transcript levels of late differentiation markers lead us to the assumption that further formation of ectoderm $\left(\mathrm{Mbd}^{-/-}\right)$and mesoderm $\left(\mathrm{Pelo}^{\Delta /-}\right)$ is arrested at an early stage of differentiation. This convergent phenotypes suggest that the defect of differentiation capacities of Pelo $^{\Delta /-}$ ES cells may result from malfunction of NuRD complex in methylation of Oct4 promoter, which in these cells is constantly active under differentiation conditions. 


\section{DISSCUSSION}

This hypothesis is supported by the fact, that pelota was found to interact with CDK2AP1 protein (unpublished data), which is also required for epigenetic silencing of the Oct4 gene during ESC differentiation (Deshpande et al., 2008). In addition, the protein was identified as a core component of MBD2/NuRD and MBD3/NuRD complexes (Le Guezennec et al., 2006). Deletion of Cdk2AP1 results in early embryonic lethality and sustained expression of Nanog and Oct4. As these findings are convergent with the Mbd3deficiency phenotype, it was assumed that CDK2AP1/MBD3/NuRD complex is responsible for silencing of genes of pluripotent markers during the differentiation process (Deshpande et al., 2008). Due to the fact that PELO protein is localized in the cytoplasm and not in the nucleus, the interaction between CDK2AP1 and PELO may have a regulatory impact on signalling pathways related to promotion of differentiation, like the transforming growth factor $\beta$ (TGF- $\beta$ ) pathway.

\subsection{Signal transduction in differentiation and pluripotency}

The development and homeostasis of most mouse tissues are controlled by the TGF $\beta$ signal transduction network, which involves distinct receptor families and mediator proteins activating target gene transcription in association with DNA-binding proteins (Massague, 1998). The TGF- $\beta$ family consists of polypeptide growth factors, which regulate various developmental processes, such as cell proliferation, lineage determination, differentiation and cell death. The TGF- $\beta$ is also an important antiproliferative factor during early stages of oncogenesis (Hill et al., 2009).

The TGF- $\beta 1$ is a member of the TGF- $\beta$ family. It is a cytokine, which exerts suppressive effects on epithelial, endothelial and hematopoietic cells by promoting synthesis of cyclin-dependent kinase inhibitory proteins (Massague, 1990; Hannon and Beach, 1994; Alexandrow and Moses, 1995; Polyak, 1996). Hu et al. (2004) demonstrated that this growth factor leads to induction of CDK2AP1 transcription and in consequence to increased CDK2AP1 association with CDK2. The interaction results in negative regulation of CDK2 activity, i.e. proliferation inhibition. This TGF- $\beta$-mediated growth suppression is affected by CDK2AP1 depletion. From these data we can assume that CDK2AP1 protein, a core component of MBD3/NuRD complex, is activated by TGF- $\beta$. As it is doubtful that PELO participates directly in the NuRD complex formation, we suppose that disruption of Oct4 promoter methylation in Pelo-deficient ES cells is an effect of upstream deregulation of TGF- $\beta$ signalling pathway, which controls pluripotent gene expression by epigenetic 


\section{DISSCUSSION}

silencing and hence differentiation of mouse ES cells. It is probable that PELO/CDK2AP1 interaction plays a role in TGF- $\beta$ promotion (Fig.49).

An alternative pathway, which may be deregulated in pelota-deleted Pelo ${ }^{\Delta /-}$ CreERT ES cells is the LIF signalling pathway. LIF signalling inhibits mesoderm and endoderm formation, whereas ectoderm formation in ESCs is blocked by bone morphogenetic protein 4 (BMP4) signalling (Ying et al., 2003). Due to the fact that ectoderm differentiation upon pelota inactivation is unaffected, we assume that BMP4 pathway is not influenced by PELO protein. In normal ES cells, LIF application leads to phosphorylation of distinct factors, including STAT3, a signal transducer and activator of transcription 3 (Boeuf et al., 1997), what leads to maintenance of pluripotent state. Inactivation of STAT3 was reported to induce spontanous differentiation (Paling et al., 2004). The studies concerning STAT3 expression revealed that this factor, activated under differentiation conditions, is capable of sustaining self-renewal of ESCs without addition of LIF (Matsuda et al., 1999). The STAT3dependent pathway is poorly understood, but it is known that c-myc and Eed genes (cell proliferation propagators) are direct targets of STAT3 (Cartwright et al., 2005; Ura et al., 2008). Recently, 58 genes were identified as target genes of STAT3 (Bourillot et al., 2009). Some of them, like Smad7 or c-myc, are negative regulators of TGF- $\beta$ signalling (Hayashi et al., 1997; Imamura et al., 1997; Nakao et al., 1997; Feng et al., 2002).

STAT3 pathway sustains pluripotent character of ES cells by inhibiting mesodermal and endodermal differentiation processes activated by TGF- $\beta$ signals. Pelota function may be associated with downregulation of STAT3 signalling. In Pelo ${ }^{\Delta /-} \mathrm{CreERT}$ cells subjected to differentiation conditions, mesoderm and endoderm are not formed, as it is shown on the transcript levels of lineage-specific markers (Fig. 39, 40). It might be connected with uncontrolled upregulation of STAT3, which is able to maintain pluripotency in the absence of LIF. However, the studies in Xenopus embryos have shown that STAT3 can also promote mesoderm formation (Ohkawara et al., 2004). In different conditions, namely various sorts and doses of signals, STAT3 can become also up- or downregulated by BMP2, a TGF- $\beta$ family member, what in consequence leads to apoptosis or differentiation (Kawamura et al., 2000; Rajasingh et al., 2007). TGF- $\beta$ and STAT3 signalling pathways form a dynamically balanced network which decides about the fate of the cell depending from incoming signals. Therefore, a putative function of PELO in negative regulation of STAT3 must be well adjusted to the signal influx.

The TGF- $\beta$ is also a regulator of immune response. It was reported to induce CD8 expression in $\mathrm{CD}^{-} \mathrm{CD}^{-}$double negative thymocyte precursors during $\mathrm{T}$ cell differentiation 


\section{DISSCUSSION}

process (Suda and Zlotnik, 1991; 1992; Inge et al., 1992; Plum et al., 1995). The maturation of $\mathrm{B}$ cells is also controlled by TGF- $\beta$, which positively and negatively regulates the expression of cell surface markers in B cell precursors and mature B cells (Stavnezer, 1996). In activated B cells, TGF- $\beta$ inhibits cell proliferation and may induce apoptosis (Lomo et al., 1995). However, in epithelial malignancies the cells may become insensitive to TGF- $\beta$ inhibitory effects what leads to an increase of the cell number and tumor progression (Berg and Lynch, 1991; Tada et al., 1991; Kadin et al., 1994; DeCoteau et al, 1997). Among its numerous functions, the TGF- $\beta$ blocks also activated lymphocyte proliferation and has been thus suggested to serve as a negative feedback mechanism to reverse the inflammatory response (Wahl et al., 1988). It was also demonstrated that the TGF- $\beta 1$ deletion leads to autoimmune disease. It indicates a substantial role of TGF- $\beta$ in self-tolerance of the immune system. It is likely to contribute in negative selection of T cells in thymus. Deletion of TGF$\beta$ leads to imbalanced production of $\mathrm{CD} 4^{+} \mathrm{CD}^{+}$double positive cells due to defective apoptosis of differentiating T cells (Letterio and Roberts, 1998).

Lymphocytes composing the immune system develop from mesodermal hematopoietic cells. Our preliminary data demonstrate that Pelo ${ }^{\Delta /-}$ CreERT ES cells fail to differentiate into mesoderm. In parallel, the phenotype of Pelo ${ }^{\Delta /-}$ CreERT mice indicates an immune system disorder, in which the number of mature B and T cells is highly diminished due to arrest in $\mathrm{T}$ cell differentiation in the thymus, and immature thymocytes are increased in number. In case of B cells, it is neccessary to evaluate the number of B cell precursors in a cell population of bone marrow, where the differentiation starts, to confirm that proliferation is not affected. However, the immune system functionality is impaired and inflammation observed in different organs of the mutant mice seems to be the consequence of the immune system malfunction. In accordance with our hypothesis, that pelota is functionally correlated with TGF- $\beta$ signalling and mesoderm formation. The mouse phenotype, observed upon Pelo inactivation, is prominent in the immune system due to the constant differentiation process occuring in hematopoietic cells. However, the bone marrow is not the only source of pluripotent cells in the adult mouse. The cell fate shift from pluripotency to differentiation happens also in gonads. 


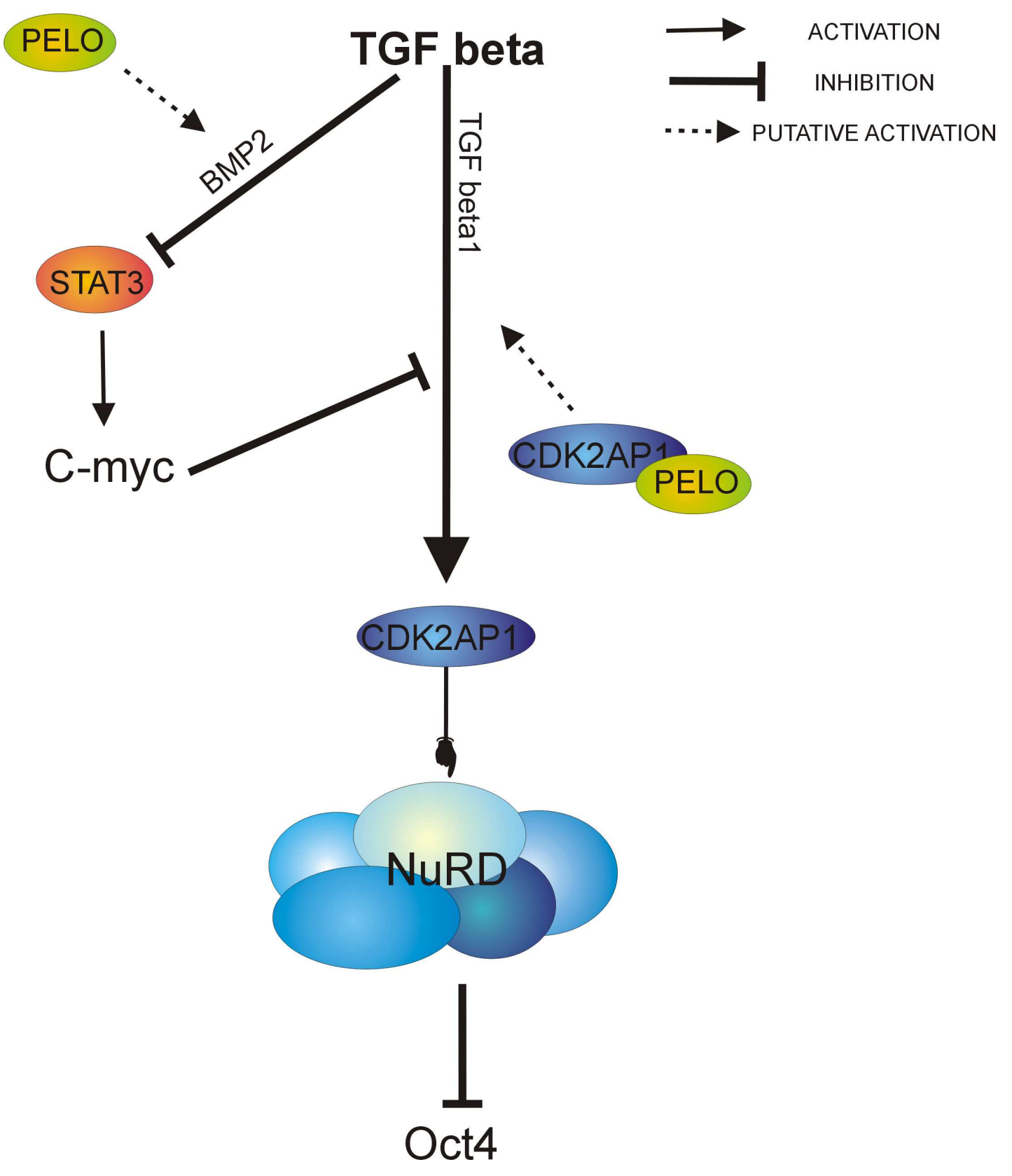

Figure 48. The scheme presenting putative PELO involvment in TGF-ß signalling during differentiation process.

TGF beta 1 activates CDK2AP1 expression. CDK2AP1 joins the NuRD complex, which is responsible for Oct4 promoter methylation and in consequence its inactivation. BMP2, a TGF- $\beta$ family member, inhibits STAT3 pathway, which participates in pluripotency maintenance. In undifferentiated ES cells STAT3 activates c-myc, a proliferation propagator, which inhibits TGF- $\beta$ pathway. PELO/CDK2AP1 may play as a positive feedback regulator in TGF- $\beta$ signalling. According to an alternative hypothesis, PELO positively regulates BMP2- mediated STAT3 inhibition. 


\subsection{Pelota in germ cell differentiation}

The testis-specific Pelota knockout mouse (chapter 3.1.6.) demonstrated that spermatogenesis is arrested at the spermatocyte stage during its first wave. Deletion of floxed Pelo region occurs in accordance with Stra8 promoter which derives Cre recombinase expression. As it was reported (Menke et al., 2003; Baltus et al., 2006; Zhou et al., 2008), Stra8 gene is active in premeiotic stages of germ cells either in male or female. However, the highest protein level is present with onset of meiosis in gonads (Fig. 49).
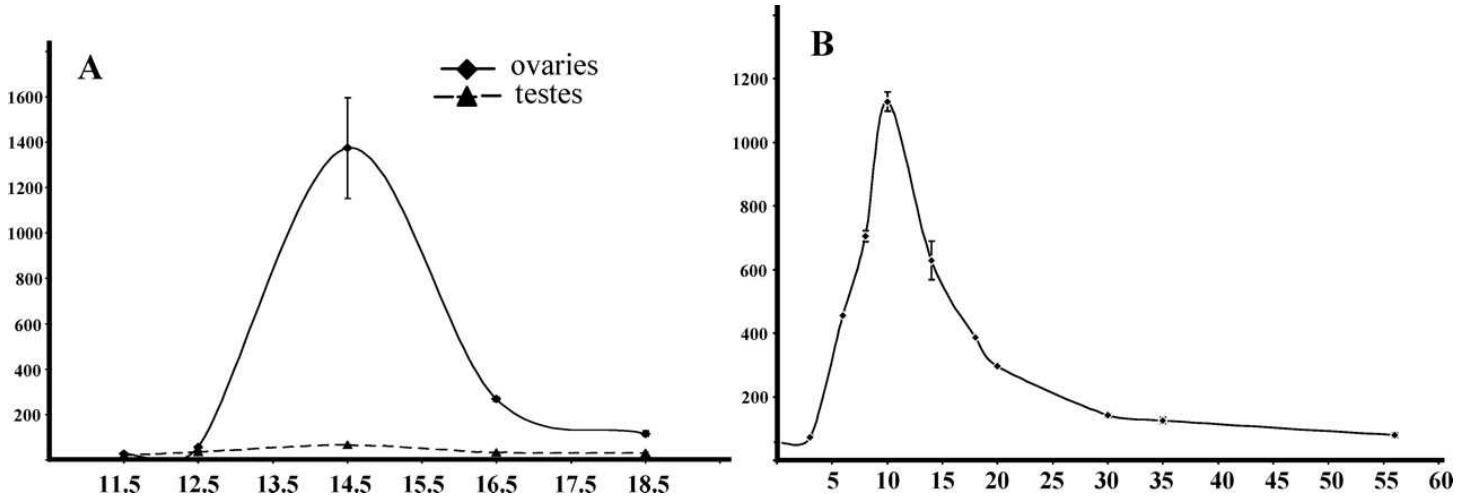

Figure 49. Stra8 expression in developing ovaries and testes (adopted from Zhou et al, 2008)

Constant line represents ovaries and doted line - testes mRNA expression during embryogenesis (A). Raw signal values are shown on the y axis, days postcoitum - on the $x$ axis (A); postnatal Stra8 mRNA expression is presented in B. Raw signal values are shown on the y axis, days postpartum - on the $x$ axis $(B)$.

In ovaries, meiosis commences at prenatal stage E14.5, whereas in males it occurs at day 10 of postnatal development. The highest level of Stra8 expression coincides with the onset of meiosis. The Stra8 expression is thereafter undetectable in ovary, and in testis it decreases to a low level, which is comparable to the state of postnatal day 5, when only premeiotic germ cells are present in the testis (Zhou et al., 2008). It is worth noting that this extreme increase of Stra8 protein happens only during the first wave of spermatogenesis (Fig. 49). It indicates that a Stra8-Cre is expressed in the same pattern and the most efficient pelota recombination coincides with this event at day 10 only in the first wave of sperm differentiation. It would explain the phenomenon of fertile Pelo ${ }^{\mathrm{F} /} \mathrm{Stra} 8-\mathrm{Cre}$ mice. Namely, Stra8 protein was demonstrated in different types of germ cells - type A and B spermatogonia, preleptotene and early leptotene spermatocytes (Zhou et al., 2008), what 


\section{DISSCUSSION}

suggests that the Stra8 promoter is activated later than in germ stem cells (GSCs). It means that in all next generations of spermatogonia, the recombination of floxed region will occur de novo and due to low expression of Stra8-Cre recombinase, Pelo is excised less sufficiently. Therefore, some amount of sperm is successfully produced and mice stay fertile (Table 3., chapter 3.1.6.5.). Moreover, Zhou et al. (2008) demonstrated that retinoic acid (RA) is critical for Stra8 expression (Koubova et al., 2006) what let us speculate that Stra8Cre recombination is variable and RA-dependent. Nonetheless, one can conclude that PELO plays a role in meiosis progression, what is convergent with experiments performed in yeast and Drosophila (Eberhart and Wasserman, 1995; Davis and Engebrecht, 1998).

The quantitative analysis of premeiotic markers revealed that expression of Stra8, Dazl and Ddx4 in 10-day-old testes is similar - all three markers exhibit a drastic increase of transcript level at that time in the control, but in mutant testes we could observe twofold reduction (Fig. 25, 26, chapter 3.1.6.4.). In case of Plzf, Sox3 and c-Kit, there is no dramatic discrepancy between the control and the mutant, despite the slight reduction at day 5 . It indicates that there is no clear effect of Pelo depletion at the stage of either undifferentiated (Plzf and Sox3) or differentiated (c-Kit) spermatogonia. It suggests that the phenotype appears with the onset of spermatogonial differentiation, that is with entry into meiotic division.

However, the question arises whether pelota has any impact on mitotic divisions, i.e. GSC self-renewal, as it was reported in Drosophila (Xi et al., 2005). The Stra8-Cre line is insufficient model to shed light on this issue. Therefore, we used CreERT-mediated Pelota deletion. Tamoxifen-induced recombination occurs independently from developmental stage of cells, what makes possible to affect GSCs and all their derivatives during ever-lasting spermatogenesis - not only its first wave.

15-day-old males were treated with tamoxifen. Histological analysis of their testes was performed 2 months later. During this period, first wave of spermatogenesis is finished and following waves take place. We found complete lack of germ cells, only Sertoli cells could be observed in seminiferous tubules of mutant testes (Fig. 33, chapter 3.1.7.2.). The phenotype resembles $\mathrm{W} / \mathrm{W}^{\mathrm{V}}$ mutant testes, where no germ cells are present, but some spermatogonia could be found. The fact worth mentioning is that $\mathrm{W} / \mathrm{W}^{\mathrm{V}}$ mutant spermatogonia are capable of proliferating, but their differentiation abilities are defective (Ohta et al., 2003). Our findings suggests that Pelota has also an impact on GSC differentiation and mitotic division is not affected. The phenotype of mutant testis confirms our hypothesis concerning an involvment of pelota in the cell fate shift. As far as TGF- $\beta$ 


\section{DISSCUSSION}

pathway is concerned, it was demonstrated that Smad proteins, which are mediators in TGF$\beta$ signalling, are upregulated in meiotic germ cells of the rat testis. It was suggested that TGF- $\beta$ may play a putative role in maturation of the first wave of spermatogenesis (Xu et al., 2003).

\section{5. miRNA in pluripotent stem cells during differentiation}

MicroRNA is a family of small ( 22 nucleotides) non-coding RNAs, which are involved in regulation of gene expression by either degradation of target mRNA transcripts or by disruption of mRNA translation (Kloosterman et Plasterk, 2006). However, it is known that there is a group of miRNAs, the members of miR-290 cluster, which are abundant in embryonic stem cells, but they become silenced upon the onset of differentiation (Houbaviy et al., 2003, 2005). Zovoilis et al. (2009) showed that miR-290 cluster inhibits ES cell differentiation process towards mesoderm through negative regulation of Wnt pathway. In Pelo ${ }^{\Delta /-}$ CreERT cells, which fail to form mesoderm, we observed upregulation of the miR-290 cluster, what is consistent with the results published by Zovoilis et al. (2009). However, after repeating the experiment, we did not obtain any increase in miR-290 expression (data not shown). Our data require further investigation to evaluate the putative miR-290 upregulation in our system. The question arises, whether this upregulation effect is directly related to PELO function or it is rather convergent result of balance impairment in the complex signalling network responsible for mesoderm formation in the cell.

\subsection{Future perspectives}

The aim of this work was to analyze pelota function in self-renewal/differentiation processes. The generated conditional knockout system allowed us to reach the goal. We demonstrated that pelota is involved in cell fate shift to mesoderm formation from pluripotent cells. However, the collected data do not give detailed answers about molecular function of PELO protein. Therefore, it would be of great value to analyze mutant ES cells, which are subjected to mesoderm formation conditions and to study the STAT3 level as well as TGF- $\beta$ signalling in NuRD complex activation. To estimate the approximal stage in mesodermal pathway which is disrupted upon PELO depletion, it is important to analyze the mRNA levels of lineage-specific markers in embryoid bodies of different age. Further 


\section{DISSCUSSION}

investigation is also neccessary for analysis of hematopoietic cells to confirm the differentiation failure and unaffected proliferation in pelota mutant mice.

To further investigate the differentiation potential of these cells, control and mutant ES cell lines were injected into blastocysts and transferred to pseudopregnant mice. The generated chimeras will help us to verify the contribution of mutant ES cells in embryonic development. Tissues of chimeras, derived from all three germ layers, will be genotyped.

An alternative way to confirm the potential of Pelo ${ }^{\Delta /}$ CreERT ES cells to differentiate, is generation of teratoma in immune-deficient (SCID) mice. Histological analysis of teratoma will help us to determine abilities of mutant cells to differentiate into different germ layers in advanced teratomas. 


\section{SUMMARY}

\section{SUMMARY}

In this work we analyzed the role of pelota in the conditional knockout mouse model. We shed light on its function during development and report the defects resulting from Pelota depletion. We demonstrated that recombination of floxed Pelo allele was complete in ESC system and sufficiently efficient to study PELO depletion in mouse.

We successfully generated a Pelo ${ }^{\Delta /-}$ CreERT ES cell line. It did not exhibit any proliferation disorder, but the cells were defective in differentiation capacities. They sustained Oct4 expression, and miR-290 cluster specific for pluripotent cells seemed to be upregulated under differentiation conditions. The ectoderm formation was not affected, but analysis of early and late markers, specific for mesoderm and endoderm revealed that both lineages are not formed in the mutant cells. To confirm the hypothesis, we studied differentiation capacities of adult stem cells, i.e. hematopoietic stem cells and spermatogonial stem cells.

Analysis of spermatogenesis revealed that all developmental stages of germ cells are absent. For more comprehensive studies, we generated testis-specific Pelo ${ }^{\Delta /-} \mathrm{Stra} 8-\mathrm{Cre}$ mice, which let us follow the effect of PELO deletion on spermatogenesis progression. The analysis of the testes showed arrest in spermatogenic progression during the onset of meiotic division (day 15). In 10-day-old testes we detected a decrease in expression of Stra8, Dazl and Ddx4, which are markers for premeiotic stages of germ cells. However, we could not find any PELO deletion effect on the level of either undifferentiated (Plzf and Sox3 markers) or differentiated (c-Kit marker) spermatogonia. This suggests that pelota exerts the effect on entry into meiosis, that is the beginning of germ cell differentiation. Unexpectedly, we also found mosaic mice with partially deleted Pelo allele (Pelo ${ }^{\mathrm{F} / \Delta /-} \mathrm{Stra} 8$ Cre) in different somatic tissues, including kidney, liver, heart, spleen, lungs, what indicates Stra8 expression in early embryogenesis.

The studies of mature B and $\mathrm{T}$ cells isolated from spleen and thymus of mutant mice revealed the reduction in cell number. Additionally, we detected strong increase of double negative cells $\left(\mathrm{CD}^{-} \mathrm{CD}^{-}\right)$, which are developmental precursors of $\mathrm{T}$ cells. Simultanously, we observed a dramatic decrease in the level of all later developmental stages of $\mathrm{T}$ cells. All these data confirm the failure in differentiation abilities of mutant cells.

Adham et al. (2003) studied pelota function in the Pelo knockout mouse. The phenotype of homozygous mutants $\left(\right.$ Pelo $\left.^{-/}\right)$was lethal during early stages of 


\section{SUMMARY}

embryogenesis. To confirm that this phenotype results from pelota inactivation, we crossed $\mathrm{Pelo}^{+-}$mice with transgenic Pelo ${ }^{\mathrm{T}}$ mice, which rescued the lethal phenotype. This clearly demonstrates the direct relation between lethality and Pelo depletion.

The transgenic mice overexpressiong PELO in testis-specific manner did not show any phenotype. The mice were fertile and histological analysis demonstrated that spermatogenesis is not disrupted. 


\section{REFERENCES}

Adham I.M., Sallam M.A., Steding G., Korabiowska M., Brinck U., Hoyer-Fender S., Oh C. and Engel W. (2003) Disruption of the pelota gene causes early embryonic lethality and defects in cell cycle progression. Mol Cell Biol. 23: 1470-1476.

Alexandrow M.G. and Moses H.L. (1995) Transforming growth factor beta and cell cycle regulation. Cancer Res. 55, 1452-1457.

Ausubel FM, Brent R, Kingston RE, Moore DD, Seidman JG, Smith JA, Struhl K. 1994. Current Protocols in Molecular Biology, (John Wiley \& Sons Inc., USA).

Avilion A.A., Nicolis S.K., Pevny L.H., Perez L., Vivian N. and Lovell-Badge R. (2003) Multipotent cell lineages in early mouse development depend on SOX2 function. Genes Dev. 17, 126-140.

Baltus A.E., Menke D.B., Hu Y-C., Goodheart M.L., Carpenter A.E., de Rooij D.G. and Page D.C. 2006. In germ cells of mouse embryonic ovaries, the decision to enter meiosis precedes premeiotic DNA replication. Nat. Genet. 12, vol. 38, 1430-1434.

Berg D.J. and Lynch R.G. (1991) Immune dysfunction in mice with plasmacytomas. I. Evidence that transforming growth factor beta contributes to the altered expression of activation receptors on host B lymphocytes. J. Immunol. 146, 2865-72.

Birnboim HC, Doly J. 1979. A rapid alkaline extraction procedure for screening recombinant plasmid DNA. Nucleic Acids Res. 7:1513-23.

Boeuf H., Hauss C., De Graeve F., Baran N. and Kedinger C. (1997) Leukemia inhibitory factor-dependent transcriptional activation in embryonic stem cells. J. Cell. Biol. 138, 12071217.

Bourillot P.Y., Aksoy I., Schreiber V., Wianny F., Schulz H., Hummel O., Hubner N. and Savatier P. (2009) Novel STAT3 target genes exert distinct roles in the inhibition of mesoderm and endoderm differentiation in cooperation with Nanog. Stem Cells 27, 17601771 .

Boyer L.A., Plath K., Zeitlinger J., Brambrink T., Medeiros L.A., Lee T.I., Levine S.S., Werning M., Tajonar A., Ray M.K., Bell G.W., Otte A.P., Vidal M., Gifford D.K., Young R.A. and Jaenisch R. (2006) Polycomb complexes repress developmental regulators in murine embryonic stem cells. Nature 441, 349-353.

Bradford M.M. (1976) A rapid and sensitive method for the quantitation of microgram quantities of protein utilizing the principle of protein-dye binding. Anal Biochem. 7, 248-254.

Bult C.J., White O., Olsen G.J., Zhou L., Fleischmann R.D., Sutton G.G., Blake J.A., FitzGerald L.M., Clayton R.A., Gocayne J.D., Kerlavage A.R., Dougherty B.A., Tomb J.F., Adams M.D., Reich C.I., Overbeek R., Kirkness E.F., Weinstock K.G., Merrick J.M., Glodek A., Scott J.L., Geoghagen N.S., Venter J.C. (1996) Complete genome sequence of the methanogenic archaeon, Methanococcus jannaschii. Science. 23:1058-73. 
Busch S.J. and Sassone-Corsi P. (1990) Dimers, leuzine zippers and DNA-binding domains. Trends Genet. 6, 36-40.

Cartwright P., McLean C., Sheppard A., Rivett D., Jones K. and Dalton S.(2005) LIF/STAT3 controls ES cell self-renewal and pluripotency by a Myc-dependent mechanism. Development 132(5), 885-896.

Castrillon D.H., Gonczy P., Alexander S., Rawson R., Eberhart C.G., Viswanathan S., DiNardo S. and Wasserman S.A. (1993) Toward a molecular genetic analysis of spermatogenesis in Drosophila melanogaster: characterization of male-sterile mutants generated by single P element mutagenesis. Genetics 135, 489-505.

Clark J.M. (1988) Novel non-templated nucleotide addition reactions catalyzed by procaryotic and eucaryotic DNA polymerases. Nucleic Acids Res. 16, 9677-86.

Crook J.M., Dunn N.R. and Colman A. (2006) Repressed by NuRD. Nature Cell Biol. 8, 212-214.

Davis L. and Engebrecht J. (1998) Yeast dom34 mutants are defective in multiple developmental pathways and exhibit decreased levels of polyribosomes. Genetics 149: 4556.

Deb-Rinker P., Ly D., Jezierski A., Sikorska M. and Walker P.R. (2005) Sequential DNA Methylation of the Nanog and Oct-4 Upstream Regions in Human NT2 Cells during Neuronal Differentiation. J. Biol. Chem. 280, 6257-6260.

DeCoteau J.F., Knaus P.I., Yankelev H., Reis M.D., Lowsky R., Lodish H.F. and Kadin M.E. (1997) Loss of functional cell surface transforming growth factor beta (TGF- $\beta$ ) type 1 receptor correlates with insensitivity to TGF- $\beta$ in chronic lymphocytic leukemia. Proc. Natl. Acad. Sci. USA 94, 5877-81.

Denhardt D.T. (1966) A membrane-filter technique for the detection of complementary DNA. Biochem Biophys Res Commun. 13, 641-646.

Deshpande A.M., Dai Y., Kim Y., Kim J., Kimlin L., Gao K., Hendrich B. and Wong D.T. (2008) CDK2AP1 is required for epigenetic silencing of Oct4 during murine embryonic stem cell differentiation. J. Biol. Chem. 284, 6043-6047.

Doma M.K. and Parker R. (2006) Endonucleolytic cleavage of eukaryotic mRNAs with stalls in translation elongation. Nature 440, 561-564.

Dooley T.P., Miranda M., Jones N.C. and DePamphilis M.L. (1989) Transactivation of the adenovirus ElA protein is restricted to mouse oocytes and preimplantation embryos. Development 107, 945-956.

Dressel R., Elsner L., Quentin T., Walter L. and Günther E. (2000) Heat shock protein 70 is able to prevent heat shock-induced resistance of target cells to CTL. J. Immunol 164, 23622371. 
Duncan S.A., Nagy A. and Chan W. (1997) Murine gastrulation requires HNF-4 regulated gene expression in the visceral endoderm: tetraploid rescue of Hnf-4 (-/-) embryos. Development 124, 279-287.

Ebenhart C.G. and Wasserman S.A. (1995) The pelota locus uncodes a protein required for meiotic cell division: an analysis of $\mathrm{G} 2 / \mathrm{M}$ arrest in Drosophila spermatogenesis. Development 121, 3477-3486.

Enders G.C. and May J.J. (1994) Developmentally regulated expression of a mouse germ cell nuclear antigen examined from embryonic day 11 to adult in male and female mice. Dev. Biol. 163, 331-340.

Eurwilaichitr L., Graves F.M., Stansfield I. and Tuite M.F. (1999) The C-terminus of eRF1 defines a functionally important domain for translation termination in Saccharomyces cerevisiae. Mol. Microbiol. 32, 485-496.

Feinberg A.P. and Vogelstein B. (1984) A technique for radiolabeling DNA restriction endonuclease fragments to high specific activity. Anal Biochem. 137, 266-267.

Feng X.-H., Liang Y.-Y., Liang M., Zhai W. and Lin X. (2002) Direct interaction of c-Myc with Smad 2 and Smad3 to inhibit TGF- $\beta$-mediated induction of the CDK inhibitor p $15^{\text {Ink4B }}$. Mol. Cell 9, 133-143.

Frolova L., Le Goff X., Rasmussen H.H., Cheperegin S., Drugeon G., Kress M., Arman I., Haenni A-L., Celis J.E., Philippe M., Justesen J. and Kisselev L. (1994) A highly conserved eukaryotic protein family possessing properties of polypeptide chain release factors. Nature 372, 701-703.

Futaki S., Hayashi Y., Emoto T., Weber C.N. and Sekiguchi K. (2004) Sox7 plays crucial roles in parietal endoderm differentiation in F9 embryonal carcinoma cells through regulating Gata-4 and Gata-6 expression. Mol. Cell. Biol. 24, 10492-10503.

Gershoni J.M. and Palade G.E. (1982) Electrophoretic transfer of proteins from sodium dodecyl sulfate-polyacrylamide gels to a positively charged membrane filter. Anal Biochem. 124, 396-405.

Goldrath A.W. and Bevan M.J. (1999) Selecting and maintaining a diverse T-cell repertoire. Nature 402, 255-262.

Graille M., Chaillet M. and van Tilbeurgh H. (2008) Structure of yeast Dom34 - a protein related to translation termination factor eRF1 and involved in No-Go decay. J. Biol. Chem. 11, Vol. 283, 7145-7154.

Hannon G.J. and Beach D. (1994) pl5INK4B is a potential effector of TGF- $\beta$-induced cell cycle arrest. Nature 371, 257-61.

Hattori N., Nishino K., Ko Y.G., Hattori N., Ohgane J., Tanaka S. and Shiota K. (2004) Epigenetic control of mouse Oct4 gene expression in embryonic stem cells and trophoblast stem cells. J. Biol. Chem. 279, 17063-17069. 
Hayashi,H., Abdollah S., Qiu Y., Cai J., Xu Y.Y., Grinnell B.W., Richardson M.A., Topper J.N., Gimbrone M.A. Jr., Wrana J.L. and Falb D. (1997) The MAD-related protein Smad7 associates with the TGFb receptor and functions as an antagonist of TGF $\beta$ signaling. Cell 89, 1165-1173.

Held T., Paprotta I., Khulan J., Hemmerlein B., Binder L., Wolf S., Schubert S., Meinhardt A., Engel W. and Adham I.M. (2006) Hspa4l-deficient mice display increased incidence of male infertility and hydronephrosis development. Mol. Cell. Biol. 21, 8099-8108.

Hendrich B., Guy J., Ramsahoye B., Wilson V.A. and Bird A. (2001) Closely related proteins MBD2 and MBD3 play distinctive but interacting roles in mouse development. Genes Dev. 15, 710-723.

Hill J.J., Tremblay T.L., Cantin C., O’Connor-McCourt M., Kelly J.F. and Lenferink A.E. (2009) Glycoproteomic analysis of two mouse mammary cell lines during transforming growth factor (TGF)-beta induced epithelial mesenchymal transition. Proteome Sci. 7:2, published online doi:10.1186/1477-5956-7-2.

Hodge R. 1994. Preparation of RNA gel blots. Methods Mol Biol. 28, 49-54.

Houbaviy H., Murray M. and Sharp P. (2003) Embryonic stem cell-specific microRNAs. Dev. Cell 5, 351-358.

Houbaviy H., Dennis L., Jaenisch R. and Sharp P.A. (2005) Characterization of a highly variable eutherian microRNA gene. $R N A$ 11, 1245-1257.

Hu G. (1993) DNA polymerase-catalyzed addition of nontemplated extra nucleotides to the 3' end of a DNA fragment. DNA Cell Biol. 12, 763-770.

Hu M., Hu G.-F., Kim Y., Tsuji T., McBride J., Hinds P. and Wong D.T.W. (2004) Role of $\mathrm{p} 12^{\mathrm{CDK} 2-\mathrm{AP} 1}$ in transforming growth factor- $\beta 1$-mediated growth suppression. Cancer Research 64, 490-499.

Imamura T., Takase M., Nishihara A., Oeda E., Hanai J., Kawabata M. and Miyazono K. (1997) Smad6 inhibits signalling by the TGF- $\beta$ superfamily. Nature 389, 622-626.

Inge T.H., McCoy K.M., Susskind B.M., Barrett S.K., Zhao G., Bear H.D. (1992) Immunomodulatory effects of transforming growth factor-beta on T lymphocytes. Induction of CD8 expression in the CTLL-2 cell line and in normal thymocytes. J. Immunol. 148, 3847-56.

Izumi N., Era T., Akimaru H., Yasunaga M. and Nishikawa S. (2007) Dissecting the molecular hierarchy for mesendoderm differentiation through a combination of embryonic stem cell culture and RNA interference. Stem Cells 25, 1664-1674.

Kadin M.E., Cavaille-Coll M.W., Gertz R., Massague J., Cheifetz S. and George D. (1994) Loss of receptors for transforming growth factor beta in human T-cell malignancies. Proc. Natl. Acad. Sci. USA 91, 6002-6. 
Kaji K., Caballero I.M., MacLeod R., Nichols J., Wilson V.A. and Hendrich B. (2006) The NuRD component Mbd3 is required for pluripotency of embryonic stem cells. Nature Cell Biol. 8, 285-292.

Kanwar N., Fayyazi A., Backofen B., Nitsche M., Dressel R. and Fisher von Mollard G. (2008) Thymic alteration in mice deficient for the SNARE protein VAMP8/endobrevin. Cell Tissue Res 334, 227-242.

Kawamura C., Kizaki M., Yamato K., Uchida H., Fukuchi Y., Hattori Y., Koseki T., Nishihara T. and Ikeda Y. (2000) Bone morphogenetic protein-2 induces apoptosis in human myeloma cells with modulation of STAT3. Blood 96, 2005-2011.

Kawasaki H., Mizuseki K., Nishikawa S., Kaneko S., Kuwana Y., Nakanishi S., Nishikawa S.-I. and Sasai Y. (2000) Induction of midbrain dopaminergic neurotechnique neurons from ES cells by stromal cell-derived inducing activity. Neuron 28, 31-40.

Kloosterman W.P. and Plasterk R.H. (2006) The diverse functions of microRNAs in animal development and disease. Dev. Cell 11, 441-450.

Koubova J., Menke D.B., Zhou Q., Capel B., Griswold M.D. and Page D.C. (2006) Retinoic acid regulates sex-specific timing of meiotic initiation in mice. Proc. Natl. Acad. Sci. USA 103, 2474-2479.

Laird PW, Zijderveld A, Linders K, Rudnicki MA, Jaenisch R, Berns A. 1991. Simplified mammalian DNA isolation procedure. Nucleic Acids Res. 19, 4293.

Lakso M., Sauer B., Mosinger Jr. B., Lee E.J., Manning R.W., Yu S.H., Mulder K.L. and Westphal H. (1992) Targeted oncogene activation by site-specific recombination in transgenic mice. Proc. Natl. Acad. Sci. USA 89, 6232-6236.

Lakso M., Pichel J.G., Gorman J.R., Sauer B., Okamoto Y., Lee E., Alt F.W. and Westphal H. (1996) Efficient in vivo manipulation of mause genomic sequences at the zygote stage. Proc. Natl. Acad. Sci. USA 93, 5860-5865.

Lalo D., Stettler S., Mariotte S., Gendreau E., Thuriaux P. (1994) Organization of the centromeric region of chromosome XIV in Saccharomyces cerevisiae. Yeast 10, 523-533.

Lan Z.-J., Chung A.C., Xu X., DeMayo F.J. and Cooney A.J. (2002) The embryonic function of germ cell nuclear factor is dependent on the DNA binding domain. J. Biol. Chem. 277, 50660-50667.

Le Guezennec X., Vermeulen M., Brinkman A.B., Hoeijmakers W.A.M., Cohen A., Lasonder E. and Stunnenberg H.G. (2006) MBD2/NuRD and MBD3/NuRD, two dinstinct complexes with different biochemical and functional properties. Mol. Cell. Biol. 26, 843-851.

Lee T.I., Jenner R.G., Boyer L.A., Guenther M.G., Levine S.S., Kumar R.M., Chevalier B., Johnstone S.E., Cole M.F., Isono K., Koseki H., Fuchikami T., Abe K., Murray H.L., Zucker J.P., Yuan B., Bell G.W., Herbolsheimer E., Hannett N.M., Sun K., Odom D.T., Otte A.P., Volkert T.L., Bartel D.P., Melton D.A., Gifford D.K., Jaenisch R. and Young R.A. (2006) 
Control of developmental regulators by Polycomb in human embryonic stem cells. Cell 125, 301-313.

Lee H.H., Kim Y.-S., Kim K.H., Heo I., Kim S.K., Kim O., Kim H.K., Yoon J.Y., Kim H.S., Kim D.J., Lee S.J., Yoon H.J., Kim S.J., Lee B.G., Song H.K., Kim V.N., Park C.-M. and Suh S.W. (2007) Structural and functional insights into Dom34, a key component of No-Go decay. Mol Cell 27, 938-950.

Letterio J.J. and Roberts A.B. (1998) Regulation of immune responses by TGF- $\beta$. Annu. Rev. Immunol. 16, 137-161.

Lomo J., Blomhoff H.K., Beiske K., Stokke T. and Smeland E.B. (1995) TGF- $\beta 1$ and cyclic AMP promote apoptosis in resting human B lymphocytes. J. Immunol. 154, 1634-43.

Massague J. (1990) Transforming growth factor- $\alpha$. A model for mrmbrane-anchored growth factors. J. Biol. Chem. 265(35), 21393-21396.

Massague J. (1998) TGF- $\beta$ signal transduction. Annu. Rev. Biochem. 67, 753-791.

Matsuda T., Nakamura T., Nakao K., Arai T., Katsuki M., Heike T. and Yokota T. (1999) STAT3 activation is sufficient to maintain an undifferentiated state of mouse embryonic stem cells. EMBO J. 18, 4261-4269.

Menke D.B., Koubova J. and Page D.C. (2003) Sexual differentiation of germ cells in XX mouse gonads occurs in an anterior-to-posterior wave. Dev. Biol. 262, 303-312.

Miller J.F.A.P. (2002) The discovery of thymus function and of thymus-derived lymphocytes. Immunol. Rev. 185, 7-14.

Mitsui K., Tokuzawa Y., Itoh H., Segawa K., Murakami M., Takahashi K., Maruyama M., Maeda M. and Yamanaka S. (2003) The homeoprotein Nanog is required for maintenance of pluripotency in mouse epiblast and ES cells. Cell 113, 631-642.

Nakao A., Afrakhte M., Moren A., Nakayama T., Christian J.L., Heuchel R., Itoh S., Kawabata M., Heldin N.E., Heldin C.H. and ten Dijke P. (1997) Identifcation of Smad7, a TGF $\beta$-inducible antagonist of TGF- $\beta$ signalling. Nature 389, 631-635.

Ng H.H., Zhang Y., Hendrich B., Johnson C.A., Turner B.M., Erdjument-Bromage H., Tempst P., Reinberg D. and Bird A. (1999) MBD2 is a transcriptional repressor belonging to the MeCP1 histone deacetylase complex. Nat. Genet. 23, 58-61.

Nichols J., Zevnik B., Anastassiadis K., Niwa H., Klewe-Nebenius D., Chambers I., Scholer H. and Smith A. (1998) Formation of pluripotent stem cells in the mammalian embryo depends on the POU transcription factor Oct4. Cell 95, 379-391.

Niwa H., Miyazaki J. and Smith A.G. (2000) Quantitative expression of Oct3/4 defines differentiation, dedifferentiation or self-renewal of ES cells. Nat. Genet. 24, 372-376.

Nomi M., Oishi I., Kani S., Suzuki H., Matsuda T., Yoda A., Kitamura M., Itoh K., Takeuchi S., Takeda K., Akira S., Ikeya M., Takada S. and Minami Y. (2001) Loss of 
mRor1 enhances the heart and skeletal abnormalities in mRor2-deficient mice: redundant and pleiotropic functions of mRor1 and mRor 2 receptor tyrosine kinases. Mol. Cell. Biol., December 2001, 8329-8335.

Ohkawara B., Shirakabe K., Hyodo-Miura J., Matsuo R., Ueno N., Matsumoto K. and Shibuya H. (2004) Role of the TAK1-NLK-STAT3 pathway in TGF- $\beta$-mediated mesoderm induction. Genes Dev. 18, 381-386.

Ohlstein B. and McKearin D. (1997) Ectopic expression of the Drosophila Bam protein eliminates oogenic germline stem cells. Development 124, 3651-3662.

Ohta H., Tohda A. and Nishimune Y. (2003) Proliferation and differentiation of spermatogonial stem cells in the W/W $\mathrm{W}^{\mathrm{V}}$ mutant mouse testis. Biol. Reprod. 69, 1815-1821.

Ormerod M.G., Collins M.K.L., Rodriguez-Tarduchy G. and Robertson D. (1992) Apoptosis in interleukin-3-dependent haemopoietic cells. Quantification by two flow cytometric methods. J. Immunol Meth. 153, 57-65.

Oulad-Abdelghani M., Bouillet P., Decimo D., Gansmuller A., Heyberger S., Dolle P., Bronner S., Lutz Y. And Chambon P. (1996) Characterization of premeiotic germ cellspecific cytoplasmic protein encoded by Stra8, a novel retinoic acid-responsive gene. J. Cell Biol. 135, 469-477.

Paling N.R., Wheadon H., Bone H.K. and Welham M.J. (2004) Regulation of embryonic stem cell self-renewal by phosphoinositide 3-kinase-dependent signalling. J. Biol. Chem. 279, 48063-48070.

Passos D.O., Doma M.K., Shoemaker C.J., Muhlrad D., Green R., Weissman J., Hollien J. and Parker R. (2009) Analysis of Dom34 and its function in No-Go Decay. Mol. Biol. Cell. 20, 3025-3032.

Pichel J.G., Lakso M. and Westphal H. (1993) Timing of SV40 oncogene activation by sitespecific recombination determines subsequent tumor progression during murine lens development. Oncogene 12, 3333-3342.

Plum J., De Smedt M., Leclercq G. and Vandekerckhove B. (1995) Influence of TGF- $\beta$ on murine thymocyte development in fetal thymus organ culture. J. Immunol. 154, 5789-98.

Polyak K. (1996) Negative regulation of cell growthh by TGF beta. Biochim Biophys. Acta 1242(3), 185-199.

Ragan M.A., Logsdon J.M. Jr, Sensen C.W., Charlebois R.L., Doolittle W.F. (1996) An archaebacterial homolog of pelota, a meiotic cell division protein in eukaryotes. FEMS Microbiol Lett. 144, 151-5.

Rajasingh J., Bord E., Hamada H., Lambers E., Qin G., Losordo D.W. and Kishore R. (2007) STAT3-dependent mouse embryonic stem cell differentiation into cardiomyocytes: analysis of molecular signaling and therapeutic efficacy of cardiomyocyte precommitted mES transplantation in a mouse model of myocardial infarction. Circ. Res. 101, 910-918. 
Raverot G., Weiss J., Park S.Y., Hurley L. and Jameson J.L. (2005) Sox3 expression in undifferentiated spermatogonia is required for the progression of spermatogenesis. Dev. Biol. 283, 215-225.

Rius C. and Aller P. (1992) Vimentin expression as a late event in the in vitro differentiation of human promonocytic cells. J. Cell Sci. 101, 395-401.

Ruggiu M., Speed R., Taggart M., McKay S.J., Kilanowski F., Saunders P., Dorin J. and Cooke H.J (1997) The mouse Dazla gene encodes a cytoplasmic protein essential for gametogenesis. Nature 389, 73-77.

Salas-Marco J. and Bedwell D.M. (2004) GTP hydrolysis by eRF3 facilitates stop codon decoding during eukaryotic translation termination. Mol. Cell. Biol. 24, 7769-7778.

Sambrook J, Fritsch EF, Maniatis T. (1989) Molecular cloning: a laboratory manual (2 ${ }^{\text {nd }}$ edition). Cold Spring Habour, New York, USA.

Sanger F., Nicklen S. and Coulson A.R. (1977) DNA sequencing with chain-terminating inhibitors. Proc Natl Acad Sci U S A. 74, 5463-5467.

Schrans-Stassen B.H., van de Kant H.J.G., de Rooij D.G. and van Pelt A.M.M. (1999) Differential expression of c-Kit in mause undifferentiated and differentiating type A spermatogonia. Endocrinology 140, 12: 5894-5900.

Shamsadin R., Adham I.M., von Beust G. and Engel W. (2000) Molecular cloning, expression and chromosome location of the human pelota gene PELO. Cytogenet Cell Genet 90, 75-78.

Shamsadin R., Adham I.M. and Engel W. (2002) Mouse pelota gene (Pelo): cDNA cloning, genomic structure and chromosomal localization. Cytogenet Genome Res. 97, 95-99.

Song H., Mugnier P., Das A.K., Webb H.M., Evans D.R., Tuite M.F., Hemmings B.A. and Barford D. (2000) The crystal structure of human eukaryotic release factor eRF1 mechanism of stop codon recognition and peptidyl-tRNA hydrolysis. Cell 100, 311-321.

Southern EM. 1975. Detection of specific sequences among DNA fragments separated by gel electrophoresis. J Mol Biol. 98, 503-17.

Starr T.K., Jameson S.C. and Hogquist K.A. (2003) Positive and negative selection of T cells. Anпu Rev Immunol 21, 139-176.

Stavnezer J. 1996. Transforming growth factor beta. In Cytokine Regulation of Humoral Immunity: Basic and Clinical Aspects, ed.CMSnapper, pp. 289-324. New York: Wiley.

Suda T. and Zlotnik A. (1991) IL-7 maintains the T cell precursor potential of CD3-CD4CD8- thymocytes. J. Immunol. 146, 3068-3073.

Suda T. and Zlotnik A. (1992) In vitro induction of CD8 expression on thymic pre-T cells. II. Characterization of 
$\mathrm{CD} 3^{-} \mathrm{CD} 4^{-} \mathrm{CD} 8$ alpha + cells generated in vitro by culturing $\mathrm{CD} 25^{+} \mathrm{CD} 3^{-} \mathrm{CD} 4^{-} \mathrm{CD} 8^{-}$ thymocytes with $\mathrm{T}$ cell growth factor-beta and tumor necrosis factor-alpha. J. Immunol. 149, $71-76$.

Tada T., Ohzeki S., Utsumi K., Takiuchi H., Muramatsu M., Li X.F., Shimizu J., Fujiwara H. and Hamaoka T. (1991) Transforming growth factor-beta-induced inhibition of $\mathrm{T}$ cell function. Susceptibility difference in $\mathrm{T}$ cells of various phenotypes and functions and its relevance to immunosuppression in the tumor-bearing state. J. Immunol. 146, 1077-82.

Toyooka Y., Tsunekawa N., Takahashi Y., Matsui Y., Satoh M. and Noce T. (2000) Expression and intracellular localization of mouse Vasa-homologue protein during germ cell development. Mech. Dev. 93, 139-149.

Tritschler F., Eulalio A., Truffault V., Hartmann M.D., Helms S., Schmidt S., Coles M., Izurralde E. and Weichenrieder O. (2007) A divergent Sm fold in EDC3 proteins mediates DCP1 binding and P-body targeting.

Mol. Cel. Biol. 27, 8600-8611.

Ura H., Usuda M., Kinoshita K., Sun C., Morl K., Akagl T., Matsuda T., Kolde H. and Yokota T. (2008) STAT3 and Oct-3/4 control histone modification through induction of Eed in embryonic stem cells. J. Biol. Chem. 283, 9713-9723.

Wade P.A., Gegonne A., Jones P.L., Ballestar E., Aubry F. and Wolffe A.P. (1999) Mi-2 complex couples DNA methylation to chromatin remodelling and histone deacetylation. Nat Genet 23, 62-66.

Wahl S.M., Hunt D.A., Wong H.L., Dougherty S., McCartney-Francis N., Wahl L.M., Ellingsworth L., Schmidt J.A., Hall G., Roberts A.B. and Sporn M.B. (1988) Transforming growth factor-beta is a potent immunosuppressive agent that inhibits IL-1-dependent lymphocyte proliferation. J. Immunol. 140(9), 3026-3032.

Williams-Simons L. and Westphal H. (1999) EIIaCre - utility of a general deleter strain. Transgenic Research 8, 253-254.

Wilusz C.J. amd Wilusz J. (2005) Eukaryotic Lsm proteins: lessons from bacteria. Nat. Struct. Mol. Biol. 12, 1031-1036.

Xi R., Doan C., Liu D. and Xie T. (2005) Pelota controls self-renewal of germline stem cells by repressing a Bam-independent differentiation pathway. Development 132, 5365-74.

Xu J., Beyer A.R., Walker W.H. and McGee E.A. (2003) Developmental and stage-specific expression of Smad2 and Smad3 in rat testis. J. Androl. 24(2), 192-200.

Xue Y., Wong J., Moreno G.T., Young M.K., Cote J. and Wang W. (1998) NuRD, a novel complex with both ATP-dependant chromatin-remodeling and histone deacetylase activities. Mol Cell 2, 851-861.

Yeom, Y.I., Fuhrmann, G., Ovitt, C.E. et al. (1996) Germline regulatory element of Oct-4 specific for the totipotent cycle of embryonal cells. Development 122, 881-894. 


\section{REFERENCES}

Ying Q.L., Nichols J., Ccambers I. and Smith A. (2003) BMP induction of Id proteins suppresses differentiation and sustains embryonic stem cell self-renewal in collaboration with STAT3. Cell 115, 281-292.

Yoshimizu T, Sugiyama N, De Felice M, Yeom YI, Ohbo K, Masuko K, Obinata M, Abe K, Scholer HR, Matsui Y. (1999) Germline-specific expression of the Oct-4/green fluorescent protein (GFP) transgene in mice. Dev Growth Differ 41, 675-684.

Zhang Y., Ng H.H., Erdjument-Bromage H., Tempst P., Bird A. and Reinberg D. (1999) Analysis of the NuRD subunits reveals a histone deacetylase core complex and a connection with DNA methylation. Genes Dev. 13, 1924-1935.

Zhou Q., Tam W.L., Tong G.Q., Wu Q., Chan H.Y., Soh B.S., Lou Y., Yang Y., Ma Y., Chai L., Ng H.H., Lufkin T., Robson P. and Lim B. (2006) Sall4 modulates embryonic stem cell pluripotency and early embryonic development by the transcriptional regulation of Pou5f1. Nat. Cell Biol. 8, 1114-1123.

Zhou Q., Nie R., Li Y., friel P., Mitchell D., Hess R.A., Small C. and Griswold M.D. (2008) Expression of stimulated by retinoic acid gene 8 (Stra8) in spermatogenic cells induced by retinoic acid: an in vivo study in vitamin A-sufficient postnatal murine testes. Biol. Reprod. 79, 35-42.

Zovoilis A., Smorag L., Pantazi A. and Engel W. (2009) Members of the miR-290 cluster modulate in vitro differentiation of mouse embryonic stem cells. Differentiation 78, 69-78. 


\section{Acknowledgements}

I am grateful for all the support I have received whilst researching and writing up this dissertation. I would like to express my gratitude to Prof. Dr. med. Dr. h.c. W. Engel for his support, encouragement, scientific supervision, financial support for my Ph.D study and in particular for his faith in my ideas.

I wish to express my appreciation to Prof. Dr. I. Adham for supervision of the project and theoretical discussions which were really inspiring.

I am also very grateful to Prof. Dr. med. R. Dressel for his invaluable help and advice in the project.

I sincerely thank PD Dr. S. Hoyer-Fender for being my co-referee. I also extend my sincere thank you to PD Dr. J. Heinrichs and Prof. Dr. R. Heinrich for being my dissertation examiners.

I would like to thank Prof. Dr. med. N. Miosge for his precious technical advice and friendly cooperation and Prof. Dr. A. Mansouri for help with neural differentiation of ES cells.

I am grateful to Ilona Paprotta, Janine Ulrich, Astrid Herwig, Maren Steckel, Lisa Hartmund and Christian Müller for a technical support in the project.

Special thanks go to Łukasz Smorag and Saskia Spangenberg for the manual support in this project.

I sincerely appreciate the help of all members of the animal house, especially Jutta Schröder and Stefan Wolf, who took care of the huge colonies of mice I worked with.

I would like to thank all my institute colleagues for their support, advice, brain storming and friendly atmosphere what helped me a lot to follow the right direction in the project. My special thanks go to Ela, Maja, Grzegorz, Marta, Pawet, Łukasz, Karina, Ania, Ilona, Denisse, Krishna, Thanasis, Jessica, Maiada, Amal, Angeliki, Janine, Odgerel, Zana, Nadja, Torsten, Ozanna, Sandra and Moneef.

I am also very grateful to my parents and sister who supported me on every step of the way, especially in the tough moments of my research.

Jestem szczególnie wdzięczna moim rodzicom i siostrze, którzy wspierali mnie podczas catego okresu studiów, a w szczególności na trudnych etapach moich badań. Dziękuję.

Thank you to all of you. 


\section{Curriculum vitae}

\section{Personal details:}

FIRST NAME:

Aleksandra

LAST NAME:

Kata

ADDRESS

Rosenbachweg 4/406

37075 Goettingen, Germany

DATE OF BIRTH:

$8^{\text {th }}$ December 1982

PLACE OF BIRTH:

Łódź, Poland

NATIONALITY/SEX:

Polish/female

PHONE No.

$+48603053353$

+4917665578847

EMAIL:

akata82@gmail.com

Education:

$2006-2010$

$2003-2006$

PhD studies, Institute of Human genetics, Georg_August University in Goettingen, Germany

Title of the thesis: On putative role of Pelota in stem cell differentiation

Graduation date: January 2010

Master of Science thesis, Experimental work in The Laboratory of Molecular Genetics, The Institute of General and Molecular Biology at Nicolas Copernicus University in Torun, Poland

Title of the thesis: The influence of temperature on catalase gene expression pattern during regeneration in embryogenic and non-embryogenic calli of Triticum aestivum and Vicia faba ssp. minor.

Graduation date: $7^{\text {th }}$ June 2006 
and Earth Sciences at the Nicolas Copernicus University in Torun, Poland

2001

High School Diploma

$1989-2001$

Primary and Secondary School (Profile:

Biology \& Chemistry), Łódź, Poland

\section{Laboratory experience:}

$2006-2010$

Experimental work in the laboratory of Institute of Human genetics in Goettingen, Germany

Scientific supervision: PD Dr I. Adham

$2003-2006$

Experimental work in The Laboratory of Molecular Genetics, The Institute of General and Molecular Biology at Nicolas Copernicus University in Torun, Poland

Scientific supervision: PD Dr A. Goc

January - June 2004

Institute of Cancer Genetics, Saint Joseph St. 53/59, 87-100 Torun, Poland

Occupation

Proffesional Practice : Laboratory Assistant (Diagnostics of hereditary cancer) 